\title{
IMPROVING THE CAREER RESILIENCE OF A SURVIVOR OF SEXUAL ABUSE
}

\author{
by \\ Cobus Venter \\ (26130905) \\ Magister Educationis \\ (Educational Psychology) \\ in the \\ Department of Educational Psychology \\ Faculty of Education \\ University of Pretoria
}

Supervisor: Prof. J.G. Maree

PRETORIA

2016 


\title{
DEDICATION
}

I dedicate this research study to my nephew Calhane Venter. Buddy, what a pleasure to have known you and to have spent the little time God gave you, having fun. I shall always carry you in my heart and remember you for the happy and kind person you were. I trust that you are happy and peaceful with our Abba Father. We will meet again one day.

"The story of life is quicker than the wink of an eye, the story of love is hello and goodbye ... until we meet again"

\author{
Jimi Hendrix
}




\section{ACKNOWLEDGEMENTS}

To have achieved this milestone in my life, I would like to express my sincere gratitude to the following people:

My Heavenly Father, who provided me the strength, knowledge and perseverance to complete this study. Everything I have, everything I am and still strive to become is because of Your grace and unfailing love for me.

Prof. J.G. Maree, my research supervisor, for his invaluable advice, guidance and inspiring motivation during difficult times. Thank you for all your patience and advice. I have truly gained much knowledge from you. Your professionalism is a virtue we should all strive to.

My parents, Pieter and Judy Venter for all your support and patience through this long journey. Without you none of this would be possible.

To Eleos, my employer, for all your support and kindness. Your compassion towards me over the past few years has been so special to me.

The participant, for your willingness to engage in a difficult process and journey.

Your strength and your zest for life will always stay with me.

My language editor, Isabel Claassen, for your assistance. 


\section{DECLARATION OF ORIGINALITY}

Full names of student: Jacobus Johannes Venter

Student number:

26130905

I hereby declare that this dissertation, "Improving the career resilience of a survivor of sexual abuse," is submitted in accordance with the requirements for the Magister Educationis degree at the University of Pretoria. I declare that this dissertation is my own original work and that it has not previously been submitted to any other institution of higher learning. All sources cited or quoted in this research paper are indicated and acknowledged in a comprehensive list of references.

Jacobus Johannes Venter (Student)

Prof. J.G. Maree (Supervisor) 


\section{ABSTRACT \\ IMPROVING THE CAREER RESILIENCE OF A SURVIVOR OF SEXUAL ABUSE}

Cobus J. Venter

Scant literature is available on victims of sexual abuse who are still presiding in the same environment in which the sexual abuse occurred. Sexual abuse has been shown to cause symptoms of depression, feelings of low self-worth, low moral judgment and feelings of guilt.

This study attempted to enhance the career resilience of a sexual abuse survivor by means of life design counselling. The research questions focussed mainly on the characteristics of sexual abuse and career resilience, the influence of sexual abuse on career resilience and how life design counselling can contribute to the career resilience of survivors of sexual abuse.

The study was based on a single case study (intrinsic) design and a QUALITATIVE-quantitative approach. The observations and qualitative findings suggested that childhood sexual abuse (CSA) did influence the survivor's intrinsic representations about herself as well as about others. The findings confirm the impact of CSA on survivors, highlighting previous research on CSA and its influence on future development (personal and emotional), as well as future career resilience and career adaptability. Life design counselling made it suitable as an intervention to be used with survivors of sexual abuse since it explores clients" subjective identity forms as influenced by their experiences and culminates in the writing of new stories. The study contributed to a more complete and comprehensive understanding of CSA and indicated that the life design counselling therapeutic intervention positively enhanced the participant's selfinsight. 


\section{DECLARATION FROM LANGUAGE EDITOR}

I herewith declare that I,

Isabel M. Claassen (APSTrans (SATI)),

full-time freelance translator, editor and language consultant

of

1367 Lawson Avenue, Waverley, Pretoria

(tel. 012332 2040; cell 082701 7922)

and

accredited member (No. 1000583) of the South African Translators' Institute (SATI)

completed the language editing ${ }^{*}$ of the M.Ed. dissertation

entitled

\section{IMPROVING THE CAREER RESILIENCE OF A SURVIVOR OF SEXUAL ABUSE}

which had been submitted to me by

Cobus J. Venter

in fulfilment of the degree

MAGISTER EDUCATIONIS

in the

FACULTY OF EDUCATION, UNIVERSITY OF PRETOR

Cellphone: 0723130126

E-mail: cbsventer@gmail.com

Date completed: 2 September 2016

*Please note that no responsibility can be taken for the veracity of statements or arguments in the document concerned or for changes made subsequent to the completion of language editing. Also remember that content editing is not part of a language editor's task and is in fact unethical. 


\section{CONTENTS}

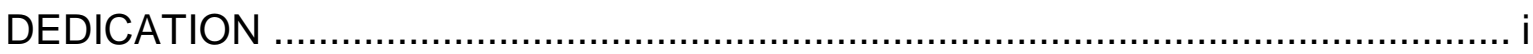

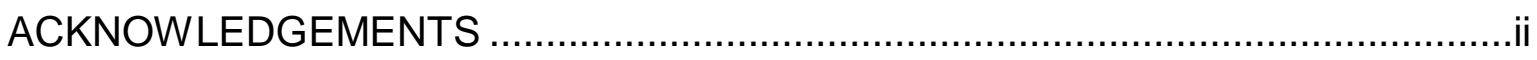

DECLARATION OF ORIGINALITY ..........................................................ii

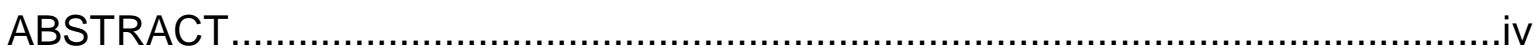

DECLARATION FROM LANGUAGE EDITOR …………............................. v

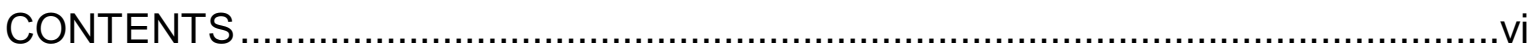

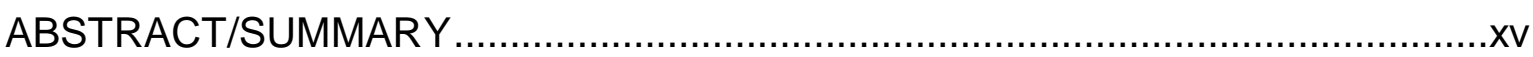

CHAPTER 1: INTRODUCTION AND ORIENTATION …....................................... 1

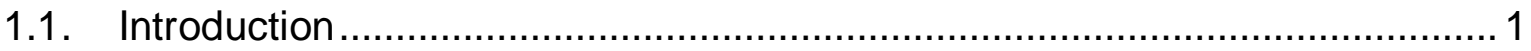

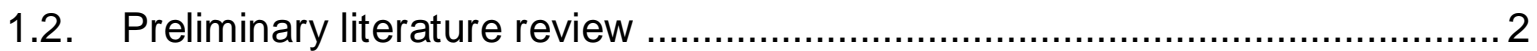

1.2.1. Traditional approaches to career counselling ..................................... 3

1.2.2. Postmodern approaches to career counselling .................................... 3

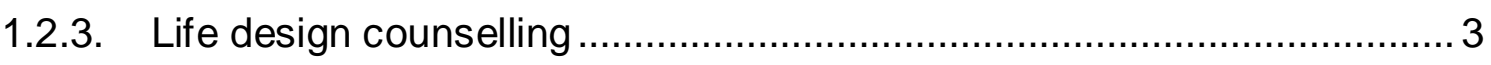

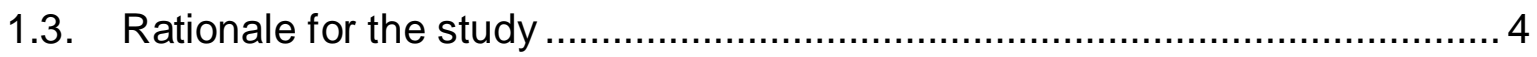

1.3.1. How my interest in the topic developed .......................................... 4

1.3.2. Why I believe the research was worth doing ...................................... 5

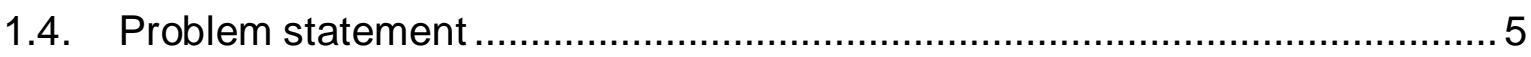

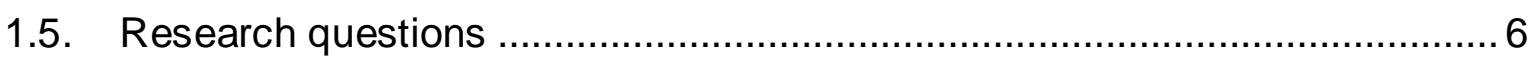

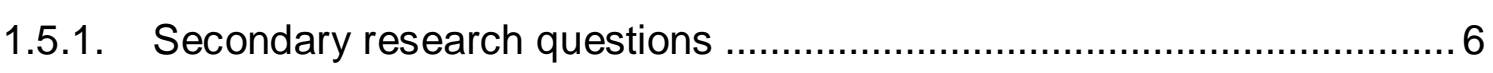

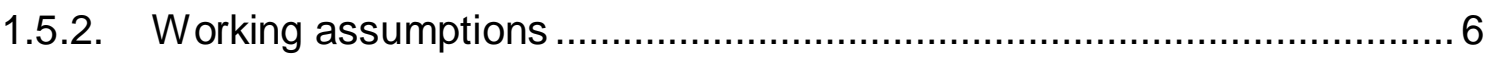

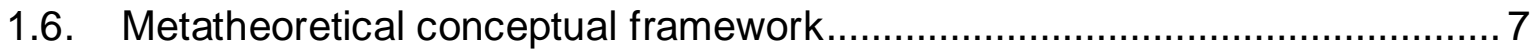

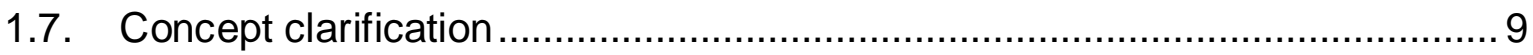

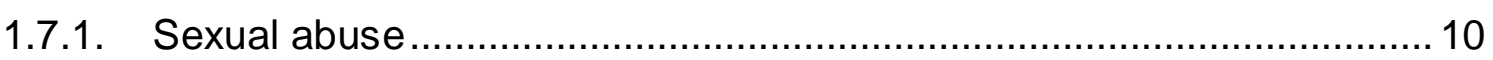

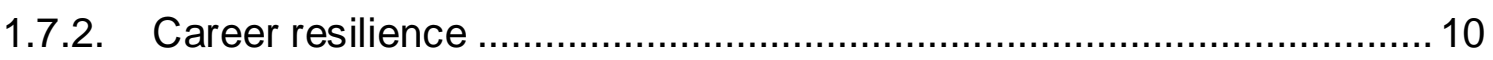

1.7.3. Narrative career counselling …...................................................... 10

1.7.4. Life design counselling ................................................................. 11

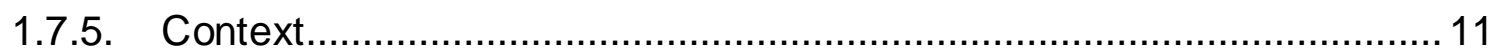

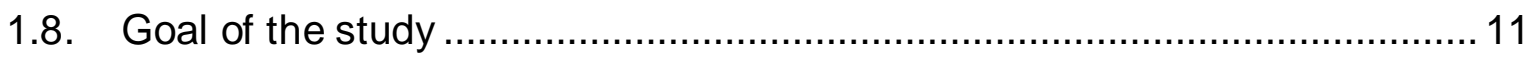

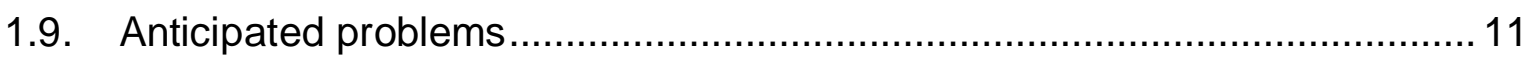

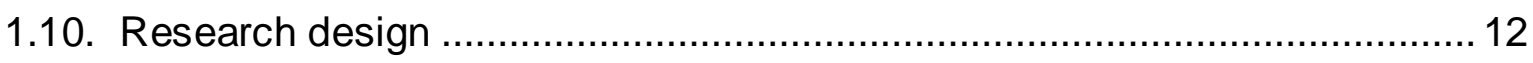

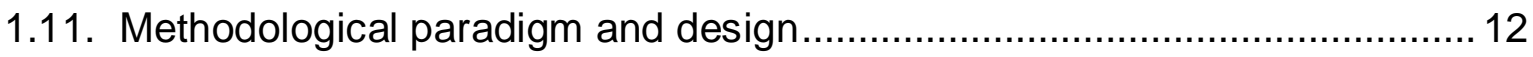




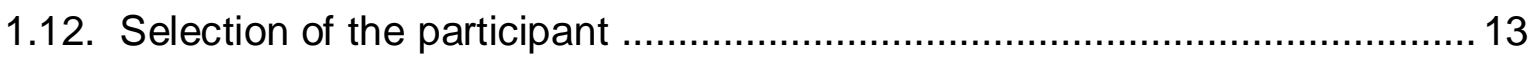

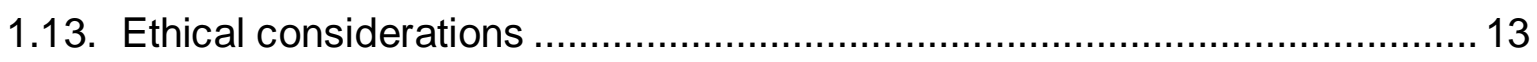

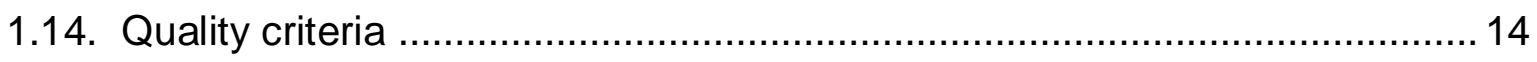

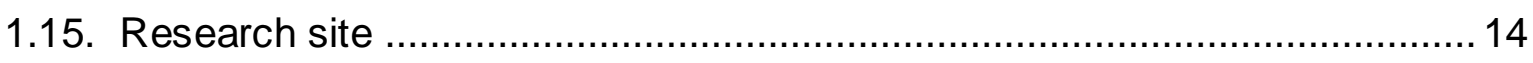

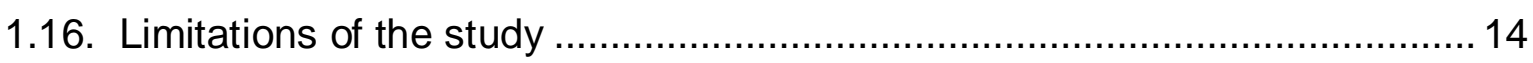

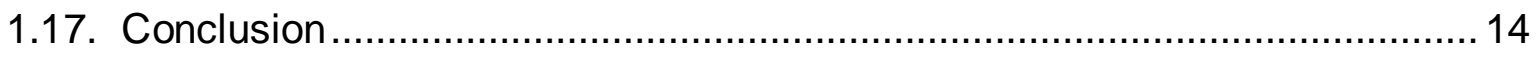

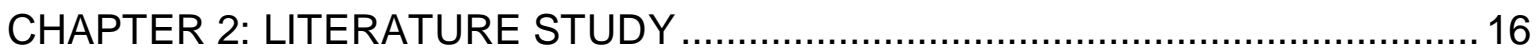

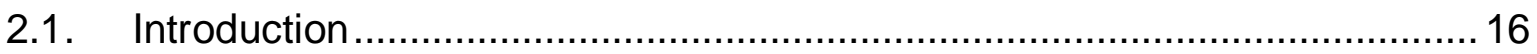

2.2. Historical background: career construction theory ................................... 16

2.2.1. Psychology of occupations ......................................................... 17

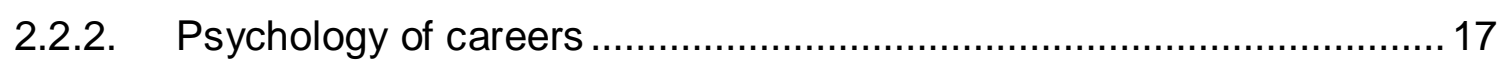

2.2.3. Psychology of life designing ....................................................... 18

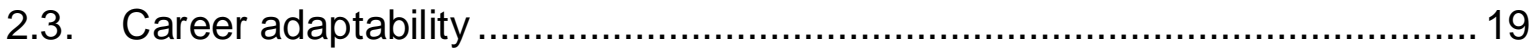

2.3.1. Central dimensions of career adaptability ......................................... 20

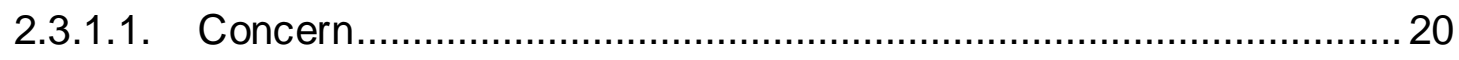

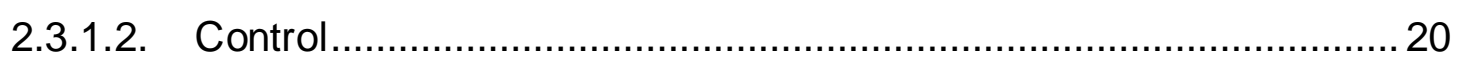

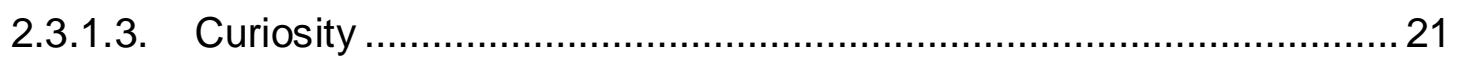

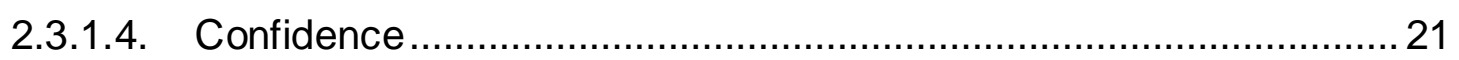

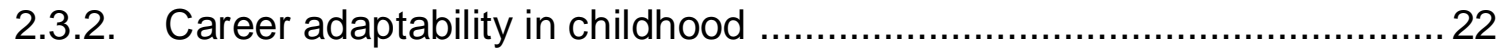

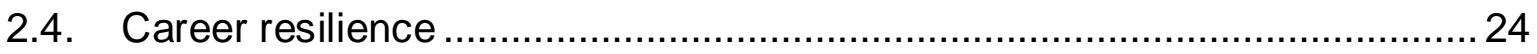

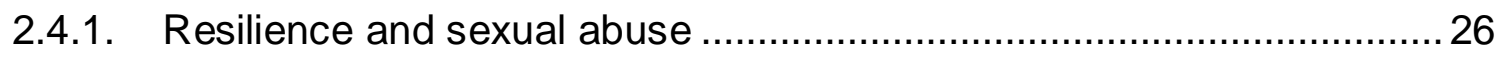

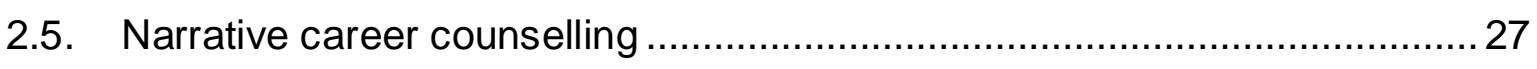

2.5.1. Life design counselling .............................................................. 28

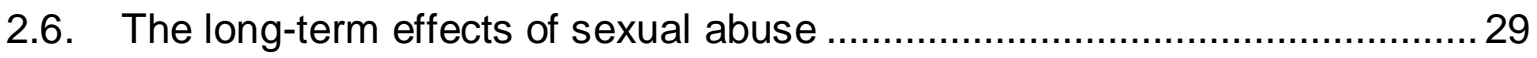

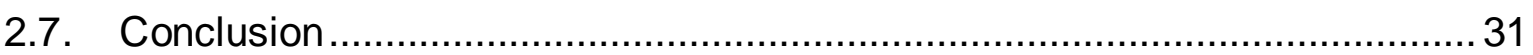

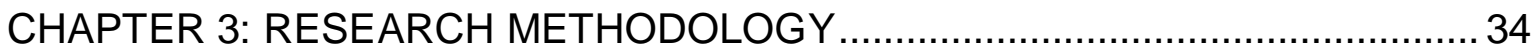

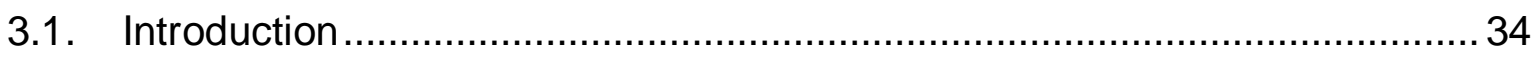

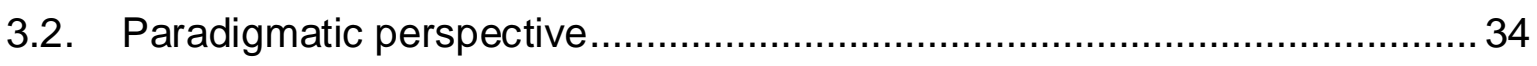

3.2.1. Interpretive/constructivist paradigm ............................................... 35

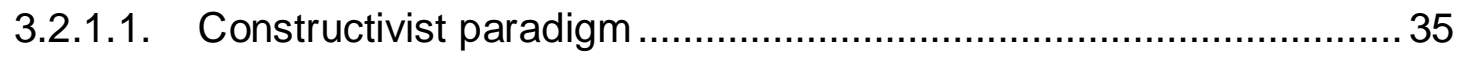

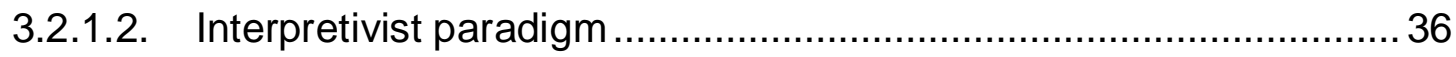

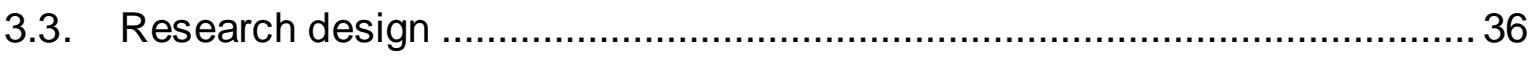

3.3.1. Characteristics of a research design ............................................. 37 


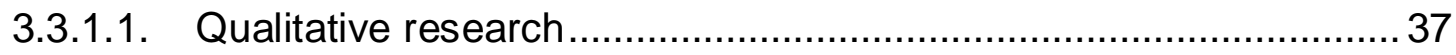

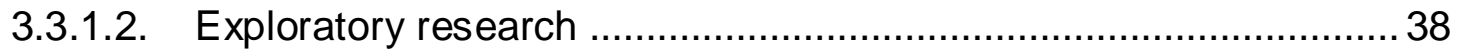

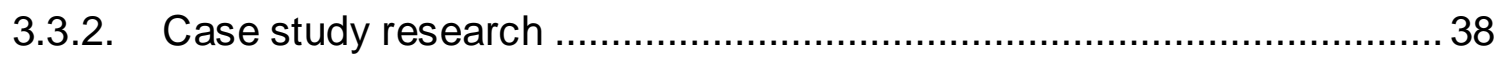

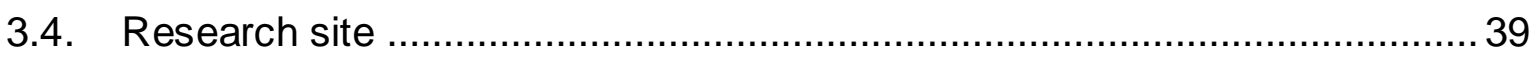

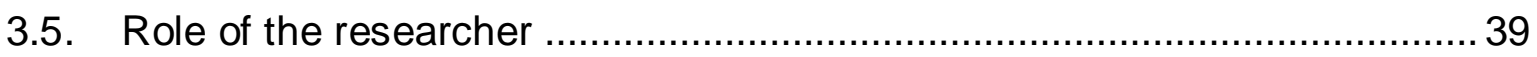

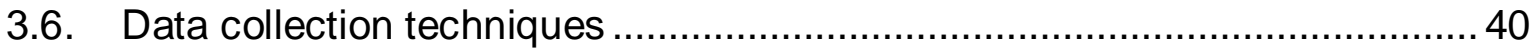

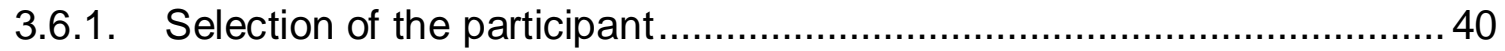

3.6.2. The life design counselling process ................................................. 41

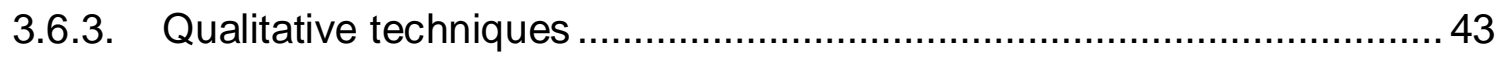

3.6.4. Postmodern data collection techniques ........................................... 44

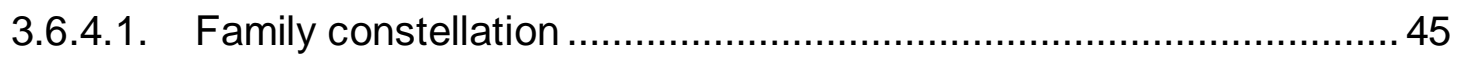

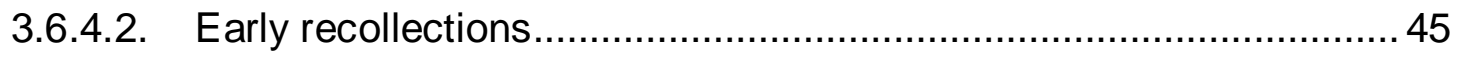

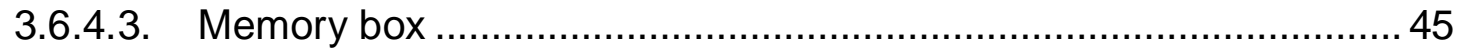

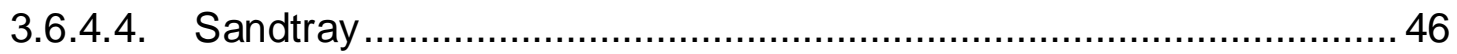

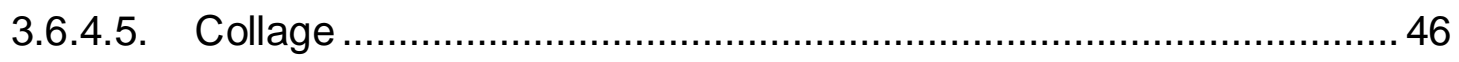

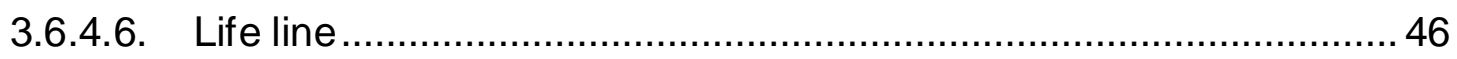

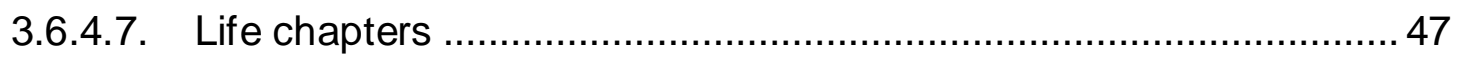

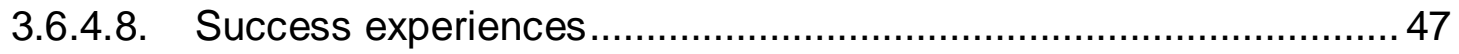

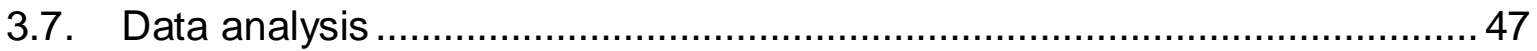

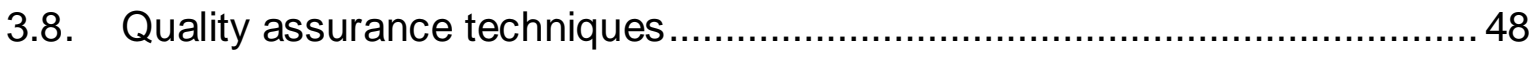

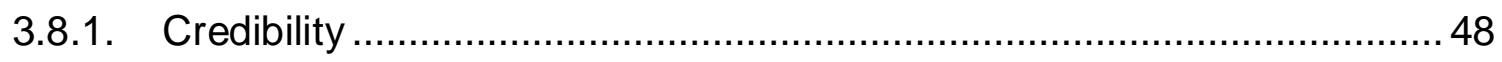

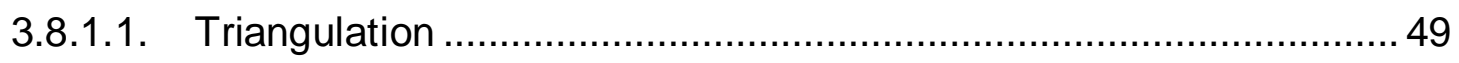

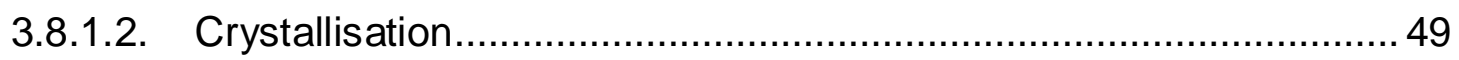

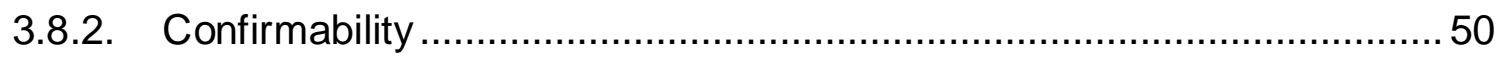

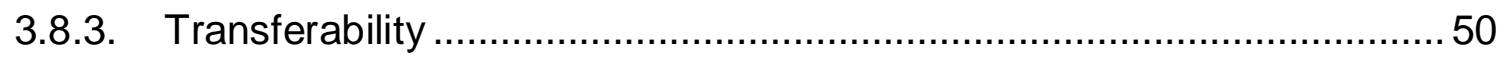

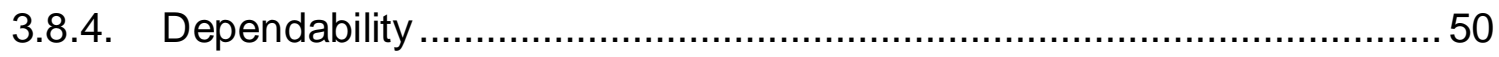

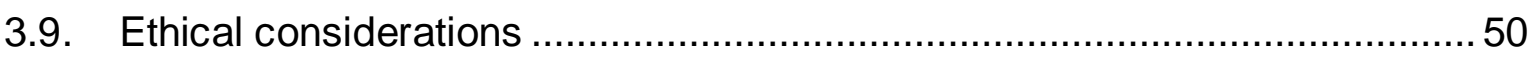

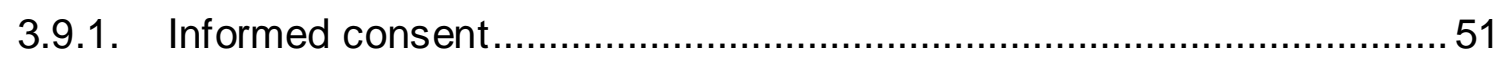

3.9.2. Privacy, confidentiality and anonymity ............................................ 51

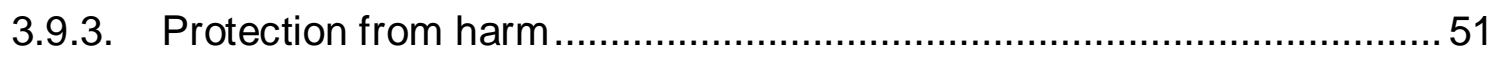

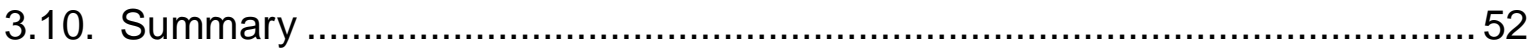

CHAPTER 4: RESULTS AND DISCUSSION ................................................... 54

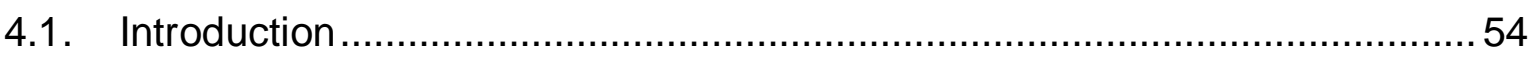


4.2. Data analysis methods.

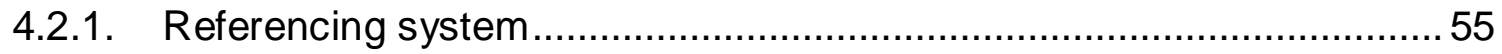

4.3. Background information of the participant............................................ 55

4.4. The process of life design counselling for Suzi .........................................56

4.4.1. Session 1: RSCA, family constellation exercise and genogram ............57

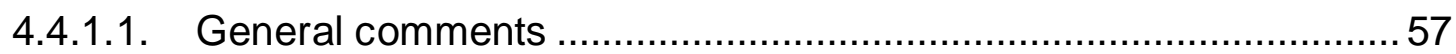

4.4.1.2. Course of the session and subthemes identified........................... 58

4.4.2. Session 2: Sandtray, Memory box, Early recollections ......................... 62

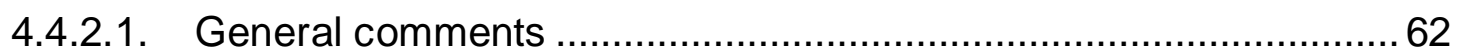

4.4.2.2. Course of the session and subthemes identified...........................62 62

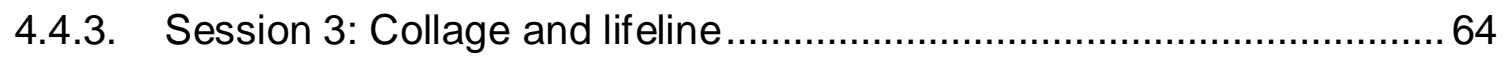

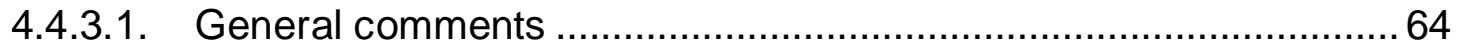

4.4.3.2. Course of the session and subthemes identified.......................... 65

4.4.4. Session 4: Life chapters (future narrative); Success experiences ........67

4.4.4.1. General comments and the researcher's observations ..................67 67

4.4.4.2. Course of the session and subthemes identified.............................67 67

4.4.5. Session 5: RSCA, Drawing (What will overcome obstacles?) ................ 70

4.4.5.1. General comments and researcher's observations ....................... 70

4.4.5.2. Course of the session and subthemes identified.......................... 70

4.5 Categorisation and summary of the identified themes ............................... 74

4.6. Comparison of resiliency scales and scale descriptions: Pre- and post-

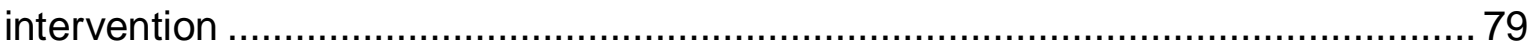

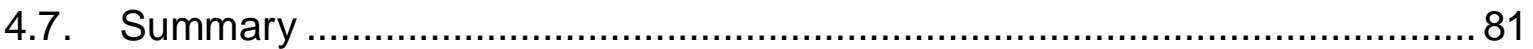

CHAPTER 5: SUMMARY AND RECOMMENDATIONS …............................... 82

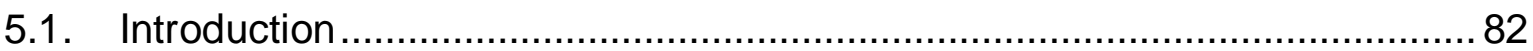

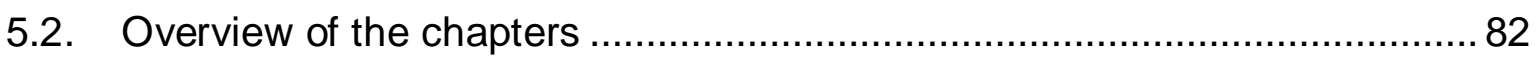

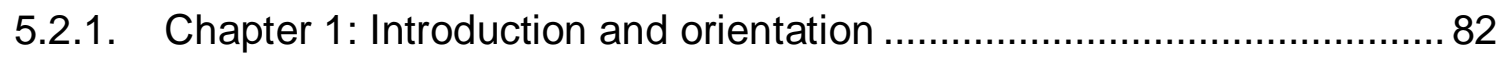

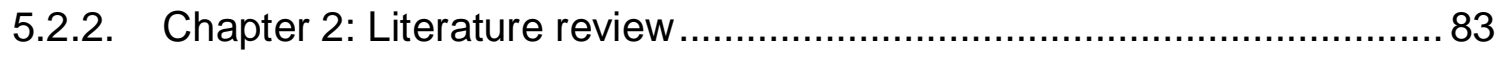

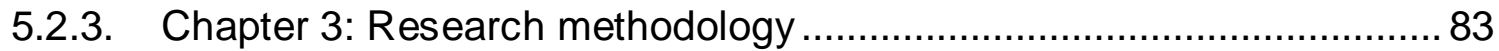

5.2.4. Chapter 4: Results and discussions ................................................... 84

5.3. Answering the primary and secondary research questions ........................ 84

5.3.1. What are the essential characteristics of sexual abuse, career resilience and life design counselling? 
5.3.2. What is the influence of sexual abuse on the career resilience of a sexual abuse survivor?.

5.3.3. How can sexual abuse survivors be assisted/how can their career resilience be enhanced through life design counselling?

5.3.4. How can the proposed study contribute to the theory and practice of life design counselling for sexual abuse survivors?

5.3.5. In which ways can using narrative career counselling enhance the career resilience of a survivor of sexual abuse?

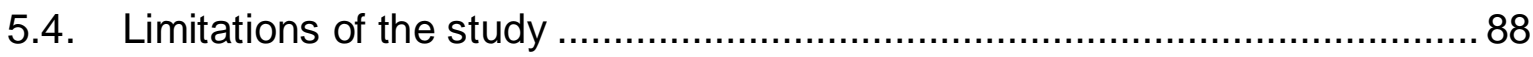

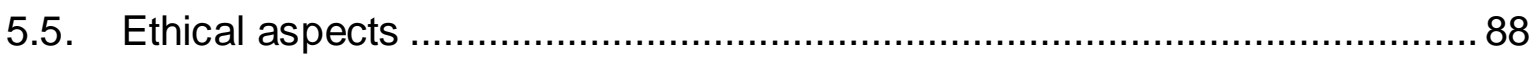

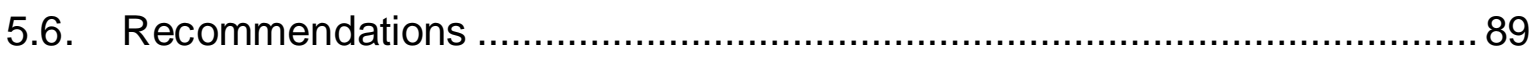

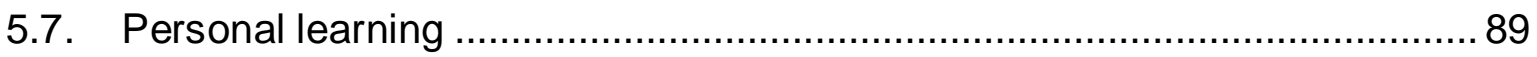

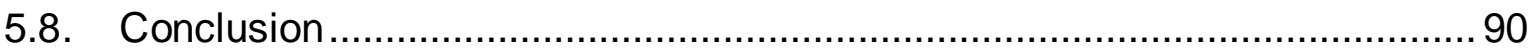

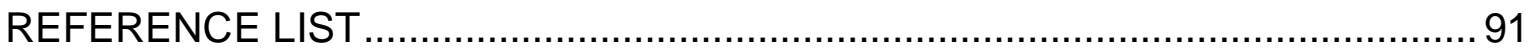


LIST OF ANNEXURES

$\mathbf{x i}$

LIST OF FIGURES

xii

LIST OF TABLES

xiii 


\section{LIST OF ANNEXURES}

ANNEXURE A: RSCA Resiliency Scales 108

ANNEXURE B: Memory Box. 110

ANNEXURE C: Sandtray 111

ANNEXURE D: Collage 112

ANNEXURE E: Lifeline. 113

ANNEXURE F: Drawing. 114

ANNEXURE G: Subthemes .115

ANNEXURE H: Reference system.... 118

ANNEXURE I: Request for informed consent from the participants' parents/guardians 119

ANNEXURE J: Request for informed assent from the participant. 124

ANNEXURE K: Ethical clearance certificate. 127

ANNEXURE L: Certificates of attendance for the research sup[port sessions..128 ANNEXURE M: CD with relevant transcripts 129 


\section{LIST OF FIGURES}

Figure 1.1: Metatheoretical, conceptual framework

Figure 3.1: Thematic content analysis process

Figure 4.1: Pre-intervention resiliency profile 58

Figure 4.2: Pre-intervention Resiliency Subscale Composition 59

Figure 4.3: Post-intervention resiliency profile 71

Figure 4.4: Post-intervention Resiliency Subscale Composition 


\section{LIST OF TABLES}

Table 3.1 Qualitative data techniques used in this study

Table 3.2: Life design intervention strategies

Table 4.1: Data analysis method 55

Table 4.2: Pre-intervention resiliency scale - descriptive categories $\quad 59$

Table 4.3: Session 1 Subthemes 61

Table 4.4: Session 2 Subthemes 64

Table 4.5: Session 3 Subthemes 66

Table 4.6: Session 4 Subthemes 69

Table 4.7: Post-intervention resiliency scale descriptive categories $\quad 71$

Table 4.8: Session 5 Subthemes 73

Table 4.9: Summary of main and subthemes 75

Table 4.10: Comparison of resiliency scales and scale descriptions 80 


\title{
ABSTRACT/SUMMARY
}

\section{IMPROVING THE CAREER RESILIENCE OF A SURVIVOR OF SEXUAL ABUSE}

\author{
Cobus J. Venter
}

\author{
Supervisor: $\quad$ Prof. J.G. Maree \\ Degree: Magister Educationis (Educational Psychology) \\ Department: Department of Educational Psychology, University of Pretoria
}

As an educational psychologist in training, my experiences over the past few years have been characterised by repeated exposure to sexual abuse among children, along with the realisation that little is being done to promote the career resilience of sexual abuse survivors. There is, according to my knowledge, only scant literature available on victims of sexual abuse who are still presiding in the same environment in which the sexual abuse occurred. The lack of research is extremely distressing. It increased my interest in how I could assist survivors of sexual abuse to create more resilient and healthy lives.

Sexual abuse has been shown to cause symptoms of depression, feelings of low self-worth, low moral judgment and feelings of guilt (Van Rensburg \& Barnard, 2005). Sexual abuse is a global phenomenon that affects the social and mental health of individuals, with calamitous consequences in different cultures. This leads to great concern about the future career paths of the victims of such abuse (Mathews, Loots, Sikweyiya \& Jewkes, n.d., p. 86).

In this study I attempt to enhance the career resilience of a sexual abuse survivor by means of life design counselling. Life design counselling is essentially a narrative approach that allows people to constantly derive meaning from their life experiences, understand them and construct better narratives (McMahon, Watson, Chetty \& Hoelson, 2012). The research questions that will be explored during this study focus mainly on the characteristics of sexual abuse and career resilience, the influence of sexual abuse on career resilience and how life design counselling can contribute to the career resilience of survivors of sexual abuse. 
The study is based on a single case study (intrinsic) that aims to determine whether life design counselling and the various narrative techniques can enhance the career resilience of a survivor of sexual abuse. The study is of a qualitative and exploratory nature, which implies that qualitative techniques and information will receive priority. Qualitative techniques that will be used include the following: Family constellation; Genogram; Early recollections; Memory box; Sandtray; Collage; Lifeline; Life chapters (future narrative); Success Experiences and Drawing (What will overcome obstacles). Quantitative techniques (in the form of a standardised psychometric questionnaire) will however also be used, which means that this study will be based on a QUALITATIVE-quantitative approach. The Resiliency Scales for Children and Adolescents (RSCA) is the only standardised questionnaire that will be used. Thematic analysis will be done along with informal interviews to interpret and make meaning of the data.

I hope to make recommendations that will contribute to the topic and phenomenon being studied and that will ultimately enhance the career resilience of the participant. 


\section{LIST OF KEY WORDS}

Narrative counselling

Life design counselling

Sexual abuse

Resilience

Adaptability

Case study

Generalisability 


\section{LIST OF ABBREVIATIONS}

CBT

Cognitive-behavioural therapy

CSA

Childhood Sexual Abuse

RSCA

Resiliency Scales for Children and Adolescents

PTSD

Post-traumatic stress disorder

SIFs

Subjective Identity Forms

SSIF

System of Subjective Identity Forms 


\section{CHAPTER 1: INTRODUCTION AND ORIENTATION}

\subsection{Introduction}

"When you feel caught in the web of childhood abuse, find words to describe it. Write them. Say them. Express them. In safe places, with safe people." Jeanne McElvaney (2015)

(http://www.gotospirit.com)

The above quote communicates exactly what this study aimed to achieve and in what manner it attempted to do so. The number of sexual abuse cases involving children under the age of 14 years in South Africa is rising annually. Moreover, research reports that Africa has the highest CSA rate in the world, estimating the number at $34.4 \%$ (Singh, Parsekar \& Nair, 2014). Not only is sexual abuse becoming increasingly prevalent among girls, but more and more research points to the fact that sexual abuse of boys is also increasing - both nationally and internationally (Singh et al., 2014). One in six of all sexual abuse cases reported in South Africa involves a girl under the age of 12 years and one in ten men report that they were sexually abused by another male during their childhood years (Mathews et al., n.d.).

Contributing factors to this deplorable increase in sexual abuse within the South African context can be listed as (a) the patriarchal constructions of masculinity, (b) unequal power relations promoting male sexual entitlement, (c) parenting practices, (d) harsh discipline, and (e) the unwavering respect for elders (Mathews et al., n.d., p. 84). Research done by Raabe, Ehring, Marquenie, Olff and Kindt (2015) on the effectiveness of trauma-focused cognitive-behavioural therapies (CBTs), particularly those used in the case of prolonged exposure to childhood sexual abuse, found that these approaches are lagging behind. Their study also indicates that most clinicians are inclined to use stabilising treatments, seeing that the effectiveness of other treatments is still questionable (Raabe et al., 2015).

Research indicates that immediate trauma-focused treatment may not be effective and claims that there is a clinical need for suitable treatments for patients with pathology related to child abuse (Dorrepaal et al., 2013). As a result, clinicians first 
engage in stabilising treatments such as psycho-education, affect regulation skills and cognitive restructuring on trauma-related and interpersonal issues before they start with trauma-focused CBT (Dorrepaal et al., 2013). Although these stabilising treatments are effective with child abuse-related PTSD, some studies cannot prove the validity of such results (de Jongh \& Ten Broeke, 2014), which reemphasises the need for an alternative intervention strategy.

Considering the positive correlation between childhood sexual abuse (CSA) and behavioural disorders, psychopathology, eating disorders, substance abuse and an increase in risky behaviours, we can appreciate the fact that a novel strategy is needed (Coles, Lee, Taft, Mazza \& Loxton, 2015). The fact that South Africa approaches CSA mainly from a medico-legal perspective with little focus on emotional well-being reiterates the importance of a strategy that strongly emphasises the restoration of CSA survivors' well-being (Mathews et al, n.d., p. 84).

This study took into account the South African context, the participants' subjective experience and the fact that in most cases these children cannot be removed to a place of safety as there are too many victims and not enough suitable places for them to go to. In Chapter 1 I give a brief preliminary overview of the literature, my goal and subsequent motivation for the research study, the problem statement and a conceptual framework. Concept clarification, my role as the researcher and possible limitations of the study are also discussed.

\subsection{Preliminary literature review}

A major movement within the field of psychology and counselling is towards a postmodern approach that takes into consideration people's subjective experiences and the meaning they assign to such experiences (Savickas et al., 2009). Contemporary methods should therefore be dynamic and emphasise life trajectories that individuals are encouraged to design so that they may gradually build their lives and assign their own meaning to it (Di Fabio \& Maree, 2013). The focus of the study in hand was therefore to determine the value of life design counselling in the South African context with regard to child survivors of sexual abuse. Sexual abuse was investigated, but also its implications for self-construction and career resilience. The investigation was hoped 
to potentially contribute positively to the negative consequences associated with this regrettable epidemic, as life designing assists people to formulate adaptive responses to developmental tasks and traumas (Van Esbroeck \& Maree, 2010).

\subsubsection{Traditional approaches to career counselling}

Traditional approaches to career counselling were based mainly on quantitative strategies. A major shortcoming of this approach was that clients were frequently objectified through psychometric measures that were unable to help clients manage, embrace and satisfactorily deal with changes within the work or career environment (Maree, 2013). The arrival of the fourth economic wave not only changed the economic arena, but also encouraged counsellors to find a more postmodern approach towards career counselling.

\subsubsection{Postmodern approaches to career counselling}

The postmodern approach allows career counsellors to take into consideration people's experiences and the meaning they construct from such experiences (Savickas, 2012; Maree, 2013). Both Savickas and Maree agree that the postmodern approach to career counselling strongly highlights people's social identity and their sense of self-worth; viewing them as infinitely more than mere test scores (Savickas et al., 2009; Maree, 2013). The fundamental changes that have taken place in the world of work over the past few decades, and the associated need for people to become more adaptable, encapsulate the central theme and concept in the life design paradigm (Di Fabio \& Maree, 2013).

\subsubsection{Life design counselling}

Nota and Rossier (2015) assert that life designing is a collaborative process that includes a holistic and contextual consideration of the various experiences and influences within a person's life, highlighting activity, intentionality, adaptability and narratability (Savickas et al., 2009; Nota \& Rossier, 2015). In life design counselling, vocational guidance no longer occurs in a vacuum and the various influences of the 
surrounding systems on the person are considered (Maree, 2010). This is the approach that applied in this study and the context in which it took place.

Nota and Rossier (2015) assert that life design as a strategy is ideally suited to apply when children are counselled. This is because children playfully construct future selves (which are central to life designing as well as parallel to the goals of life designing) during their childhood years. Children repeat and rehearse behaviours that are influenced and shaped by home and school environments, and that essentially form part of the child's emerging socially situated reputation (Nota \& Rossier, 2015).

\subsection{Rationale for the study}

The rationale of a research project involves two components: it serves to indicate how the researcher developed an interest in the particular topic and it explains why the researcher finds the project worth doing (Maree, 2007; Maree \& Van der Westhuizen, 2009; Vithal \& Jansen, 2004).

\subsubsection{How my interest in the topic developed}

As an educational psychologist in training, my observations and experiences over the past few years allowed me to witness many victims of sexual abuse. What was disconcerting to me was the fact that these children could not be removed to a place of safety because (a) sexual abuse could not be proven via concrete evidence and/or (b) there were not enough places of safety for these children due to the overwhelming number of reported cases. Although working with these children posed a major emotional challenge to psychologists and social workers alike, protecting the psychological well-being of such children was even more challenging. It was especially worrying to me that so little was being done to promote the career resilience of survivors of sexual abuse. These children remained behind in unsafe environments, and this had a detrimental effect on their future success. In addition, not enough was being done to stem this inexcusable epidemic. 


\subsubsection{Why I believe the research was worth doing}

Sexual abuse has been shown to cause symptoms of depression, feelings of low selfworth, low moral judgment and feelings of guilt (Van Rensburg \& Barnard, 2005). Fryda and Hulme (2015) confirm the effects of CSA and indicate its role in the development of anxiety, depression, hostility, interpersonal sensitivity and interpersonal problems, to name a few. Sexual abuse is a global phenomenon that affects the social and mental health of individuals, with calamitous consequences in different cultures. This leads to serious concerns about the future career paths of such individuals (Mathews et al., n.d., p. 84).

It seems clear from what has been stated so far that much research has been conducted on sexual abuse and the effects thereof on the child victim. However, I found it quite a challenge to find any information or intervention strategies that focused on survivors of sexual abuse who still presided in the environment in which the sexual abuse had taken place. I therefore believe that research on the topic is sorely needed; not only to fill a gap in the literature but, more importantly, to find ways to empower counsellors to curb the effects of sexual abuse.

Life design counselling is essentially a narrative approach that brings into the equation a sense of authorship and control for individuals, as it allows them to deconstruct previous unsought and unwanted stories. Research indicates that through this approach people are constantly allowed to give meaning to their life experiences, to understand them and construct better narratives (McMahon et al., 2012). Life design counselling has been proven successful in allowing people to make sense of trauma and construct newer, healthier stories in anticipation of a better future (Lara \& Vess, 2014). I therefore undertook this research as I believed that it would not only (a) contribute to existing knowledge within the field of resilience, life-design and sexual abuse, but also (b) improve intervention strategies aimed at survivors of sexual abuse.

\subsection{Problem statement}

In my work situation over the past five years I have been continually exposed to child victims of sexual abuse and I consequently became increasingly concerned about the universal nature thereof. Even more disconcerting was the fact that there exists very 
little literature that addresses the situation of victims of sexual abuse who have remained in the same environment in which the sexual abuse took place. In fact, I could not find any such literature. This is distressing and subsequently increased my interest in how I could assist survivors of sexual abuse in creating more resilient and healthy lives for themselves. If one considers that in Gauteng one in every six rape cases (heavily underestimated) reported to the police during 2003 involved a girl under the age of 12 who had been repeatedly abused (Mathews et al, n.d., p. 84), it becomes apparent that research on the topic of child abuse and enhancing the resilience of survivors of sexual abuse can be extremely valuable. We need to find ways in which to deal with this universal challenge, which is what I aimed to accomplish in my study.

\subsection{Research questions}

The primary research question that was answered in this study is as follows:

In which ways can using narrative career counselling enhance the career resilience of a survivor of sexual abuse?

\subsubsection{Secondary research questions}

The following secondary questions were derived from the primary research question:

- What are the essential characteristics of sexual abuse, career resilience and life design counselling?

- What is the influence of sexual abuse on the career resilience of a sexual abuse survivor?

- How can sexual abuse survivors be assisted/ how can their career resilience be enhanced through life design counselling?

- How can this study contribute to the theory and practice of life design counselling for sexual abuse survivors?

\subsubsection{Working assumptions}

The following working assumptions were made within the context of the current study:

- Life design counselling can potentially enhance the career resilience of a sexual abuse survivor. 
- Sexual abuse can potentially influence the career resilience of a sexual abuse survivor.

- Life design counselling can provide sexual abuse survivors with a means to articulate previously unexpressed, deep emotional needs and experiences.

- The results of the proposed study might contribute to theoretical knowledge and equip career counsellors to provide better services for sexual abuse survivors.

\subsection{Metatheoretical conceptual framework}

According to Maree a conceptual framework provides the researcher with a platform to approach a proposed study based on ideas already existing in the field, aiding as a lens or perspective through which one can understand the specific construct you are investigating (Maree, 2012; Maree \& van der Westhuizen, 2009). In short, a conceptual framework does not exist in the context of theories but is a well-developed explanation for events (Vithal \& Jansen, 2004). This study investigated the influence of life design counselling on enhancing the career resilience of a survivor of sexual abuse within the theoretical paradigms of social constructionism and systems theory.

Maree (2013) contends that life designing is grounded in social constructionism, and that people construct their reality through language and social interaction. Burr (2015) makes the argument that social constructionism focuses on the social practices and consequent interactions between people and therefore re-locates problems away from the individual. Problems are subsequently not viewed as inherent to the individual but as a result of social interactions.

The abovementioned theory conforms to what psychologists call the self-concept or subjective identity forms (SIFs), which indicate various ways of being, acting and interacting within a given setting (Di Fabio \& Maree, 2013). Guichard contends that each person constructs a variety of identities depending on the context (Guichard, Pouyaud, de Calan \& Dumora, 2012). Such identities are based on (a) how a person interacts at a certain point in their life, (b) future aspirations regarding one's own identity or self-expectations, and (c) past experiences that have a lasting impression on the individual's identity (Di Fabio \& Maree, 2013). SIFs can therefore be multiple, diverse 
identities stretching over time through various contexts, a construct that is known as a system of subjective identity forms (SSIFs) (Guichard et al., 2012).

Working from a social constructionist viewpoint we can subsequently presuppose that individual identity revolves around the individual's SSIFs, while future expectations will largely depend on these ideals/roles placed on the individual (Di Fabio \& Maree, 2013). Viewed from this perspective we need to contemplate the effects of sexual abuse on the future SIFs of survivors of sexual abuse. If future SIFs in children are based primarily on a certain character image with which the child associates, then the importance of good role models and a safe environment becomes even more influential (systems theory).

Being a survivor of sexual abuse will inherently mean that SIFs that could lead to positive future aspirations are in possible dispute, especially if the individual still resides within the toxic environment where the abuse took place. From this mindset, systems theory can be seen as allowing for greater contextual consideration, as well as emphasising and highlighting the effect of sexual abuse on individuals, as well as on their SIFs. Guichard supports the above view and asserts that each person constructs a variety of identities depending on the context (Guichard et al., 2012).

For the purposes of the current study, the existential-phenomenological worldview was also incorporated into the framework, emphasising individual choice and experience, and accentuating the fact that both professional and personal identities could be changed by a person's actions (Teixeira \& Gomes, 2000). The focus therefore was on the individual being the primary agent of change, invoking self-efficacy and the belief to influence his/her own behaviour. Grounded in social constructionism and career construction, counselling is the narrative framework that aims to promote the construction of new realities through the storied approach. It also emphasises narratability, which refers to an individual's ability to tell his/her own life story (Maree, 2013; Di Fabio \& Maree, 2013). According to Maree (2010) this approach allows individuals to make meaning, write their own life stories and in the process construct a new future. Operating from a storied approach allows the acknowledgement of difficult histories while transcending them in the process of creating a new reality (Maree, 2013). The inclusion of the above theories in the study aimed to increase the narrative identity 
of the participant, thereby increasing who she was as lead character within her own life story.

It is worth noting that this study was conducted within a specific and unique context that had to be taken into consideration. A visual illustration of the conceptual framework underpinning the proposed study follows.

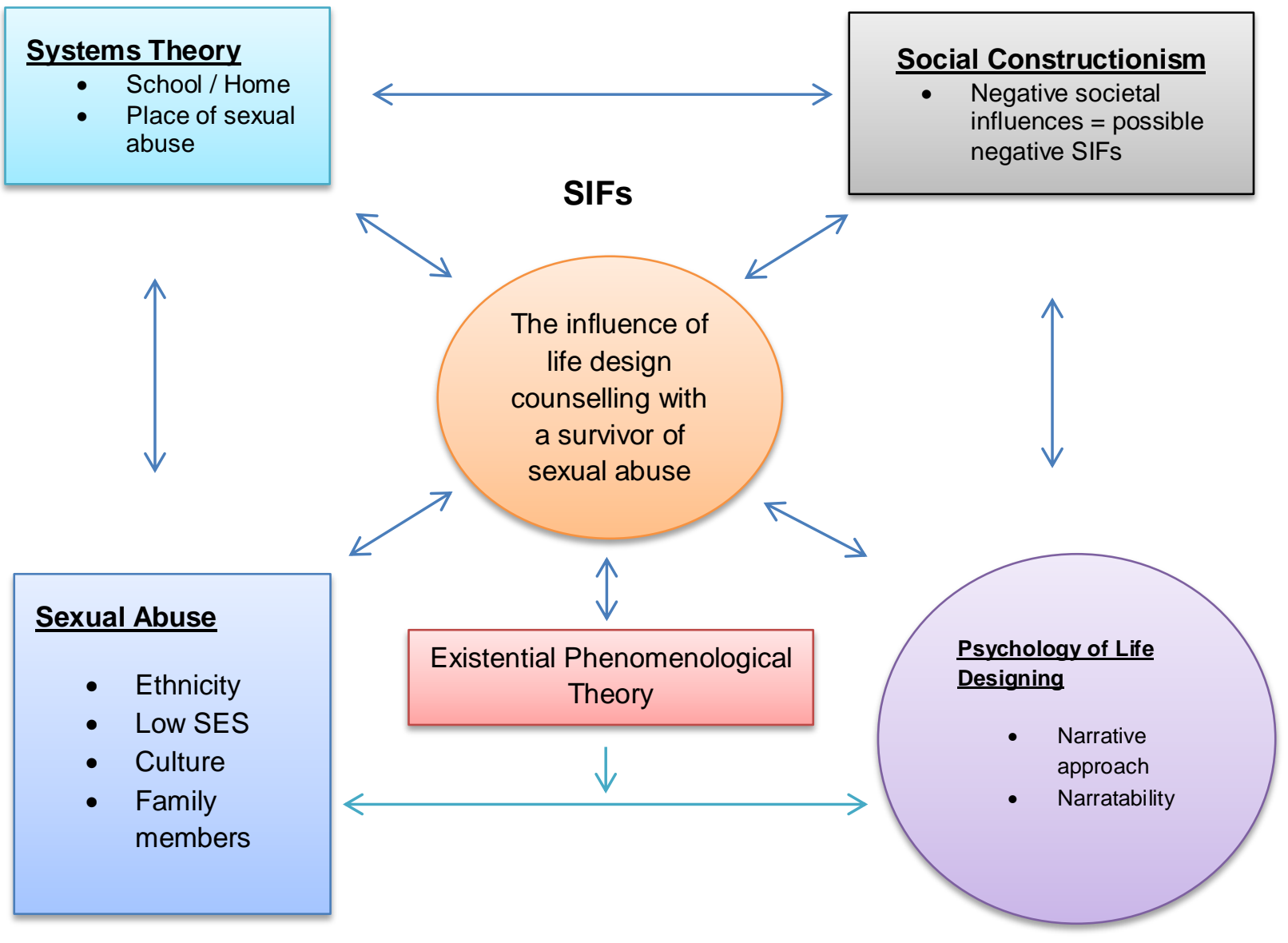

Figure 1.1 Metatheoretical conceptual framework

Due to the complex nature of the above concepts, the following section will discuss each concept individually to provide more clarity on the core concepts and how they will subsequently direct this research study within a specific context.

\subsection{Concept clarification}

The following concepts that were used in this study are clarified and defined in more detail below. 


\subsubsection{Sexual abuse}

In accordance with the Criminal Law Amendment Act of 2007, sexual abuse is "any act which results in the exploitation of a child, whether with their consent or not, for the purposes of sexual or erotic gratification" (Criminal Law Amendment Act, 2007, p. 14). Because of South Africa's diverse social context, definitions on child sexual abuse can be limited; at times inaccurately defining what sexual abuse involves. In the South African context the patriarchal constructions of masculinity still motivate male over female dominance and sexual abuse may be seen as an act of dominance or sexual entitlement (Mathews et al., n.d.). Child sexual abuse within the proposed study therefore refers to any unlawful act, such as rape or exposing a child to pornography, in such a way that it carries a sexual connotation. This interpretation is motivated by the variety of cultures within South Africa, taking into consideration the social context, economic class, ethnicity, as well as the role of the family. The interpretation is crucial to ensure that any acts of sexual abuse are identified without ambiguity, regardless of race, social context or gender.

\subsubsection{Career resilience}

Career resilience is seen as the ability to adapt to changing environments, coping with adversity and change, while maintaining a positive attitude in the process of moving towards a state of self-actualisation (Bimrose \& Hearne, 2012). Paul and Garg (2014) conceptualise career resilience as the individual's ability to endure and recover from extreme conditions, setbacks, trauma and other adversity, indicating a high level of persistence during adversity.

\subsubsection{Narrative career counselling}

Narrative career counselling refers to guiding individuals in creating more complete life stories while regarding them as active participants in constructing their identity by emphasising constructs of connectedness, meaning making and agency (Maree, 2012; Nota \& Rossier, 2015). Mcllveen and Patton (2007) define narrative career counselling, (within the context of systems theory framework), as an attempt to bring meaning to the 
variety of personal and environmental influences on a person in construing their own career.

\subsubsection{Life design counselling}

Life design counselling implements Guichard's theory of self-construction and Savickas's theory of career construction counselling, which are based on social constructionism that views the individual's knowledge and identity as products of social interaction that were co-constructed through discourse (Savickas et al., 2009). Life design counselling is life-long, holistic and contextual, focusing on designing preferred futures (Nota \& Rossier, 2015).

\subsubsection{Context}

Context refers to the relationship between the individual and his/her environment and the interaction that occurs within this system, inclusive of social, political and relationship influences (Zunker, 1998).

\subsection{Goal of the study}

The goal of this research study was to investigate the possibility of enhancing the career resilience of a survivor of sexual abuse through life design counselling. By investigating the effect of life design counselling, the researcher aimed to identify strengths within the life design counselling process that could possibly lead to the improvement of career resilience with regard to survivors of sexual abuse.

\subsection{Anticipated problems}

The first aspect of the study that could be challenging involved finding a suitable participant. The possibility existed that a suitable participant for the study would not be found within the organisation in which the study was taking place. If such a scenario occurred, the researcher would need to look outside the organisation for a participant that embodied all the characteristics needed by the participant as delineated in Section 1.10.2, the selection of a participant. Possible logistical arrangements would also need to be altered to accommodate the new participant. 
Secondly the participant might well decide to withdraw from the study. This would mean that the researcher would need to repeat the process of selecting a suitable participant, as well as the data collection process.

\subsection{Research design}

A research design can be seen as a plan for studying the research problem, guided by the research questions and the purpose of the study (Glatthorn \& Joyner, 2005; Maree, 2012). Mason (2013) rejects the idea of establishing a blueprint or an a priori strategy, but views research design in qualitative research as fluid and flexible in facilitating coherent and rigorous development of the research project. The following section will describe the research design of the current study in detail.

\subsection{Methodological paradigm and design}

Creswell (2008) and Stake (2005) distinguish between two main types of single case studies. In the intrinsic case study, researchers are primarily interested in understanding a specific individual or situation. The particulars of an individual case are described to shed light on the matter at hand and not so much to understand a broad social issue. In the instrumental case study, a social issue is investigated to demonstrate the issue, understand it and facilitate possible generalisations. In my study generalisation was not the aim at all.

The study in hand was a qualitative one with an intrinsic case study design. Nieuwenhuis (2007) observes that qualitative research aims to understand people in their natural environments rather than doing so by means of statistical analysis. Qualitative research wishes to understand and make sense of a person's experiences, feelings, social situations or a certain phenomenon that occurs in the real world (Terre Blanche, Durrheim \& Painter, 2006). An intrinsic case study, as defined by Robert Stake, is described as an exploratory study in which the researcher desires to know more about the uniqueness of a certain case and/or phenomenon (Stake, 1995). The case study is subsequently used by researchers who have a genuine interest in the proposed case study (Stake, 1995). An intrinsic case study design will therefore allow the researcher/counsellor to focus on the specific participant, as well as the 
phenomenon. One advantage of this methodological paradigm is the fact that it is not tightly prefigured. This means that research questions can be configured or altered as the research process unfolds and new themes come to the fore (Cresswell, 2003).

A qualitative research paradigm will provide a good foundation for the collection of data, considering important factors and dominant themes that unfold as the research proceeds.

\subsection{Selection of the participant}

As stated previously, sampling within a case study consists of finding a case either through probability or purposive sampling in a manner that is consistent with the purpose of the study (Maree, 2012). In the current study, a single participant therefore had to be selected through purposive sampling on the basis of certain characteristics which he/she had to possess. The participant had to meet specific selection criteria, namely he/she had to be:

- between the age of 9 and 14 years;

- $\quad$ still in primary school;

- $\quad$ residing with the family where sexual abuse occurred;

- a survivor of sexual abuse; and

- motivated to engage in life design counselling as this would increase the personal enrichment experienced by the participant, which is intrinsic to the study.

\subsection{Ethical considerations}

In my study I followed the ethical guidelines delineated by Orb, Eisenhauer and Wynaden (2001) who predict that a balanced qualitative research relationship will foster and encourage awareness of possible ethical issues, disclosure and trust. Orb et al. (2001) refer to justice as being a cornerstone of research, implying that the participant will not be abused or exploited - a principle that was central to the study in hand. The participant was able to withdraw from the study whenever he/she felt that he/she did not want to continue anymore, without experiencing any consequences. Privacy, anonymity and confidentiality was assured by using a pseudonym throughout the study and 
ensuring that his/her identity would not be made known during the different stages of the study. Additional ethical considerations are discussed comprehensively and in more detail in Chapter 3.

\subsection{Quality criteria}

Quality assurance strategies were implemented during the data collection and data analysis phases to ensure the dependability and trustworthiness of the study. These strategies are discussed in more detail in Chapter 3.

\subsection{Research site}

The research study was conducted at Eleos, a non-profit organisation. Since the researcher was already employed by the organisation and the potential participant lived in this area, the research site would be easily accessible by both the researcher and participant. The offices of Eleos also had all the necessary facilities needed for data collection to be done in a trustworthy and dependable manner.

\subsection{Limitations of the study}

Case study research is by no means without its pitfalls. Because only a single participant was used, generalisation of results was not an aim of the study. Crowe et al. (2011) argue that the subjectivity of the researcher may also influence the study negatively. Potential barriers affecting the quality of information gained from the current study were the availability of participants and the validity of information gained from the participant(s) (Kelliher, 2012; Maree, 2012).

\subsection{Conclusion}

This chapter served as a backdrop to the study that was undertaken. I briefly explored the motivation behind this study as well as how it relates to the South African context. Literature was briefly explored, situating the study and the study problem within sound theoretical knowledge. I explored the importance and need for this study and focused on specific research questions to which the study would aim to provide answers. 
Furthermore, the conceptual framework that directed the research and that would act as a lens through which the study would be approached, was explored. I clarified constructs as they pertained to my study, the requirements for how the participant would be selected, as well as ethical considerations that would ensure the execution of the research in accordance with good and ethical practice. 


\section{CHAPTER 2: LITERATURE STUDY}

\subsection{Introduction}

The purpose of this chapter is to provide the reader with a methodical and extensive description of theory that underlines and guides this study. The modus operandi and structure of this chapter will firstly entail providing an overview on the historical evolution of career construction theory, as well as the various waves of psychology supporting this movement in a foundational sense. Career adaptability will be reviewed next with a focus on the reciprocal relationship between individuals and their environment, its central dimensions and what specific aspects of it relate to childhood. Then career resilience will be considered, how it relates to survivors of sexual abuse, as well as various separate factors influencing career resilience. Narrative career counselling as well as life design counselling will be discussed extensively before concluding this chapter with a discussion on sexual abuse-related legislation pertaining to the South African context and why research focusing on survivors of sexual abuse is greatly needed.

\subsection{Historical background: career construction theory}

The career construction theory of Savickas builds on Super's construct of thematic extrapolation, which emphasises self-reflection and the meaning of certain events for one's own life (Stead \& Watson, 2006). Savickas places much focus on a contextualist ${ }^{1}$ worldview in career construction theory, implying that career development is an ongoing adaptation from the individual in relation to context (Stead \& Watson, 2006). As a result, Savickas replaced Super's concept of career maturity with career adaptability (this concept will be carefully reviewed later on), which better describes the fact that individuals need to constantly adapt to meet the changes within their environment (Stead \& Watson, 2006). Maree (2013) avers that career construction theory ultimately

\footnotetext{
${ }^{1}$ Contextualism within the context of careers refers to observing individuals within work and relationships, the meanings and constructs they assign to certain experiences that influence how they interpret the world and the interrelated events within that particular context.
} 
updates Super's lifespan, life space theory. Individual development depends on adjustment to the external environment, rather than on internal growth structures (Di Fabio \& Maree, 2013).

Savickas defined career construction as an important psychological process that helps clients add meaning to their work role and subsequently support an adequate selfconcept (Di Fabio \& Maree, 2013). Working from such a premise, Savickas regarded career construction as a method to enhance life purpose, allow individuals to make themselves whole and derive meaning as they design their self, identity and career (Savickas, 2012). Career construction counselling subsequently evolved throughout the three waves of psychology, namely the psychology of occupations, careers and life designing. Each wave joins with the following one to offer a better insight into individual behaviour and processes (Di Fabio \& Maree, 2013).

In the next section, I elaborate on the importance of each wave.

\subsubsection{Psychology of occupations}

The psychology of occupations period coincides with the person-environment (PE) fit paradigm or trait-factor career theory, which used to serve as the foundation for vocational guidance (Maree, 2007). Individual differences and congruencies were emphasised (Stead \& Watson, 2006; Di Fabio \& Maree, 2013). John Holland's career choice theory is an example of this wave of psychology, which can be best described as having a focus on matching individuals to an environment that is congruent with their personality styles or traits. Holland's RIASEC ${ }^{2}$ model [Realistic (R), Investigative (I), Artistic (A), Social (S), Enterprising (E), and Conventional (C)], embodies this approach which held an objective perspective on occupational choice and work adjustment (Maree, 2007).

\subsubsection{Psychology of careers}

The psychology of careers marked the emergence of the developmental perspective on careers (Maree, 2007). It focused on growth, change and stages in a career over an

${ }^{2}$ Holland's RIASEC model is based on six personality types, namely: Realistic (R), Investigative (I), Artistic (A), Social (S), Enterrising (E), and Conventional (C). 
individual's lifespan (Di Fabio \& Maree, 2013). Savickas and Super stated that career choice is an ongoing process and thus conceptualised work development as an ongoing process rather than a once-off event (Super, Savickas \& Super, 1996). Rather than focusing on individual differences, the psychology of careers focused on how individuals develop themselves and progress through the life-cycle (Maree, 2007). Hartung (2013, p. 17) states:

It most values career choice readiness, or the planning attitudes and decisionmaking competencies needed to maximally implement one's self-concept in work roles, as a main outcome of its core service of career education that assists people to answer the question "How do I prepare for a work career?"

The career developmental theory of Super firmly supports this movement, emphasising his life-span, life-space theory, portrayed as a Life Career Rainbow (Super et al., 1996; Stead \& Watson, 2006). The psychology of careers movement would later be developed into life designing as a new career paradigm by Savickas (Maree, 2013).

\subsubsection{Psychology of life designing}

Recognising the dynamic process of career development, life designing continues to personify career construction with meaning (McMahon, 2014). By advancing a contextualist approach to epistemology, the life design approach emphasises traits, diversity, uniqueness and how individuals can give meaning to their lives through work and social consequence or relationships (Maree, 2007; Di Fabio \& Maree, 2013). The psychology of life designing focuses on life themes and assists people to answer the question, "What purpose does work serve in my life?" (Di Fabio \& Maree, 2013). In essence, the psychology of life designing values deriving meaning for the self through the process of narratability, adaptability and intentionality.

Through considering the above traditions or waves within career psychology we are able to surmise that career construction combines these approaches to form a welldeveloped and effective career counselling approach. The career construction theory approaches the individual from a viewpoint of being an actor, agent and author who forms and reforms him/herself continually through work (Di Fabio \& Maree, 2013). 
Having elaborated on the previous statement, I will next discuss career adaptability as an important aspect of career construction theory.

\subsection{Career adaptability}

Although there are arguments supporting the viewpoint that career adaptability is closely related to career resilience in its basic definition, literature indicates the opposite. Career resilience refers to an individual's ability to survive change, while career adaptability refers to an individual's ability to negotiate transitions successfully, which indicates a more proactive stance (Bimrose \& Hearne, 2012). According to Creed, Fallon and Hood (2009), career adaptability can be associated with certain benefits, including the motivation for individuals to develop both individually and personally.

Career adaptability subsequently stresses the importance of the reciprocal relationship between individuals and their environment and how they confront nonmaturational processes and self-regulatory processes (Creed, Fallon \& Hood, 2009). Savickas and Porfeli (2012) define career adaptability as a psychological construct that is influenced by self-regulatory processes that over time are influenced by people, the environment and the reciprocal interaction between them (Savickas, 1997; Savickas \& Porfeli, 2012). Koen and colleagues support this description of career adaptability and indicate that as a psychological construct it is expected to be malleable rather than fixed (Koen, Klehe \& van Vianen, 2012).

Savickas (1997, p. 254) defines career adaptability as " $A$ readiness to cope with the predictable task of preparing for and participating in the work role and with the unpredictable adjustments prompted by changes in work and working conditions". As mentioned earlier, Savickas replaced Super's construct of career maturity with career adaptability as he believed career adaptability (a) better coincides with the changing technology and economic environment, (b) aids counsellors to focus their attention on developing a readiness to cope in individuals of all ages, (c) highlights the problems associated with transition in life-cycles, beginning with the transition from school to work, and (d) lacks the evaluative undertone associated with career maturity, making career adaptability more acceptable (Savickas, 1997). Career adaptability can be 
described and explained along four dimensions, each of which will next be discussed in turn.

\subsubsection{Central dimensions of career adaptability}

Career adaptability accommodates four central dimensions or constructs as delineated by Savickas (2001), namely concern, control, curiosity and confidence. These dimensions serve to increase adaptability related to career planning, career choice and work adjustment, and they allow individuals to adjust to their constantly changing contextual and social environment (Nota \& Rossier, 2015). In our discussion of each of the four dimensions of career adaptability, the importance of these constructs is explained as it became apparent during recent studies.

\subsubsection{Concern}

The concern dimension of career adaptability is concerned with how people orientate themselves towards the future and subsequently increase optimism regarding the future (Di Fabio \& Maree, 2013; Koen et al., 2012). Concern refers to an individual's ability to reflect on his/her situation, how past experiences influence the present, and designing possible future developments as a function of career planning (Koen et al., 2012). According to Di Fabio and Maree (2013) a lack of concern will cause a sense of pessimism and detachment towards the future.

In his study on career adaptability and subjective career success, Zacher (2014) suggests that career concern is an important variable and indicator for future subjective career success. Career concern, as stated by Savickas (2005), demands a futureorientated mindset as it requires or allows individuals to align present actions to ensure desired future outcomes, which possibly makes it the most important dimension within career adaptability (Guan et al., 2013; Savickas, 2005). Career concern in short refers to an individual's concern about having a future (Di Fabio \& Maree, 2013).

\subsubsection{Control}

The control dimension refers to a future-orientated approach towards owning the future. It involves individuals taking responsibility for their actions in constructing their careers 
and independently making decisions that affect their careers (Di Fabio \& Maree, 2013). Career control ultimately refers to taking ownership of the future (Di Fabio \& Maree, 2013) and exerting a degree of ownership over the future (Bimrose \& Hearne, 2012). Guan et al. (2013) found career control, in conjunction with career concern, to be a positive predictor of self-efficacy when considering job success. Although no positive correlation was found between employment and career control, it was found that career control led to a higher rate of self-efficacy in the job search and hence increased the likelihood of securing employment (Guan et al., 2013). A lack of career control causes indecision and uncertainty about the future (Di Fabio \& Maree, 2013), which Savickas termed a state of confusion rather than dependence (Savickas, 2013).

\subsubsection{Curiosity}

Career curiosity refers to exploring possible selves as well as different career opportunities in relation to one's own abilities and traits (Di Fabio \& Maree, 2013). It encapsulates and embodies an inquisitive attitude that initiates productive career exploration and broadens one's horizons through social opportunities and possibilities (Bimrose \& Hearne, 2012). A lack of curiosity can lead to a limiting of career exploration, which inherently limits realistic career expectations (Di Fabio \& Maree, 2013).

\subsubsection{Confidence}

Career confidence indicates a sense of optimism and poise in pursuing one's career goals and aspirations in the face of obstacles and barriers (Di Fabio \& Maree, 2013; Zacher, 2014). Confidence refers to the positive perception about one's ability to solve career problems across various situations, which should relate to positive emotions and resilience in career transitions (Turban, Stevens \& Lee, 2009). A lack of career confidence could cause inhibition and self-consciousness in pursuing a better future (Di Fabio \& Maree, 2013). Career confidence determines the degree to which a person will persist when facing challenges in a job search, and it will ultimately increase the likelihood of finding employment. Research findings are undecided on the effect that 
curiosity and confidence have on career satisfaction, as some results indicate a positive correlation and others a negative one (Guan et al., 2013; Zacher, 2014).

In view of the above it can be deduced that these four dimensions of career adaptability are not necessarily individual processes. They interact with one another and play different roles in predicting different career outcomes (Guan et al., 2013). Career adaptability in general positively predicts career satisfaction, which suggests that career adaptability is a self-regulatory, transactional process that allows individuals to achieve future career success (Zacher, 2014).

Due to the nature of this study, which focused primarily on child intervention, the next section will apply the above dimensions of career adaptability to children and investigate how these dimensions pertain to them.

\subsubsection{Career adaptability in childhood}

The following section aims to give the reader a general impression of career adaptability and why it is influential in both childhood as well as adolescent years.

"Why not rather focus on resilience than on career resilience in children?"

"Why do children need to be concerned about careers this early in their life?"

The above questions are some of the responses that the topic of this study elicited from colleagues in the field of psychology and social work. I therefore decided to include career adaptability in childhood as a way to clarify the importance of career adaptability in childhood and adolescent years.

Hartung, Porfeli and Vondracek (2008) posit that childhood is a period in which playful early experiences shape interests, values, curiosities and fantasies that will be the foundation upon which a child will construct a future self. Hirschi (2009) in turn states that career adaptability is related to positive youth development and personal striving during adolescent years, while Guichard (2005) argues that individuals start shaping themselves and their lives during the early years of life, through their interaction with the social environment. Life design counselling works from the assumption that children playfully construct future selves from early social interactions which they project

in work and social roles (Nota \& Rossier, 2015). Realising that childhood then is the beginning of vocational development and a platform for the development of career 
adaptability, it becomes important to consider the antecedents related to career adaptability during childhood (Hartung et al., 2008).

According to Hartung et al. (2008), viewed from a childhood perspective, the four dimensions of adaptability can be described in the following manner:

1. Concern: Activities, experiences and dependency on adults as well as caretakers during childhood years allow children to foster a sense of hopefulness and optimism about the future. Career adaptability in childhood can be enhanced by focusing on future planning abilities, optimism and an increase in awareness.

2. Control: Childhood relationships characterised by safety and security with parents and/or caregivers set a platform for the child to develop autonomy, self-reliance, personal ownership, self-direction and assertiveness.

3. Curiosity: Curiosity allows a child to explore the world of work realistically with realistic expectations about the future. A lack of curiosity can diminish inquisitiveness and interest in the world of work.

4. Confidence: This dimension involves problem-solving abilities as well as selfefficacy beliefs. Career confidence increases a child's self-efficacy beliefs and his/her ability to overcome obstacles or barriers in the future. A lack of confidence leads to timidity, a lack of inhibition and a sense of helplessness.

According to Hirschi (2009), a psychologically healthy social environment with adequate social support provides children with a platform for successful career development. He also argues that positive emotional antecedents embodied in the four dimensions of career adaptability indicate a positive correlation in the increase of career adaptability among adolescents (Hirschi, 2009). Savickas (2002) states that these four dimensions of career adaptability serve as a good intervention strategy that enables children to work and strive more effectively for the changing of opportunities and constraints.

Maree's (2007) research provides evidence for Super's views on developmental career stages through careful explanations of growth, exploration, establishment, management and disengagement. Since the current study focuses on a single participant between the ages of 9 to 14 years, I will briefly discuss the first two stages only: 
1. Growth: This stage spans across the ages of 4 to 13 years. It involves the formation of the initial and realistic self-concept of the child in the process of answering "who am I?" (Maree, 2007). What makes this stage fundamental in the development of early career adaptability is the fact that during this period mental representations of strengths, limitations, interests, values, abilities, personality and talents relating to the child are engrained (Maree, 2007). Stead and Watson (2006) state that this stage is characterised by individuals becoming concerned about the future, increasing control over their lives, seeking to achieve both in work and at school, and acquiring the necessary attitudes and habits towards a sense of competency.

2. Exploration: The exploration stage spans the age spectrum of 14 to 24 years and requires from individuals to implement their self-concept and sense of self in the world of occupations (Maree, 2007). This stage signifies a time when they have to crystallise their identity and implement that identity in choosing or finalising a career choice (Stead \& Watson, 2006).

What has been stated above about the four dimensions of career adaptability as well as the developmental stages of Super, confirms that increasing career adaptability within the framework of career construction and life designing should positively contribute to the improvement of career resilience in survivors of sexual abuse. Hartung and Taber (2008, p. 79) state that "[c]areer construction attends to the developmental tasks and role transitions that people confront and the coping strategies that they use to deal with these changes". Career construction counselling enhances adaptability. Therefore, if one wishes to promote career resilience in survivors of childhood sexual abuse, early, rapid and immediate intervention is required to ensure that both future selves and career success are enhanced.

\subsection{Career resilience}

According to Bimrose and Hearne (2012, p. 339) "[r]esilient qualities are protective factors or developmental assets that help individuals survive adversity and involve a range of variables identified in the field including self-esteem, self-efficacy, subjective well-being, self-determination, locus of control and support systems". Pearce and Morrison (2011) define resilience as the ability to adapt successfully despite challenging 
circumstances, and Ebersöhn (2010) agrees that resilience is becoming more and more prominent in career counselling as people need to deal with adversity. The belief that resilience is influenced by the reciprocal interaction between people and their environment is very prominent, and will ultimately influence the degree of positive outcomes experienced (Ungar, 2008). Schreuder and Coetzee (2011) support the above definitions, referring to career resilience as an individual's ability to adapt to the changing social circumstances and/or environment.

Liebenberg and Ungar (2008) emphasise an ecological model of resilience, stating that personal characteristics, social resources and cultural factors all play an important role in resilience. They refer specifically to resilience in youth, stating that the resilience of youth is closely related to the resilience of the families and communities in which they live (Liebenberg \& Ungar, 2008). Viewed from this perspective, career resilience encompasses more than just individual interpersonal traits. For this reason a thorough conceptualisation of the external influencing factors is crucial to understand the role of career resilience in the lives of youths and, more specifically, survivors of sexual abuse.

Paul and Garg (2014) refer to career resilience as the ability to recover from adversity, trauma, setbacks and disruptions. Career resilience therefore refers to a sense of overcoming barriers and adversities that influence one's self-confidence, need for achievement and independence (Paul \& Garg, 2014). Liebenberg and Ungar (2008) state that resilience is firstly the capacity to navigate one's way through resources in order to sustain well-being; secondly it refers to the ability of social and physical ecologies to provide these resources, and thirdly to negotiate in the sharing of resources that are culturally acceptable.

Ungar states that the emergence of resilience in career studies helped to shift the focus from stress and dangers to designing interventions that aim to enhance strengths and build capacity in individuals (Liebenberg \& Ungar, 2008). Resilience according to Ungar is adaptive and context specific. This means that survivors of sexual abuse may adapt in different ways depending on their context. Ungar furthermore claims that 'problem' behaviours can sometimes be adaptive behaviours (strengths) and may represent behaviours necessary for survival; hence, the more disordered the 
environment, the more 'problematic' the behaviour (Liebenberg \& Ungar, 2008). The question therefore remains "How can we enhance career resilience in children from disordered environments in such a way that adaptive, healthy behaviours are generated?" Looking at resilience from a behavioural, educational and emotional level, each produces its own challenges (Walsh, Dawson \& Mattingly, 2010) and for the purposes of the present study, intervention focused on enhancing career resilience by enhancing resilience across all domains.

Although most definitions on career resilience refer to the same idea of surviving and overcoming adversity, career resilience in children needs to be defined carefully as it is a future-orientated concept that cannot yet be measured. Walsh et al. (2010) therefore base definitions of resilience in childhood on various research studies that in general conceptualise resilience as having peer attachments, academic achievement and performance, as well as behavioural and emotional regulation. Resilience can subsequently entail different behaviours in different contexts, which demonstrate adaptive strengths for the individuals.

\subsubsection{Resilience and sexual abuse}

There is general consensus that childhood sexual abuse has detrimental effects on the long-term healthy functioning of individuals and that it precipitates calamitous consequences towards their emotional and psychological functioning (Coles et al., 2015; Dorrepaal et al., 2013). Spaccarelli and Kim (1995) state that resilience in survivors of sexual abuse is influenced by the severity as well as the duration of the abuse, the closeness of the relationship to the perpetrator, as well as the responses of significant people within the child's life. Research suggests that childhood sexual abuse is often committed by family members or people close to the child, is of a repeated nature and normally happens between the ages of 7 to 12 years (Valentine \& Feinauer, 1993). Valentine and Feinauer (1993) identified themes that were prominent in resilient survivors of sexual abuse, such as having a positive self-concept brought about by external support structures, as well as supporting people enabling them to make constructive decisions in going to school, starting a career and choosing positive relationships. 
Cognitive coping strategies that have been found to have a measurable impact on the future emotional and psychological functioning of survivors of sexual abuse are (a) changing perceptions of stressors or cognitive reappraisal; (b) fostering an internal locus of control; (c) disclosure of the childhood sexual abuse; (d) positive reframing in terms of viewing the incident as a vehicle for change, learning from the experience and finding meaning in adversity; and (e) refusing to dwell on the childhood sexual abuse (Himelein \& McElrath, 1996).

Marriot, Giachritsis and Harrop (2014) posit that the manifestation of resilient behaviour in the long term is less likely if sexual abuse took place before the age of 11 years, suggesting that career resilience intervention strategies, such as those proposed in this study, need to be implemented with survivors of sexual abuse as soon as possible following the abuse. Studies done on depression following CSA indicate that resilience curbed the effects of depression later on (Wingo et al., 2010), while increasing self-esteem, social relationships, ego resilience, coping skills and the development of a positive future orientation have been positively correlated to resilience after CSA (Marriot et al., 2014).

From the above it can be deduced that focusing on intervention strategies such as increasing self-esteem, increasing positivity towards the future and finding meaning in adversity will possibly enhance resilience in survivors of sexual abuse. Put differently, it seems that a positive correlation exists between these intervention strategies and healthy future psychological and emotional functioning. I am of the opinion that life designing (see the next section) has the potential to increase the career resiliency constructs as discussed above. The following section will therefore focus on the lifedesigning paradigm.

\subsection{Narrative career counselling}

Maree (2010) claims that the general aim of narrative career counselling is to support people in scripting their life stories, as it views them as the main actors in their own careers and life stories. Guichard et al. (2012) state that the world of work in the 21st century requires from people to assess their career capital. This includes knowing how and knowing who they have constructed. The aim of using narrative career counselling 
is to have people reflect on their life stories and then reflect on their reflections (metareflection). This process allows them to break through the limitations in their lives and enables them to advise themselves during times of future career decisions (Maree, 2012).

Seeing that it is embedded in social constructionism, narrative career counselling places great importance on showing respect and providing a safe environment for clients (Maree, 2013). The narrative approach is also related to the systems theory framework in which people construct their identities over time through a process of coconstructing new identities (McMahon et al., 2012). Therefore, not only does the narrative approach to career counselling allow individuals to construct new and healthier stories with regard to their future, it also allows them to deconstruct previous stories that they do not prefer (in the case of the current study, sexual abuse experienced by the individual).

Individuals need not passively accept past stories about themselves, as narrative career counselling provides them with an opportunity to create new, healthier stories (Maree, 2013). Early life experiences shape a person's future life and therefore the pain, trauma and unresolved issues often remain part of that person (Maree, 2012). A narrative approach seems applicable in a South African context and may be effective in helping adolescents reflect on their life stories in a way that will help them to become the architects of their own lives and construct and live successful lives (Maree, 2012).

Life design counselling is also embedded in the narrative approach, which allows individuals to determine the meaning of past events and construct new stories about their lives. It employs a process of externalising the old stories and replacing them with new, healthier stories about themselves.

\subsubsection{Life design counselling}

Life designing aims to focus primarily on issues surrounding work or career issues that are life-long, holistic, contextual and preventive (Nota \& Rossier, 2015). Life designing attaches great value to narratability (the ability to coherently tell one's own story), adaptability (as discussed in Section 2.3), as well as intentionality (the ability to meaningfully enact one's own life story) (Di Fabio \& Maree, 2013). 
Guichard et al. (2012) contend that to support clients in designing their lives, career counsellors should integrate new knowledge into their already existing intervention models. I believe that life design counselling supplements this process, as it acknowledges that there are certain aspects in life that have greater value for individuals than other aspects, and we as career counsellors need to take this into account when working with clients. It is these aspects that are at the heart of a life narrative (Savickas et al., 2009).

Moreover, the life design process is collaborative and includes a holistic and contextual consideration of the various experiences and influences within a person's life, highlighting adaptability intrinsic to an individual (Savickas et al., 2009). Any life design intervention model however has to be based on the following five presuppositions: a) from traits and states to context; b) from prescription to process; c) from linear causality to non-linear dynamics; d) from scientific facts to narrative realities; and e) from describing to modelling (Savickas et al., 2009).

In life design counselling, vocational guidance no longer occurs within a vacuum. Instead, career counsellors consider the various influences of the surrounding systems on the person (Maree, 2010). Life design counselling can also be useful in exploring the client's subjective identity forms and co-constructing new stories through the rewriting of existing stories (Crous, 2011). Underpinning life design counselling is the goal of assisting people to design and reshape their lives, and in the process to adapt and become more resilient to changing needs, interests and experiences (Maree, 2012). As career counsellors we should therefore no longer talk of career development or vocational guidance, but rather focus on how people negotiate major transitions in their lives that are characterised by changes in health, wealth and social relationships (Savickas et al., 2009).

\subsection{The long-term effects of sexual abuse}

Childhood sexual abuse is a pervasive and extensive problem that is prominent across countries as well as in various socio-economic environments. Before we continue, it becomes imperative to define what childhood sexual abuse constitutes within a South African legal and social setting, as well as within the wider scope of this study. As stated 
in Section 1.7.1, the Sexual Criminal Law Amendment Act of 2007 (p. 14) defines sexual abuse as "any act which results in the exploitation of a child, whether with their consent or not, for the purposes of sexual or erotic gratification".

The Centre for Justice and Crime Prevention (CJCP) at the University of Cape Town makes the argument that South Africa is in desperate need for a child protection protocol. This protocol should (a) focus on a system that manages childhood sexual abuse more effectively (b) makes the reporting of sexual abuse by young people easier and more effective and (c) enhances the effectiveness of medical interventions and legal prosecutions (Artz et al., 2016).

Studies indicate that the long-term prognosis for survivors of sexual abuse is neither favourable nor positive, characterised by continuous pathology. Research conducted by Fryda and Hulme (2015) concludes that childhood sexual abuse (CSA) is multicyclical, meaning that given enough time, the abused will often (but not always) become the abuser. It also claims that CSA has a causal relationship with an increased risk for certain mental and physical health problems in adulthood. The above research is supported and correlates with various other studies which report that survivors of childhood sexual abuse are at risk of depression, feelings of guilt, decrease in selfworth, apathy, a decrease in moral judgment, substance abuse and the development of mental disorders (Singh et al., 2014; Van Rensburg \& Barnard, 2005; Raabe et al., 2015). According to Cambron, Gringeri and Vogel-Ferguson (2014) childhood abuse has also been linked to problems in academic performance, mental health and behavioural difficulties. From recent research it seems clear that the effect of childhood sexual abuse on individuals is detrimental across the lifespan in all spheres of social and emotional functioning.

Van Rensburg and Barnard (2005) highlight five themes that predispose survivors of sexual abuse to psychological resilience. These are:

1. Close family ties: Families characterised by involvement, closeness and a general sense of cohesion potentially foreshadow good and positive outcomes for children in the midst of a traumatic event and/or experience.

2. Internal locus of control: An internal locus of control positively influences a person's level of adjustment after trauma. 
3. Positive self-concept: Resilient children not only have a good understanding of the environment in which they find themselves, but also a sense of peace regarding the stressful situation.

4. Social support: The degree or level of social support that people enjoy influences their level of adjustment after a traumatic event.

5. Personality factors: Factors such as emotional stability, extroversion, adjustability (adaptability), and being good-mannered and cordial all play a role in facilitating healing after sexual abuse (Van Rensburg \& Barnard, 2005).

Although some children function very well in later life after having been sexually abused, they are by far in the minority. Most children suffer but do not necessarily provide any evidence of their suffering on an external behavioural level (Grobbelaar \& De Jager, 2013). Children may function well behaviourally, socially and scholastically, but on an internal level they may experience extreme emotions of depression, anxiety and turmoil (Grobbelaar \& De Jager, 2013). Most of these symptomatic reactions experienced by survivors of sexual abuse worsen and could possibly manifest themselves as long-term side effects (Grobbelaar \& De Jager, 2013). Coles et al. (2015) support this finding, postulating that anxiety and depression in child survivors of sexual abuse are symptoms that worsen considerably in adulthood. Survivors of sexual abuse who did not disclose their sexual abuse and receive appropriate stabilising treatments or alternative interventions report a negative self-perception as well as a disintegrated self-identity (Collin-Vézina, De La Sablonnière-Griffin, Palmer \& Milne, 2015).

There appears to be a serious need, therefore, to devise a novel strategy to help survivors of sexual abuse to deal with the accompanying trauma. Using a narrative approach towards the co-constructing of new identities and life stories (where the person is seen as the expert), career counsellors can potentially provide a useful and functional strategy in their quest for finding ways in which to promote a sense of career resilience and resilience in general among survivors of sexual abuse.

\subsection{Conclusion}

The purpose of this chapter was to provide the reader with a methodical and extensive description of the theory that underlined and guided this study. The modus operandi as 
well as the structure of this chapter was discussed, and an overview of the historical evolution of career construction theory was provided. This was followed by a focus on career adaptability, specifically the reciprocal relationship between individuals and their environment, the central dimensions and what specific aspects relate to childhood.

Career resilience was considered next. I focused on how it relates to survivors of sexual abuse and touched on factors influencing career resilience. Narrative career counselling as well as life design counselling was discussed extensively, followed by sexual abuse, legislation pertaining to the South African context and the reasons why research focusing on survivors of sexual abuse is greatly needed.

Life designing posits that one of the main goals of this approach is to assist people in determining what purpose work serves in their lives. Considering that over the past decade unemployment in South Africa has increased to $25 \%$, we are left with a vexing question: "If unemployment is rising, where or from what do/will people derive meaning?" In dealing with this dilemma we consider career adaptability, which emphasises the reciprocal interaction between people and their environment, as well as career construction, which views the person as an agent, actor and author of the own career.

Theoretically, career adaptability and construction appear attainable, but practically it implies that one should already have a degree of insight into and wisdom regarding one's own actions and thoughts. Furthermore, it is assumed that individuals aim to strive for career adaptability, and that they negotiate the challenges of a $21^{\text {st }}$ century economy while growing in the process. However, over the past decade South Africa has become more and more dependent on a government/bureaucracy to provide employment and to support families. The focus therefore is no longer on the individual being adaptable but rather on the extent to which government can help people survive. Career adaptability and career construction constitute (in my view) a virtue and a kind of ethic in work life that requires the incentive and encouragement from a government. This is unfortunately not the case in a post-apartheid, post-colonial South Africa.

In view of the depletion of social resources, the dispersion of cultures both throughout South Africa and internationally, and the focus shifting more to the external than the internal, we have to question the working premise of career resilience and its 
foundation within a South African context. Sexual abuse, the variables as well as the pathology associated with them can be considered an area of specialisation and should therefore warrant closer investigation. However, due to limitations in current research, the information above provides motivation why research into this aspect of sexual abuse requires attention, providing good motivation for this study.

Considering the above I believe that this chapter accomplished what it set out to achieve. I realise that from a critical perspective this can by no measure be viewed as a holistic and inclusive explanation of all the theories involved and the constructs associated with such theories. Chapter 2 in essence provided a good overview for the novice reader, a good foundation for the more accomplished and informed reader, as well as a modest starting point for further research and investigation into the topics of career resilience, career adaptability, sexual abuse and the probable reciprocal interaction between them. 


\section{CHAPTER 3: RESEARCH METHODOLOGY}

\subsection{Introduction}

Chapter 3 considers and discusses various aspects that form part of the research process that was followed in the current study. The paradigmatic perspective is firstly discussed from an interpretivist/constructivist point of view, followed by the research design and data collection techniques used. Qualitative as well as postmodern data collection techniques applied in the research are discussed next, and an explanation follows of how the quality of the results obtained from this study was guaranteed. Compliance with ethical issues surrounding the current study and a brief summary conclude the chapter.

\subsection{Paradigmatic perspective}

Maree (2012) states that research is based on qualitative and/or quantitative research paradigms that mostly concern themselves with interpretation and meaning. In essence, the qualitative paradigm is concerned with how people assign meaning to their experiences, which are subsequently planted in philosophical tenants such as interpretivism $^{3}$, constructivism, phenomenology, the humanistic philosophies and postmodernism (Maree, 2012). The following form part of the research paradigm:

- Ontology: Ontology concerns the nature of reality and being, and therefore refers to what can be known (Ponterotto, 2005; Maree, 2012, 2007; Mason, 2013).

- Epistemology: Epistemology concerns itself with how something can be known (Maree, 2012), and refers to the relationship between the participant (knower) and the researcher (would-be-knower) (Ponterotto, 2005).

- Methodology: Methodology refers to which processes and procedures will be used i.e. how research will be conducted (Ponterotto, 2005; Maree, 2012, 2007).

Being aware of one's own ontological and epistemological stances is of crucial importance and Maree (2012) warns that being unaware of such stances could potentially influence the research process. This study will therefore be conducted from

${ }^{3}$ Proponents of interpretivism argue that human experience is socially constructed, which implies that multiple realities exist. 
an interpretivist/constructivist paradigm. These two concepts, how they relate and differ, will be discussed next.

\subsubsection{Interpretive/constructivist paradigm}

The interpretivist-constructivist approach is both idiographic ${ }^{4}$ and emic ${ }^{5}$ and concerns itself with understanding "lived-experiences" (Ponterotto, 2005, p. 129). The interpretivist-constructivist paradigm therefore provides a good foundation for qualitative methods as it is concerned with multiple constructed realities (Ponterotto, 2005). Morrow (2005) argues that the interpretivist-constructivist paradigm should make more claims to research results being credible and socially valid. She maintains that research from this perspective is "real science" and to expand this paradigm we should focus on how the participant's meanings are understood, as well as the mutual construction of meaning between the researcher and participant (Morrow, 2005, p. 229).

Interpretivists-constructivists believe that separating the researcher's experience and subjective values from the research is impossible. Hence, when capturing the "lived experiences" it is important to capture the relationship between the researcher and the participant (Ponterotto, 2005). The constructivist and the interpretivist paradigms will now be discussed separately.

\subsubsection{Constructivist paradigm}

Constructivism at its roots implies that (a) knowledge is actively created and/or constructed and (b) these constructions have an adaptive function (Raskin, 2011). People are therefore active in meaning making that has its roots in philosophical pragmatism (Raskin, 2011). This implies that people actively construct meaning as a way to organise experiences and realities in an attempt to distinguish between constructs and concepts (Raskin, 2011). The constructivist paradigm contends that multiple realities exist, but at the same time recognises that the values and experiences of the researcher cannot be separated from the research (Mason, 2013; Tuason, 2013).

${ }^{4}$ Idiographic research refers to research that investigates a person in an in-depth manner in order to achieve a unique understanding of the individual.

${ }^{5}$ An emic approach to research works from the perspective of viewing participants as a starting point by setting aside prior theories and allowing the data to speak for itself. An emic approach is especially useful in cases where little research has been done on the specific topic or phenomenon. 
Ponteretto (2005) supports this view and states that constructivism supports a relativist position. Realities are constructed in the mind of individuals and these can be uncovered in the researcher-participant interactional dialogue. Constructivism therefore places tremendous emphasis on (a) the interaction between individuals; (b) the context; (c) the meaning that they acquire from such interactions; (d) how this meaning shapes their realities; and (e) separating the researcher's values and experiences from the research project (which is not possible).

\subsubsection{Interpretivist paradigm}

Interpretivism, according to Mason (2013), is interested in understanding the social world and the social realities of people, which are embedded in language. Interpretive researchers subsequently view people as the primary data source and seek to obtain an "insider view" of people's experiences and perceptions (Mason, 2013). Crous (2011) parallels Mason's view by stating that human life can be understood from an "insider's" perspective rather than an "outsider's" perspective. Interpretivism thus emphasises the viewpoints of people, as well as the meaning they assign to events (Maree, 2012). Working from a perspective where knowledge was created in the current study based on a first-hand, personal account of the individual's perceptions contributed and added both trustworthiness and credibility to this study.

The paradigm as discussed was used in this study to guide the manner in which reality is understood and what is considered to be valid evidence and/or conclusions. The research paradigm subsequently influenced the research design, which is discussed in the following section.

\subsection{Research design}

A research design can be defined as a particular plan that provides the researcher with structure in how he/she aims to accomplish tasks and also informs the researcher as to which instruments, methods and theories to use (Maree, 2012). Maxwell (2012) seems to be in agreement with Maree that a research design can be seen as a protocol to accomplish something. He also postulates that a qualitative research design should be 
reflexive where every stage of the study is in some sense happening simultaneously and affecting one another.

A research design provides the researcher with a structure as to how the study will be conducted in an effort to promote its efficiency and success. The current study was qualitative and exploratory, while the research design for the study involved an intrinsic case study. The characteristics of the research design are discussed in more detail in the next section.

\subsubsection{Characteristics of a research design}

\subsubsection{Qualitative research}

Recent trends in psychology indicate that researchers are beginning to favour qualitative research methods more and more, instead of the traditionally established quantitative approaches (Gough \& Deatrick, 2015; Gergen, 2015; Jackson, 2015). One reason that could possibly account for the move to qualitative methods is that the latter place greater emphasis on the individual's experiences.

Epistemologically speaking, qualitative research posits that reality is socially constructed, meaning that multiple realities are created by individuals (Jackson, 2015). Madill (2015) suggests that qualitative research focuses on lived experience, which stands in agreement with Walsh (2015) who states that from an epistemological stance qualitative research is interested in experiences embedded in a real-life context. Maree (2012) seem to support the above statements, and defines qualitative research as working from the assumption that there are multiple realities that are socially constructed and presented as subjective realities (facts) through narrative (Landrum \& Garza, 2015).

Working from the above perspectives it can be argued that qualitative research assumes that multiple realities exist and that meaning can be given only from an individual perspective. In an epistemological sense, meaning is socially constructed in a subjective manner and relayed in narrative. 


\subsubsection{Exploratory research}

According to Stebbins (2001) social research is always exploratory and characterised by particular interests and broad discoveries. Hill (1990) identifies exploratory research as pantheoretical ${ }^{6}$ where researchers are open to learn about a process from their observations as well as from the experiences of the participant(s). Stebbins (2001) describes exploratory research as lengthy and involving personal concern with the researcher who must have a longstanding interest in the topic. Exploratory research can further be seen as the best type of design for areas in research about which little is known (van Wyk, 2012). Exploratory research hence aims to identify salient factors and/or variables that could potentially have an influence on the phenomenon being studied.

Taking into consideration (a) the scant literature that exists on enhancing career resilience among survivors of sexual abuse who still reside in the same environment where the abuse transpired and (b) the influence of life design counselling on the survivors of sexual abuse, I believe that exploratory research was applicable in the current study.

Qualitative research includes and describes case study research as a specific research design. The following section clarifies the characteristics of case study research design, as well as the practicality of such a study.

\subsubsection{Case study research}

Although various types of qualitative research exist, the researcher decided to use a case study design. As mentioned earlier, Creswell (2008) and Stake (2005) distinguish between two main types of single case study designs: intrinsic and instrumental. In the intrinsic case study, researchers wish to understand the unique nature of a specific individual or situation (Stake, 1995; Grandy, 2010), while in the instrumental case study they examine a social issue to demonstrate and understand the issue, and facilitate possible generalisations. The intrinsic case study was the research design that was selected, as the aim of the study in hand was not to generalise.

\footnotetext{
${ }^{6}$ Because exploratory research is not aligned with any single theory, it can explain findings using multiple theories. Hence it is aware of various perspectives (Hill, 1990).
} 
An intrinsic case study design allowed the researcher-counsellor to focus on the specific participant as well as the phenomenon, providing contextual depth and insight (Kelliher, 2012). The reader's attention is next directed towards the research site where the study was conducted.

\subsection{Research site}

The research was performed at Eleos ${ }^{7}$, a non-profit organisation in Pretoria West, Gauteng. The organisation was easily reachable by the researcher as well as the participant. Eleos also had all the necessary facilities to provide a safe environment where the research could be conducted. Using these facilities meant that the participant did not have to undertake any unnecessary travelling.

\subsection{Role of the researcher}

According to Haverkamp (2005) the role of the researcher (as well as the participant) in qualitative research differs from that in quantitative research. He states that postmodern thinking inclines that all of the qualitative researcher's thoughts, beliefs, biases, values, opinions, own paradigm, ideologies and history intertwine within the study (Haverkamp, 2005). As the researcher my role was therefore emic, as I did not observe the study from an outsider's perspective, but participated in it as an "insider". My role therefore entailed having to:

- conduct research in an ethical manner;

- always work in a manner respecting the best interests of the participant;

- $\quad$ report and be aware of any conflicts of interest;

- ensure that my knowledge and skills were developed appropriately;

- acknowledge the limitations of my skills and knowledge;

- keep clear boundaries and avoid multiple relationships;

- play a substantial role during the research process by ensuring that data is collected in a manner that enhances trustworthiness and validity.

Our attention now turns to how data was collected during the study.

\footnotetext{
${ }^{7}$ Written permission has been requested by the researcher and granted by the organization to reveal its name.
} 


\subsection{Data collection techniques}

Maree (2013) asserts that discussing data collection and performing data analysis simultaneously can foster better understanding. Data gathering in qualitative research aims to provide evidence of the phenomenon that is being experienced (Polkinghorne, 2005). However, in qualitative research, data takes the form of narratives that aim to capture the gist of human experience and the meaning they assign to such experience (Polkinghorne, 2005). The first step in the current research was to obtain access to a participant for the research project (Maree, 2012). The data collection process, which entailed the selection of the participant, as well as life design counselling and various qualitative techniques are discussed next.

\subsubsection{Selection of the participant}

Polkinghorne (2005) posits that qualitative research aims to describe, understand and clarify the experiences of the participant. Sampling as a construct within qualitative research is done with the focus on the experience that underlines research rather than its distribution within the population (Polkinghorne, 2005). This being said, it can be surmised that the selection of participants in qualitative studies depends on the participant's substantial contributions and input with regard to the experience under investigation. The success of a study lies in the participants chosen and therefore sampling decisions should not be made in isolation of the rest of one's study (Maree, 2012; Maxwell, 2008).

As mentioned before, sampling in a case study involves finding a case either through probability or purposeful sampling in a manner that is consistent with the purpose of the study (Maree, 2012). Purposeful sampling refers to selecting a participant on purpose due to the valuable first-hand information he/she can provide and which cannot be obtained from other sources (Maxwell, 2008). The advantages of purposeful sampling according to Maxwell (2008) are twofold, namely:

1. it can be used to ensure representativeness of the setting, individuals and the phenomena, and

2. it can successfully capture the heterogeneity of the population. 
In the current research, a single participant was selected through purposeful sampling on the basis of certain characteristics displayed by the participant. The participant had to:

- be between the ages of 9 and 14 years;

- still be in primary school;

- be a survivor of sexual abuse;

- $\quad$ still reside with the family where the sexual abuse occurred;

- be motivated to engage in life design counselling as this would increase his/her personal enrichment, which was intrinsic to the study.

After the participant had been chosen and the ethical requirements had been satisfied, certain qualitative techniques were implemented to assess the successfulness of life design counselling with this survivor of sexual abuse. The applicable techniques are discussed next.

\subsubsection{The life design counselling process}

Savickas et al. (2009) argue that interventions based on life designing should be lifelong, holistic, contextual and preventative. Life designing therefore aims to enhance lifelong development while it also considers all salient roles in self-construction, the importance of the environment/context and being preventative by fostering narratability, adaptability, activity and intentionality (Savickas et al., 2009). According to these researchers, the life design process involves six general steps:

1. Define the problem: During the initial stage the researcher should focus on establishing a working alliance with the participant that will allow the participant to narrate his/her problems through stories. The focus point of the researcher will be to assist the participant to become aware of the main domains in his/her life (Savickas et al., 2009).

2. Explore subjective identity forms: This stage necessitates that the researcher along with the participant investigate how the self is organised in different domains. Experiences, relationships and future expectations should also be articulated by the participant (Savickas et al., 2009). 
3. Open perspectives: During this step the researcher has to assist the participant to view his/her stories from a distance by objectifying the stories and experiencing silenced stories. Re-authoring, reorganising, revising and revitalising stories also play an important role (Savickas et al., 2009).

4. Place the problem in the new story: Allowing the participant to put his/her problem in a new perspective encourages problem resolution and change. It ultimately motivates him/her to consider the problem from a new perspective with new SIFs (Savickas et al., 2009).

5. Actualise the new identity: Throughout this step the participant is motivated to engage in activities that are related to the "new" self. This requires from the participant to create a plan to deal with potential barriers and tell stories of the new life to other individuals (Savickas et al., 2009).

6. Follow-up: The researcher should in this step be focused on short- and long-term follow-ups, and must provide the participant additional consultation if necessary.

Life design offers a useful way for individuals to process trauma and navigate changes in their lives associated with careers, relationships, health, etc. (Lara \& Vess, 2014). Duarte (2010, p. 363) states:

The life-design framework for counseling aims to face counseling as a process of continuous interactions, which helps in the resolution of problems which places the process of decision making within a systematic and realistic frame, and which allow the conjunction of the necessities of individuals with those of the contexts they act, develop and live.

The life designing process performed in this study therefore aimed to support children in future career construction that could transcend their past traumas, both as a process and an outcome (Savickas et al., 2009). Our attention next shifts to the qualitative techniques that were used during data collection. 


\subsubsection{Qualitative techniques}

Qualitative data techniques that were used in this study included the following:

Table 3.1: Qualitative data techniques used in this study

\begin{tabular}{|c|c|c|}
\hline Data collection technique & Description & Format of data \\
\hline Conversations & $\begin{array}{l}\text { These conversations were seen as } \\
\text { part of the life design process where } \\
\text { the aim was to learn about the } \\
\text { participant's ideas, beliefs, views and } \\
\text { opinions. The general purpose of } \\
\text { these conversations mirrors to some } \\
\text { extent that of a semi-structured } \\
\text { interview where the goal is to gain as } \\
\text { much descriptive information from the } \\
\text { participant in order to allow the } \\
\text { researcher to gain a better } \\
\text { understanding of the participant's } \\
\text { social reality (Maree, 2013). }\end{array}$ & $\begin{array}{l}\text { Audio recordings } \\
\text { and verbatim } \\
\text { transcripts }\end{array}$ \\
\hline Observations & $\begin{array}{l}\text { Observations in qualitative research } \\
\text { are a way of collecting data in an } \\
\text { unstructured manner. Maree (2013) } \\
\text { however warns that the researcher's } \\
\text { observations by nature can be } \\
\text { subjective and therefore the } \\
\text { researcher should be cognisant of the } \\
\text { above. The researcher made use of } \\
\text { field notes, audio and video } \\
\text { recordings as well as a researcher's } \\
\text { diary to record his observations } \\
\text { during the current study. }\end{array}$ & Field notes \\
\hline Psychometric tests & $\begin{array}{l}\text { The Resiliency Scales for Children } \\
\text { and Adolescents (RSCA) was used. }\end{array}$ & Questionnaires \\
\hline
\end{tabular}




\begin{tabular}{|l|l|}
\hline & $\begin{array}{l}\text { This instrument was ased } \\
\text { qualitatively to assess whether } \\
\text { transformation and/or change } \\
\text { occurred in the participant during the } \\
\text { course of the intervention. For this } \\
\text { reason the instrument was only used } \\
\text { qualitatively in an attempt to identify } \\
\text { dominant themes. By qualitatively } \\
\text { comparing dominant themes voiced } \\
\text { by the participant, the researcher was } \\
\text { able to assess the effectiveness of } \\
\text { the therapeutic intervention. }\end{array}$ \\
\hline
\end{tabular}

\subsubsection{Postmodern data collection techniques}

As mentioned in Chapter 1, postmodern techniques in career counselling allow researchers to take into consideration people's subjective experiences and the meaning they assign to such experiences. Both Savickas and Maree agree that postmodern approaches strongly highlight social identity and the individual's sense of self-worth (Savickas et al., 2009; Maree, 2013). Based on the six steps of life design counselling (see Section 3.6.2), the following data collection techniques were implemented.

Table 3.2: Life design intervention strategies

\begin{tabular}{|ll|l|}
\hline \multicolumn{2}{|l|}{ Intervention steps } & Techniques \\
\hline $1 . \quad$ Define the problem & $\begin{array}{l}R S C A \quad \text { measure; Family constellation; } \\
\text { Genogram }\end{array}$ \\
\hline 2. $\quad$ Explore subjective identity forms & Early recollections; Memory box, Sandtray \\
\hline 3. $\quad$ Open perspectives & Collage; Lifeline \\
\hline $4 . \quad$ Place the problem in the new story & $\begin{array}{l}\text { Life chapters (future narrative); Success } \\
\text { Experiences }\end{array}$ \\
\hline
\end{tabular}


5. Actualise the new identity

Drawing (what will overcome obstacles); RSCA

\subsubsection{Family constellation}

Originating from the work of Adler (1956), the family constellation exercise involves a person describing every member of the family. The participant is asked to describe his/her position and role in the family and then plot all the members of the family on a portrait. Cochran (1997) believes that this is a good activity to identify characteristic strengths and weaknesses of family members involved in the participant's story. In the present study the family constellation exercise was done in conjunction with the genogram.

\subsubsection{Early recollections}

Early recollections entail asking the participant to record three memories from his/her past, preferably from between the ages of 3 and 6 years old (Taber, Hartung, Briddick, Briddick \& Rehfus, 2011) which, according to Cochran (2011), are deeply profound and can help the participant identify his/her life stories. Events during childhood have a significant influence on people's future and therefore early recollections provide valuable insight as they aim to deconstruct a person's worldviews, self-image, values, interests, perceptions about the self and the world.

\subsubsection{Memory box}

A memory box, as part of memory work, has been used as a way to allow people to tell their life stories as supportive strategies for psychological purposes (Ebersöhn, 2007; Ebersöhn, Ferreira \& Mnguni, 2008). Denis (2005) states that memory boxes have been found to help increase resilience in children, while Ebersöhn (2008) contends that memory box making provides a way for people to share stories in the process of constructing their life narrative. Ebersöhn, Eloff and Swanepoel-Opper (2010) state that, as part of narrative therapy, memory box making assists people to create alternative life stories rather than to remain stuck in their stories of trauma. Memory box making 
therefore assists not only in creating a 'safe place' for telling stories, but also in helping people create alternative stories as a way to transcend past trauma and pain.

\subsubsection{Sandtray}

Sandtray activities involve all five senses and brings unconscious thoughts to conscious allowing an individual to bring nonverbal experiences into verbal expression (Boik \& Goodwin, 2000). According to Boik and Goodwin (2000) this process enables clients to create new, healthier experiences which enable them to move away from a "victim of experiences" position. Gallerani and Dybicz (2011) state that through sandplay children gain control over traumatic events experienced in the past which in turn allows them to feel secure. Through this activity I aim to allow the participant to gain control over past experiences and in the process create better experiences, feeling more secure in their environment.

\subsubsection{Collage}

Collages in narrative work assist clients to use pictures, photographs, written words, slogans, cards, symbols etc. to tell their stories, and hence the researcher/counsellor manages to identify from the collage relevant themes and patterns (Fritz \& Beekman, 2007). Fritz and Beekman (2007) state that collage making has a developmental aspect as individuals foster personal awareness and growth when they are confronted with information about the self that was previously hidden. A collage allows the counsellor to gain important insight into a person's attitudes and feelings about the self, and it generates important psychodynamics that is conveyed by the narrative describing the collage (Ikiugu \& Ciaravino, 2007).

\subsubsection{Life line}

Building on the collage follows the lifeline exercise, which allows the participant and counsellors to unpack themes and patterns that have been discovered. These then serve as a foundation upon which the participant can start the construction of an alternative future life story (Fritz \& Beekman, 2007). 


\subsubsection{Life chapters}

Participants are asked to think of their life in terms of an autobiography that sums up various periods in their life. The focus of this activity is to narrate not only past events but also a possible future narrative that may be beneficial to the participant.

\subsubsection{Success experiences}

This activity focuses on success experiences that the participant enjoyed and appreciated. Further details are gathered, such as how it happened, and what the client was thinking, feeling and doing throughout the experience.

In the current study, the above techniques were used to gather qualitative information from the participant. The next section deals with how this information was analysed.

\subsection{Data analysis}

Leech and Onwuegbuzie (2011) highlight the fact that although many instruments exist to interpret quantitative data, the same can unfortunately not be said for qualitative studies - which possibly contributes to most qualitative researchers struggling with this area of research. They further state that qualitative research is helpful in understanding a certain phenomenon and/or experience and the meaning people attach to such phenomena/experiences (Leech \& Onwuegbuzie, 2011). Henning, Van Rensburg and Smit (2004) states that data analysis in qualitative research is an ongoing, cyclical process because the researcher needs to constantly reflect as the research unfolds.

Data analysis in this study was done using thematic content analysis, a method used to identify themes within data that are descriptive rather than interpretive in nature (Braun \& Clarke, 2006). Advantages of this approach (according to Braun and Clarke (2006)) are the flexibility that thematic content analysis offers and the fact that it is compatible with a constructionist paradigm. Using thematic content analysis allows for the interpretation and organising of information in such a manner that the primary research question will be answered effectively. 
The following diagram is a representation of the steps that were followed during thematic content analysis.

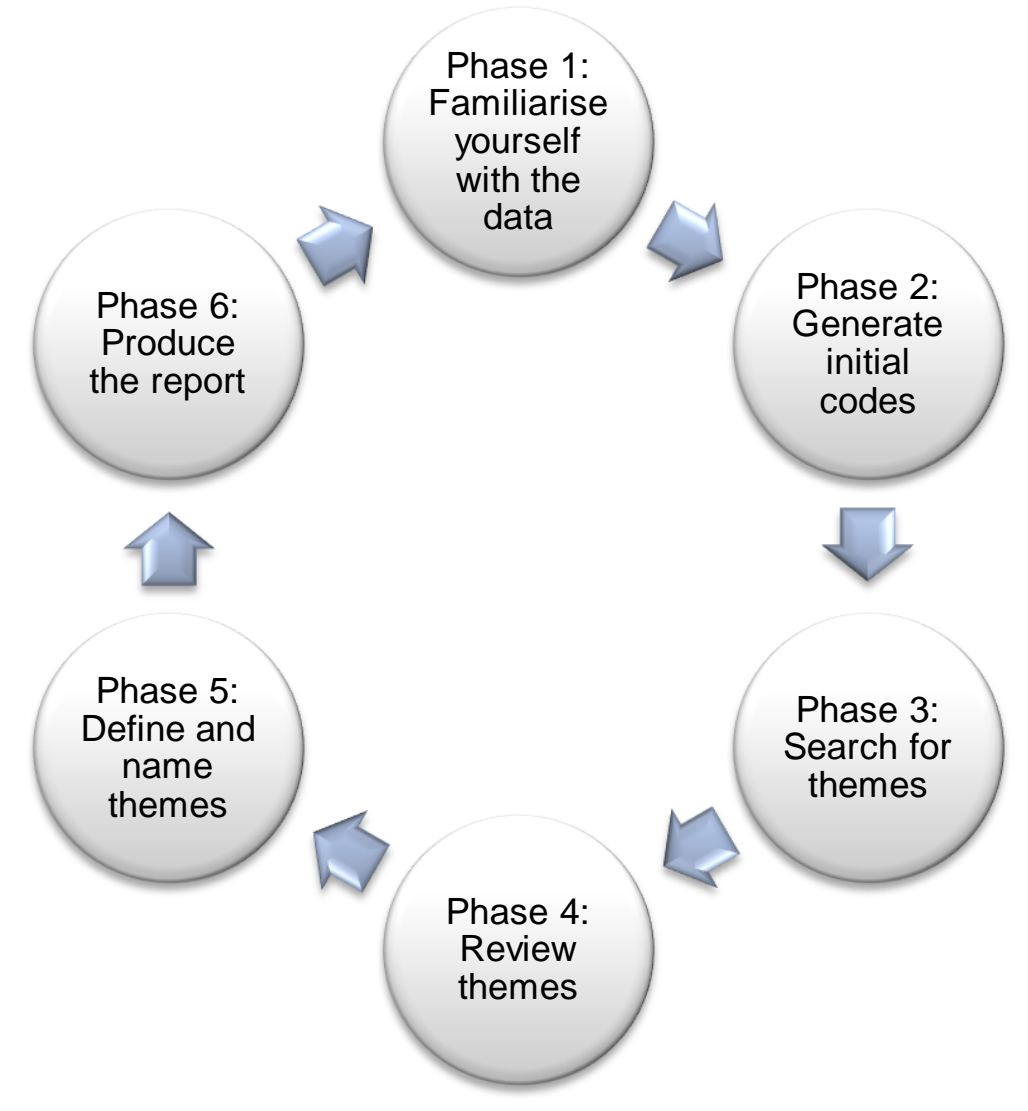

Figure 3.1: Thematic content analysis process (adapted from Braun \& Clarke (2006))

\subsection{Quality assurance techniques}

In an attempt to facilitate trustworthiness, Lincoln and Guba (1985) suggest that certain aspects such as credibility, confirmability, transferability and dependability should be part of a study. Below, I elucidate the techniques I implemented to ensure that these qualities are achieved.

\subsubsection{Credibility}

Credibility refers to the extent to which the results of a study are valid and trustworthy (Cutcliffe \& McKenna, 1999). In this study, I carried out the following steps 
(recommended by Baxter and Jack (2008)) to ensure that my research would be credible or valid:

- I articulated the research question clearly and unambiguously.

- I ensured that the research design was appropriate for the study/research question.

- I ensured that purposeful sampling strategies were appropriate.

- I collected and managed the data systematically.

- I ensured that the data analysis was done correctly.

Cutcliffe and McKenna (1999) argue that one cannot measure credibility in qualitative studies with quantitative concepts. Credibility in qualitative research should therefore be contingent on whether the researcher and reader agree that, in their experience, the results are meaningful and applicable. To ensure the trustworthiness and validity of themes and results that emerged from the study, I implemented triangulation and crystallisation, which are discussed next.

\subsubsection{Triangulation}

According to Di Fabio and Maree (2012), triangulation involves an in-depth exploration of different sources of information as well as methods. It can therefore minimise faulty interpretations or associations due to the fact that it is based on various sources (Di Fabio \& Maree, 2012).

\subsubsection{Crystallisation}

Merriam (1998) posits that crystallisation of the research findings will be accomplished through the use of various data collection methods. This implies that researchers should consider various interpretations and perspectives when analysing data. Although some scholars believe that either triangulation or crystallisation should be in a study, Richardson (2000) states that crystallisation holds marked advantages as it allows the researcher more ways in which to analyse data. 


\subsubsection{Confirmability}

Lincoln and Guba (1985) refer to confirmability as the degree to which the results can be confirmed by another person/research study. Confirmability therefore questions if the research findings that were collected support the researcher's conclusion or whether there is some degree of bias present. Confirmability can be increased by a research audit that (a) leaves a clear trail of the methods used to gather information, (b) identifies prominent themes and (c) shows how decisions were made.

\subsubsection{Transferability}

Transferability can be defined as the degree to which results can be transferred to other contexts. Finfgeld-Connett (2010) warns that if a researcher intends to transfer a theoretical framework and/or intervention strategy from one context to another, great thought should go into acquiring knowledge regarding such other contexts, interactional elements should be clear, and drawing conclusions should have meaning outside of that context.

\subsubsection{Dependability}

Dependability refers to the repeatability of the results (Lincoln \& Guba, 1985). Wasserman, Levy and Loken (2009) define the above as the extent to which results can be generalised to other contexts and repeated with the same results. Dependability in this study was practically ensured by conceptualising the study, collecting the data, interpreting the findings and reporting results in a manner that was both consistent and clear.

\subsection{Ethical considerations}

In my study I upheld the ethical guidelines delineated by Orb et al. (2001) who predicted that a balanced qualitative research relationship would foster and encourage awareness of possible ethical issues, disclosure and trust. The ethical issues to which I adhered during my research are next discussed in detail. 


\subsubsection{Informed consent}

In my study, I carried out the following steps to ensure informed consent was gained in an ethical manner, thereby adhering to the steps as recommended by Haverkamp (2005):

- I informed the participant of all contributing factors and/or facets involved in the study that could possibly influence her decision to consent/assent to the study.

- I discussed potential limitations of the study with the participant.

- Informed consent was gained and the participant was free to voluntarily participate in the study. (Due to the limitlessness of potential issues in qualitative research, Haverkamp (2005) suggests that informed consent should be viewed as a continuous process rather than a once-off information event.)

- The participant was ensured that she would be able to withdraw from the study whenever she felt that she did not want to continue anymore, without experiencing any consequences.

- Due to the age of the participant, communication with the parents/legal guardian took place on a continuous basis.

\subsubsection{Privacy, confidentiality and anonymity}

Privacy, anonymity and confidentiality were assured by using a pseudonym throughout the study and ensuring that the participant's identity would not be made known during the different stages of the study. Such care was taken not only with regard to the participant, but also towards any third parties that could potentially be mentioned by the participant.

Richards and Schwartz (2002) insist that all possible measures must be taken to protect confidentiality as well as anonymity, which entail securely storing all data that was gathered. Throughout the current study, all the data gathered was stored on password-protected laptops/desktops, as well as in locked cupboards.

\subsubsection{Protection from harm}

Richards and Schwartz (2002) emphasise that the research process, methods, techniques and intervention strategies should be applied in a manner that does not 
cause stress, anxiety or exploitation. Findings should also be reported in a way that does not misrepresent the views of the participant in a wrongful, negative manner. Orb et al. (2001) support this requirement and claim that justice is a cornerstone of research. Hence the participant may not be abused or exploited, a principle that was also central to the current study. The participant was under no circumstances harmed and support was given throughout the study, ensuring that all ethical principles were adhered to.

I was aware in advance that the participant in my study might manifest behaviours and emotions that would warrant counselling during the course of the research. As a psychologist in training, I hoped to be able to identify these behaviours and emotions if and when they arose. However, I also realised that my function as researcher in the study should not be blended or integrated with my role as psychologist (to avoid role confusion/multiple roles). Therefore, to ensure the wellbeing of my participant I arranged for counselling to be provided by the relevant professionals should this be required.

\subsection{Summary}

In this chapter, I discussed the paradigmatic perspective underlying this study from an interpretivist-constructivist point of view. The research design and data collection techniques as well as the measures used were discussed. Qualitative as well as postmodern data collection techniques were discussed and each strategy was explained. A discussion followed on how quality within this study was guaranteed, as well as how ethical issues were adhered to. This included the roles of the researcher and his responsibility to ensure the safety and psychological wellbeing of the participant.

Although thematic content analysis is widely used in qualitative research, critique surrounding this approach claims that it has no clear demarcation of how to apply this method, that it fails to state what constitutes a theme, and that some results are not founded in data. Furthermore, as a researcher doing qualitative research, I have to acknowledge that some degree of subjectivity existed throughout the research process. Although various steps were taken to ensure unbiased data collection and the reporting of findings, the fact that a degree of subjectivity existed is undeniable. This is however not necessarily a negative aspect, as the researcher has to understand an environment 
(context) in order to understand the phenomenon being researched, along with participants' accompanying behaviour.

The study in hand and the accompanying methodology used were by no means perfect and I believe that being aware of these challenges allowed me to confront them in a proactive, positive manner, thus ensuring trustworthy and reliable findings. 


\section{CHAPTER 4: RESULTS AND DISCUSSION8}

\subsection{Introduction}

In the previous chapter I presented the empirical and methodological basis of my study by describing the paradigmatic perspective, research design, research methodology, as well as my approach to data analysis and interpretation. I concluded Chapter 3 by shedding light on the quality assurance and ethical guidelines that this study was based on. In this chapter I intend to

- report on the results of my study by discussing the themes that emerged during the thematic analysis process of the raw data;

- present my data, enriching it with direct quotations, brief evocative descriptions as well as diagrams;

- provide a summary of the data analysis method used, as well as a short description on the history and background information of the participant;

- discuss the main themes as well as subthemes that arose during data analysis, and

- conclude with a brief summary of this chapter.

\subsection{Data analysis methods}

The specific data analysis method $^{9}$ that was implemented during this study is summarised in Table 4.1.

Furthermore, in an attempt to facilitate trustworthiness, dependability and credibility, I followed the techniques delineated by Lincoln and Guba (1985) during my collection and analysis of the data. ${ }^{10}$

\footnotetext{
${ }^{8}$ I am aware that it is more customary to separate the Results and Discussion sections of a research report, but for reasons of space, and after discussing the matter with my supervisor, it was decided to include the Discussion section in the current chapter as well (after the presentation of the Results). Moreover, it should again be noted that I could not find any studies on the career resilience of survivors of sexual abuse who remained in the environment in which the abuse took place. There are very few, if any, studies that I could realistically use as a benchmark. I was therefore left with no choice but to deviate from the usual style adopted during the execution of literature control, namely "My research confirms/ supports/ $\ldots$ the findings of ..." or "My finding refutes/ differs from/ ... the findings of ..."

${ }^{9}$ Refer to Chapter 3 for a detailed discussion on the data analysis method.

${ }^{10}$ Refer to section 3.8 in Chapter 3 for these guidelines/techniques.
} 
Table 4.1: Data analysis method (adapted from Braun and Clarke (2006))

\begin{tabular}{|l|l|}
\hline Phases & Description \\
\hline Phase 1 & $\begin{array}{l}\text { Familiarise yourself with the data, in other words immerse yourself in the } \\
\text { data to the point of becoming entirely familiar with the data (Braun \& } \\
\text { Clarke, 2006). }\end{array}$ \\
\hline Phase 2 & $\begin{array}{l}\text { Generate initial codes that will serve to identify your subsequent themes } \\
\text { (Braun \& Clarke, 2006). }\end{array}$ \\
\hline Phase 3 & $\begin{array}{l}\text { Search for themes that refer to collating all relevant data and re-focus the } \\
\text { data by identifying specific themes (Braun \& Clarke, 2006). }\end{array}$ \\
\hline Phase 4 & $\begin{array}{l}\text { Review themes by considering them all and discerning whether a } \\
\text { particular theme is indeed a theme or just an occurrence (Braun \& Clarke, } \\
\text { 2006). }\end{array}$ \\
\hline Phase 5 & $\begin{array}{l}\text { Define and name themes in order to define and identify the essence of } \\
\text { each theme (Braun \& Clarke, 2006). } \\
\text { Phase 6 }\end{array}$ \\
\hline
\end{tabular}

\subsubsection{Referencing system}

The three-digit coding system that was used to reference data appears at the end of this document (Please refer to Annexure G).

The relevant background information of the participant who was involved in the study is discussed next.

\subsection{Background information of the participant ${ }^{11}$}

The participant (hereafter called Suzi ${ }^{12}$ ) is an 11-year-old white girl. Her home language is Afrikaans and she can also speak and understand English well. Suzi is currently in Grade 4 and lives with her biological parents in a low socio-economic environment.

\footnotetext{
${ }^{11}$ Certain relevant information is not discussed here since it appears as themes during the contact sessions.

${ }^{12}$ A pseudonym was used to protect the identity of the participant.
} 
Suzi's mother is a housewife and her father is a mechanic/artisan. Suzi has an older sister who, according to SAPS (South African Police Service) investigations, was not sexually abused. It is alleged that Suzi was sexually abused by a friend of the family, and the abuse occurred on their farm where they are currently staying. The purported sexual abuse took place about 12 months ago and since then the matter has been reported to the SAPS investigators and a case has been opened.

Suzi was not removed from this environment as a court case is still underway. Moreover, welfare workers could not remove her from this environment due to a lack of resources. Although Suzi is a good performer in school with an average grade, the school reports that there has been a decline in her scholastic performance over the last few months and that Suzi has been acting out in class. Suzi has one friend with whom she feels she can share anything. Suzi's mother states that since the alleged abuse Suzi and her sister have been engaging in fights that involve physical aggression towards one another. Suzi also started engaging in self-harming behaviour. She was referred to me by professionals in the field of social work as they were concerned that the allegations of sexual abuse and ongoing legal procedures might influence her emotional well-being negatively. I chose Suzi as the participant in my study because she met all the selection criteria for the study and my subsequent research ${ }^{13}$.

I discussed the purpose and scope of my study with both Suzi and her biological parents, after which the parents gave informed consent and Suzi provided informed assent. Suzi also stated that she would like to be part of the therapeutic intervention because she was sad and she wanted to be happy again.

The life design counselling process, as experienced by Suzi, is discussed in the following section.

\subsection{The process of life design counselling for Suzi}

Detailed discussions of all the counselling sessions are next presented in chronological order. Subthemes are highlighted using different colour shadings and presented in bold. After I have presented all subthemes, I will identify the main themes and categorise all subthemes under these main themes.

\footnotetext{
${ }^{13}$ Refer to Chapter 1 for a detailed discussion on the selection criteria.
} 
Appendices B - F contain visual information about Suzi's work. In order to clearly and accurately reflect what she communicated to me during the sessions, verbatim conversations have been included to provide the reader with a good idea of what the participant attempted to relay to the researcher. All identifying information was changed to protect her identity.

It should be stated that at the outset it was quite challenging at times to analyse the participant's responses, because she would give short, non-descriptive, concrete answers and examples. In order to truly understand Suzi's thought processes and underlying feelings, I had to at times probe excessively in order to get her to communicate her true thoughts and feelings. The participant's well-being was considered and sessions were broken into two or three separate sessions to allow her to process information.

Our attention now shifts to an analysis of the life design counselling sessions.

\subsubsection{Session 1: RSCA, family constellation exercise and genogram}

\subsubsection{General comments}

Suzi came into the first session very quiet and withdrawn. Her approach to the session was characterised by openness, yet withdrawn and protective at the same time. She participated in the various therapeutic activities while engaging in conversation with me as the researcher. As the session continued, she became more comfortable around me and began to express herself more openly. She was comfortable talking about herself as well as about her family.

During the first session her body language would dramatically change whenever I would refer to any aspect relating to the alleged sexual abuse that she had experienced. Suzi would hunch down in the chair, raise her shoulders, bend the top of her body forward to make her profile smaller, look down and play with her hands. Initially her willingness to talk about the alleged sexual abuse was non-existent. She would ask increasingly more questions about what we were going to do next as the session continued. 


\subsubsection{Course of the session and subthemes identified}

\section{i. Quantitative results}

a. Results obtained from the administration of the Resiliency Scales for Children and Adolescents (RSCA)

Suzi was asked to complete the RSCA questionnaire by ticking the relevant response to each question. The figures below indicate Suzi's Resiliency Profile ${ }^{14}$ (Figure 4.1), as well as the combined scores of all the subscales (Figure 4.2) as per our first session.

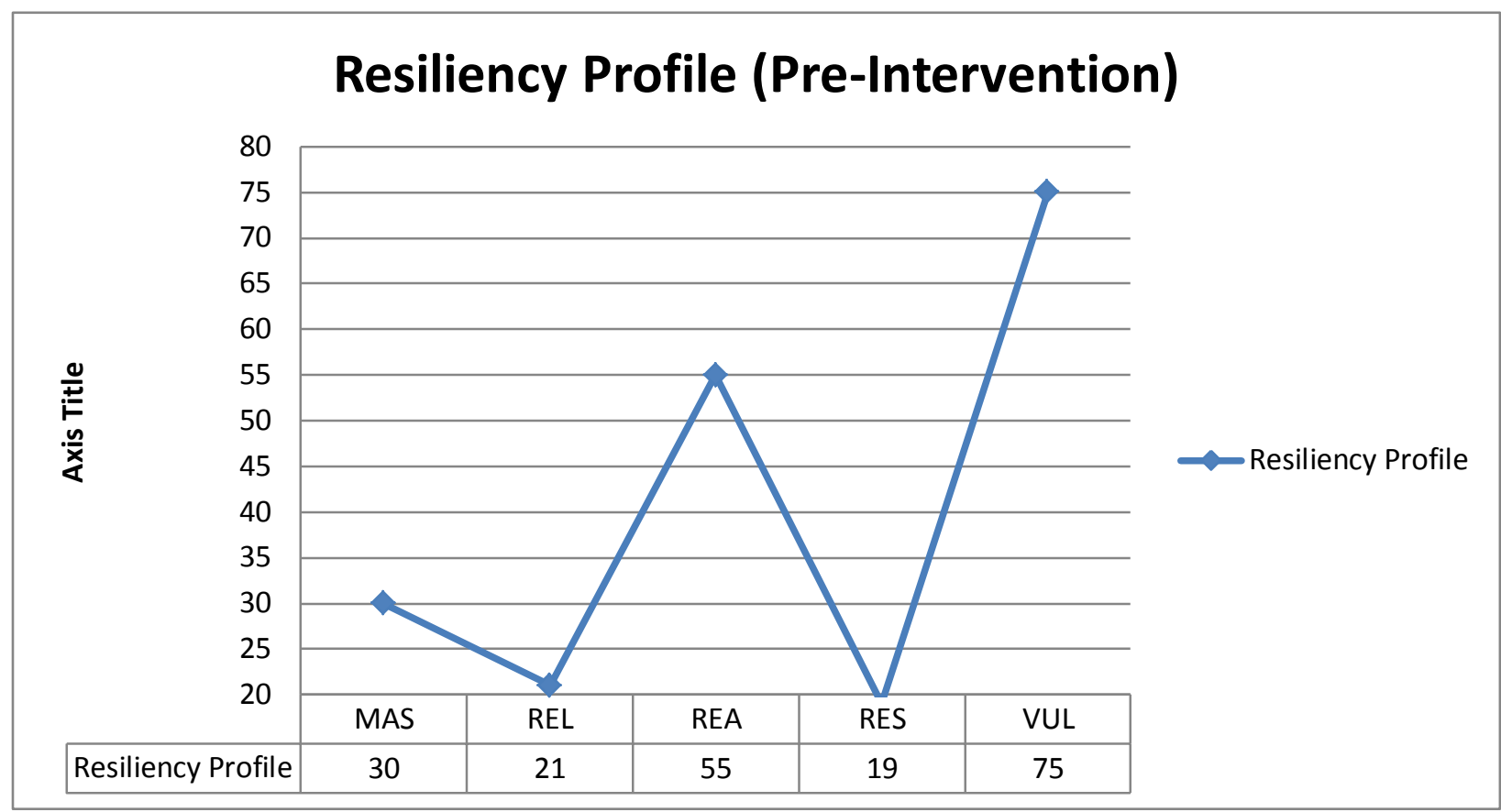

Figure 4.1: Pre-intervention resiliency profile

The following results were obtained on the RSCA along with their descriptive categories $^{15}$.

\footnotetext{
${ }^{14}$ The resiliency profile is made up of three self-report scales designed to identify areas of perceived strength and/or vulnerability in a way that translates these qualities into wording that is easily understood by youths and their caregivers (Prince-Embury, 2006).

${ }^{15}$ Refer to Appendix A for a full description of all the categories involved.
} 
Table 4.2: Pre-intervention resiliency scale - descriptive categories

\begin{tabular}{|c|c|c|}
\hline Resiliency Scale & Subscales & Scale descriptions \\
\hline \multirow{3}{*}{$\begin{array}{l}\text { SENSE OF } \\
\text { MASTERY } \\
\text { (MAS) }\end{array}$} & Optimism & Low \\
\hline & Self-efficacy & Below average \\
\hline & Adaptability & Low \\
\hline \multirow{4}{*}{$\begin{array}{l}\text { SENSE OF } \\
\text { RELATEDNESS } \\
\text { (REL) }\end{array}$} & Trust & Low \\
\hline & Support & Low \\
\hline & Comfort & Below average \\
\hline & Tolerance & Below average \\
\hline \multirow{3}{*}{$\begin{array}{l}\text { EMOTIONAL } \\
\text { REACTIVITY } \\
\text { (REA) }\end{array}$} & Sensitivity & Above average \\
\hline & Recovery & Average \\
\hline & Impairment & Average \\
\hline
\end{tabular}

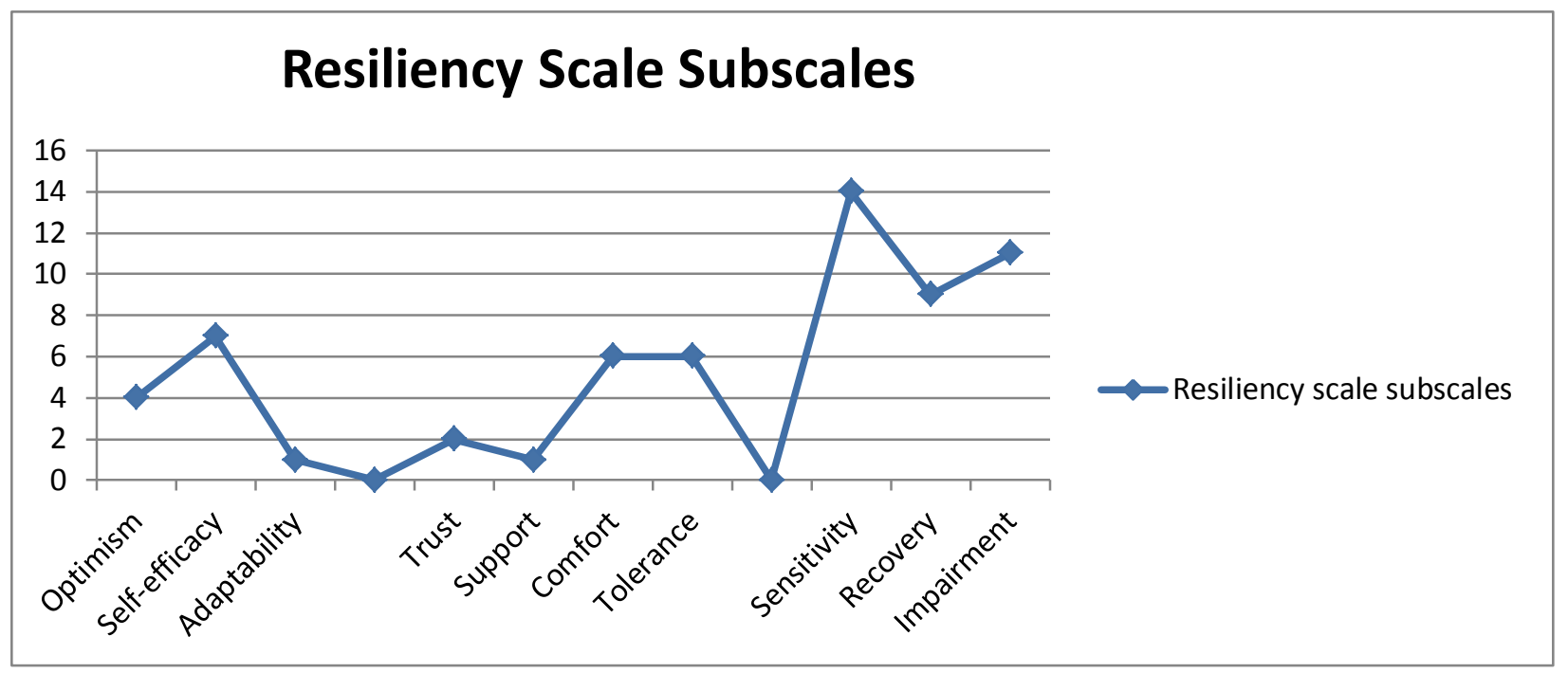

Figure 4.2: Pre-intervention Resiliency Subscale Composition 


\section{ii. Qualitative results}

\section{a. Resiliency scales for children and adolescents}

In respect of the sense of mastery (MAS) subscale of the questionnaire, Suzi answered: "I can learn from my mistakes but it depends what mistakes these are" $(1 ; 1 ; 4)$. She also stated: "I don't like to ask for help as I like to do things myself" $(1 ; 1 ; 6)$. With regard to the sense of relatedness (REL) subscale, she replied: "I can feel calm around others depending on who they are" (1;1;8). Suzi also remarked: "I can't say NO to others" $(1 ; 1 ; 10)$ and: "I can forgive people who let me down but it depends on what they did wrong"(1;1;12). Suzi continued completing the emotional reactivity subscale (REA) by saying: "When someone hurts me, I will strike back depending on who hurt me" $(1 ; 1 ; 14)$.

In a study involving 1073 adult woman and survivors of CSA, Cambron et al. (2014) posit that childhood sexual abuse will not only have a detrimental long-term impact on the quality of interpersonal relationships, but also cause difficulty in forming healthy relationships. My findings above seem to confirm and extend the above results and would appear to predict a possible negative impact on Suzi's future career resilience.

\section{b. Family constellation exercise}

Throughout the family constellation exercise, Suzi described her parents as being proud of her as well as of her sister. She stated: "they are proud because me and my sister are good girls and we behave ourselves" (2;1;19). She continued by describing her sister as the happiest person in the family and someone she can $(2 ; 2 ; 23)$ trust by remarking:

$(2 ; 2 ; 24)$. Suzi described herself as silly because she thinks she is always funny.

According to Schultheiss (2003), relational perspectives in career development such as social support from parents, siblings, extended family as well as significant others, serve as a source for maturation in career decision making and transition. In view of Schultheiss's assertion, Suzi's trust in her sister seems to augur well for her maturation potential. 


\section{c. Genogram}

During the genogram exercise, Suzi mentioned that she loves her mother and acknowledged: "I love my mom a lot and I always want to stay with her" (3;2;40). Suzi did not mention her biological father during this exercise, but only referred to him in the course of identifying all the family members, saying "My dad works hard" (3;2;42).

The following subthemes were identified during Session 1:

All extracts of data have been colour-coded and listed as subthemes below each session to simplify identification of subthemes ${ }^{16}$. These colour-coded sub-themes are further reviewed and summarised under main themes that arose during data analysis. This is done according to the guidelines as set out in Section 4.2, Table 4.1, which explains the ongoing refinement of themes during phase 5 of the thematic content analysis, as delineated by Braun and Clarke (2006).

\section{Table 4.3: Session 1 Subthemes}

- Adaptability

- Anxiety

- Autonomy/Independence

- Comfort

- Comfort around others (emotional reactivity)

- Conditional forgiveness

- Feelings of acceptance

- Impairment

- Love/intimate family relationships

- Optimism

- Poor tolerance

- Recovery

- Self-efficacy

- Sensitivity

${ }^{16}$ Note that quotes highlighted in a specific colour provide substantiation for those themes and subthemes that appear in my tables and that are also highlighted in that specific colour. 
- Support

- Tolerance

- Trust

- Unforgiving/vindictive

- Work ethic

\subsubsection{Session 2: Sandtray, Memory box, Early recollections}

\subsubsection{General comments}

Suzi came into the second session with a sense of excitement and willingness to engage in the exercises. Her body language was more confident and open than during the first session. Suzi was also more verbal during these exercises and was happy to express her feelings and thoughts throughout the session. Her thinking pattern was concrete during this session, but during the sandtray exercise she was able to move from concrete thinking to more abstract thinking. As the session continued, my observation was that Suzi and I established rapport as she appeared to be open and relaxed inside the therapeutic room.

\subsubsection{Course of the session and subthemes identified}

\section{i. Qualitative results}

\section{a. Sandtray}

During the sandtray exercise, Suzi was not able to verbalise what had happened to her the night when the alleged sexual abuse took place. Her response was: "I don't want to" and she shook her head from side to side. She was, however, willing to create a scene of this event in the sandtray. When asked if she can play out what happened, she said: "No, I do not want to play out what happened that night" $(4 ; 3 ; 64)$. She appeared to get agitated and anxious as she displayed the same hunch-over body language as in the first session. Suzi also verbalised that the events that took place that night (alleged sexual abuse) did not change how she views herself or her life $(4 ; 4 ; 81)$. Suzi said this in a manner that suggested she didn't want to talk about the event but would rather choose to avoid any such conversations. Suzi said: "I want to stop thinking about what happened." (4;3;70). 
Suzi did however later choose to change the scene in the sandtray into one where she takes control/power back over the situation. She said: "I made the scene safe because I added a door to my room which can lock. I also made it (the room) happy again" (4;4;70). A study by King, Wardecker and Edelstein (2015) investigated CSA and personal mastery in a sample of 265 women, and found that personal mastery or sense of mastery in victims of childhood sexual abuse successfully prevents a variety of unwanted psychological effects. It actually enables these individuals to better cope with various stressors (King et al., 2015). My findings ${ }^{17}$ indicate that Suzi was able to gain a sense of mastery over the experienced traumatic event, and this could possibly have a positive influence on her emotional stability and future career resilience.

\section{b. Memory box}

Suzi started with the construction of her memory box during the second session and took her time to creatively decorate the box. She took tremendous pride in how her memory box was decorated. Her memory box was filled with objects such as a teddy bear frog, an acorn which she decorated, five white rocks which she also decorated, and colour beads. She brought all these objects from home and explained: "it reminds me of things in my life that make me happy" (5;5;123). Suzi also said: "when I look at the box I would rather want to be reminded of the things that make me happy. I don't want to put things inside the box that will remind me of the sad and hurtful things that happened to me" $(5 ; 5 ; 123)$. Suzi mentioned that she likes the way she can decorate things to make it beautiful, because "it makes me happy" $(5 ; 5 ; 128)$.

\section{c. Early recollections}

Suzi's early recollections were very concrete in nature and the central theme that linked all these recollections together was the fact that they made her experience feelings of happiness. She would mention: "it made me happy when I turned 10 years old and when my mother took me to the shops" (6;5;136). Another central theme that was prevalent throughout all the activities was her longing to be protected by her parents.

\footnotetext{
${ }^{17}$ I am aware that some people prefer the phrase "findings of the study". This is a matter of personal choice.
} 
A longing for security was clearly prevalent during the sandtray exercise, as she placed her father and mother in the sandtray, in a separate room to protect her.

The following subthemes were identified during Session 2:

\section{Table 4.4: Session 2 Subthemes}

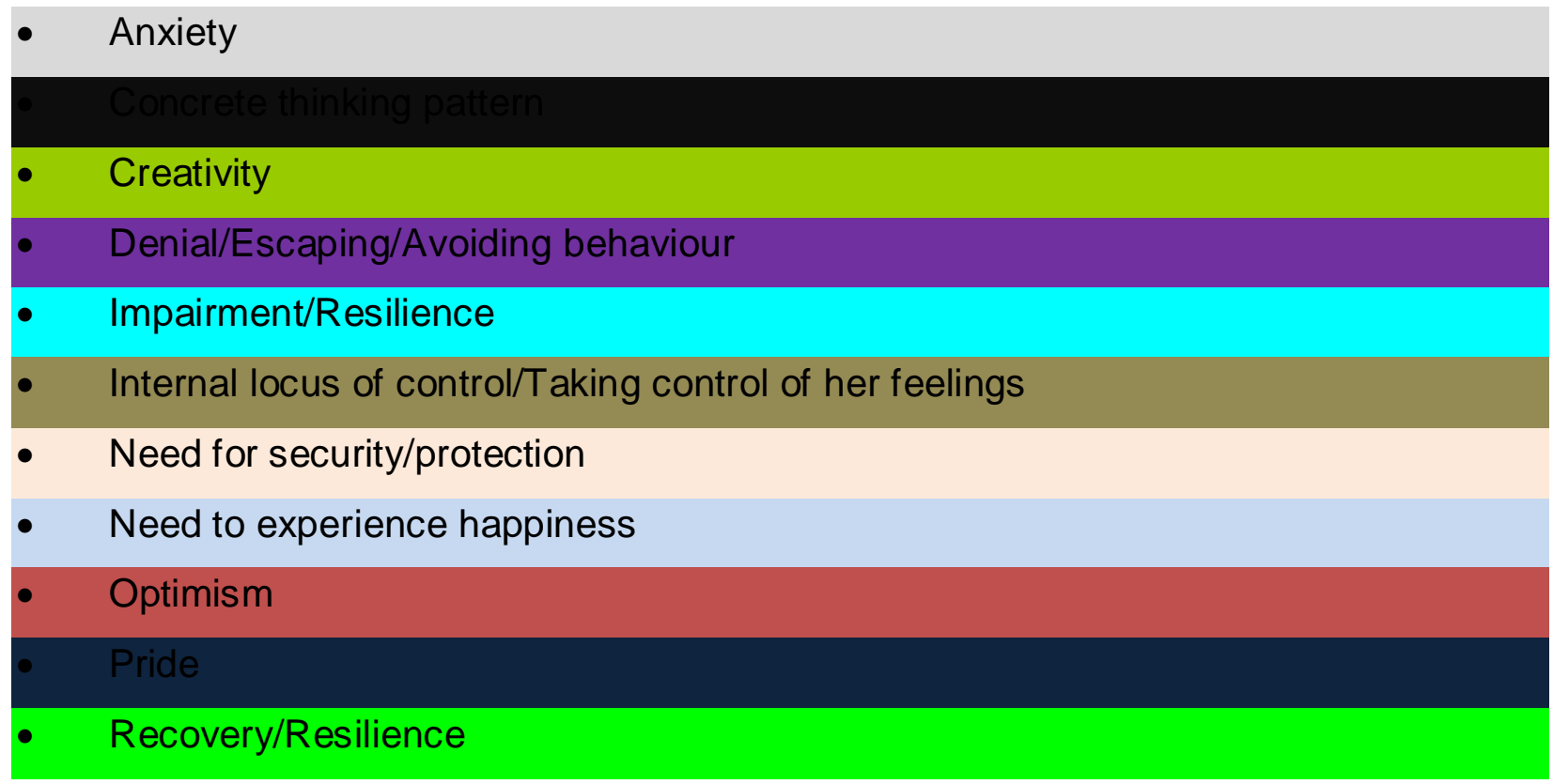

\subsubsection{Session 3: Collage and lifeline}

\subsubsection{General comments}

During this third session, Suzi was extremely quiet and withdrawn. She had fallen ill the last couple of weeks after Session 2 and was admitted to hospital on various occasions. According to her mother the medical doctors could not find any physical cause for her abdominal pain and Suzi was subsequently sent home. These undiagnosed physical symptoms indicated possible vulnerability to psychosomatic illnesses, which supports the results of a study conducted by Sigurdardottir and Halldorsdottir (2013). Their sample of seven women were victims of sexual abuse who all displayed various degrees of symptoms that could be linked to psychological trauma. My observations were also supported by Fortin and Jenny's (2012) report on the psychosocial issues of sexual abuse, in that children who have been survivors of sexual abuse may be vulnerable to non-specific physical or emotional distress, such as abdominal pain. 
Suzi came into the session extremely quiet as she started with the collage. She took her time and her emotional affect increased as she started getting happier during the course of the activity until she was finished with the collage. Suzi also engaged with the lifeline and was more than willing to explain everything she included in detail. During this session Suzi did not want to talk about the alleged sexual abuse and she omitted any mention of it during these two activities. Her explanation for the omission was:

would rather focus on things that make me positive than the bad stuff that happened in the past". Although she didn't want to talk about the alleged sexual abuse that took place, she did at times admit that it had happened and that it was bad, but she was choosing to focus on the good things in life.

\subsubsection{Course of the session and subthemes identified}

\section{i. Qualitative results}

\section{a. Collage}

The collage that Suzi made was done on a very concrete level. Her collage was filled with objects that she would like to have one day. She included a picture of a mother and her baby, saying: "I want to be a mother one day because babies are cute" (7;7;152). Suzi did however express her doubts regarding what it will take from her to be a mother. She also communicated that she would be able to go into a relationship with a man, saying: "Yes I will be able to marry a man but it all depends on what type of man he is $(7 ; 7 ; 161)$. He must not swear, shout or hit me or the child (see referred to physical aggression). He must be able to discipline the child but he musn't hit the child for no reason" (7;7;163). Suzi remarked: "not all men are like that (like the alleged sexual abuser) and there are good men out there" (7;8;170).

She also commented: "I have to start working hard in school, study, listen to teachers and stop misbehaving in school. I have to do this so that I can pass matric and get a good job" (7;8;180). Suzi and I discussed whether or not she can choose between being happy or not, and whether or not she can make this decision easily. Suzi replied saying: "it is easy to choose between happy and sad but sometimes it's also hard. Like when I choose sad, I cry and my eyes hurt and I am 
just angry the whole time and I hit people. But when I choose happy, I do things that make me happy like watch television" (7;8;197).

\section{b. Lifeline}

Suzi's lifeline focussed on events in her life characterised by events that made her happy on the one hand, and events that made her worry. She expressed her happiness commenting that: "it made me very happy when my sister came out of the hospital. I was also very happy during my $9^{\text {th }}$ birthday party because the whole day was just fun" (8;9;209). Sadness was expressed when members of her family or she herself was sick and/or had to go to the hospital. One event that stood out was the fact that her aunt had died recently and she remarked: "I was extremely sad when my aunt died because I was very close to her. I do miss her a lot and sometimes it sounds as if she is still talking to me" $(8 ; 9 ; 216)$. Suzi chose not to add the alleged sexual abuse event to her lifeline, commenting that: "it will only make me sad and I don't want to be sad" (8;9;204).

The following subthemes were identified during Session 3:

\section{Table 4.5: Session 3 Subthemes}

\section{- Denial/Escaping/Avoiding behaviour}

- Experience of loss

- Expression of sadness

- Good judge of character

- Internal locus of control/taking control of her feelings

- Longing for/Need to experience happiness

- Love/intimate family relations

- Need to nurture

- Recovery

- Self-actualisation

- Self-assertive behaviour

- Self-efficacy

- Self-insight 


\subsubsection{Session 4: Life chapters (future narrative); Success experiences}

\subsubsection{General comments and the researcher's observations}

At the start of Session 4, Suzi came across as extremely excited to find out what activities we will be doing today. Her openness and acceptance of the process appeared to be increasing with each session and she really felt safe to express herself, her feelings and views. Suzi started immediately with the life chapters by asking if she could first decorate the front cover of the book. Expressing herself in creative ways was a theme that came through in all the sessions, beginning at the memory box.

\subsubsection{Course of the session and subthemes identified}

\section{i. Qualitative results}

\section{a. Life chapters}

Suzi's account of her life chapters began by focusing on her first birthday, saying that "it was a happy day because there were many different colours and colourful objects. There was also a cake" $(9 ; 12 ; 302)$. What made this day happy, was that I did not have to worry about what will happen tomorrow". When asked what changed from her first birthday till now, she replied: "I am older, I am bigger, I am taller and I still worry about a lot of things. I worry about my mother, my father, my sister and my grandmother. I also worry if I am eating correctly" (9;12;308). A recent study done by Natsuaki, Leve and Mendle (2011) on a sample of 93 girls in state-owned safe houses found that CSA can increase symptoms of anxiety (excessive worrying), especially in pubescent girls. My findings supported the above research findings, which did not bode well for Suzi's future career and personal development.

Where Suzi chose to make the first chapter a happy one, she chose to make the second one a sad one characterised by pain. She talked of a time when she broke her arm, which was the first time she broke her arm. Suzi again mentioned that she did not want to mention or include the sexual abuse experience that she went through, because she just wanted to ignore it and move on with her life. She said: "my book is full of happy things and I don't want to put sad things in it" $(9 ; 12 ; 322)$. When asked what 
her final chapter would say about her future, if she had the opportunity to narrate one, she said: "The title would be MY BETTER LIFE and it would consist of rules. The rules would be like to never think you are better than others or think that other people are better than you. Nobody is perfect" $(9 ; 8 ; 338)$. She said that it's more values than rules because "if you don't have respect for yourself then you don't have respect for anyone. I don't have respect for people who don't have respect for me" $(9 ; 13 ; 343)$. At the end of the session Suzi drew a heart in the book and said: "If I live according to these values then one day all the sadness will be out of my heart. I don't want my heart to be sad, I don't want it to be like that" $(9 ; 13 ; 352)$.

\section{b. Success experiences}

Suzi began describing memories that were related to success and described the success of that specific event. She described her $10^{\text {th }}$ birthday as a success because "all my friends were there and we swam. My mom also took me to buy some clothes and I got a piano" (10;10;238). Her memories were all narrated as successes on a concrete level. She did however state: "I was very happy, I was not sad at all" $(10 ; 10 ; 237)$. Probing further into her memories, we discovered that she engaged in certain actions which she viewed as successes in relation to her own personal values and actions. Suzi commented: "I bought mom a present which was a surprise" $(10 ; 10 ; 244)$. She also remarked: "I am generous and like to share my money with others, I am thoughtful and I care about others" (10;10;250).

When asked what actions Suzi could engage in that would benefit her future success, she replied: "I need to behave myself at school and study in order to get my matric. This would help me become an air hostess one day" $(10 ; 11 ; 278)$. When asked what she needed to do to be happy one day, Suzi said: "I need to study hard to ensure that I past my test. I must have good marks and make sure that the teachers do not give me negative merit points for my behaviour" $(10 ; 11 ; 280)$. When asked what she needed to do to ensure that she was emotionally healthy, Suzi

commented: "I need to be positive, forget all the negative things around me and rather think of butterflies or flowers. Everything that makes me happy. I must not 
be sad or angry because that will not work" (10;12;292). In their study (which, admittedly, involved 233 adult sexual abuse survivors),

Arora and Rangnekar (2015) state that emotional stability ${ }^{18}$ is positively related to and a strong predictor of career resilience. They further contend that those who score lower on emotional stability are more vulnerable to emotional distress and subsequently score lower on the career resilience dimension (Arora \& Rangnekar, 2015). My findings in Section 4.4.4.2 indicate some improvement in Suzi's adaptability as regards her thought processes and behaviour relating to her school work and future success. The findings of my study further indicate some improvement in Suzi's adaptability in respect of her emotional responses toward emotional distress and trauma, which may have positive implications for her career resilience (Arora \& Rangnekar, 2015).

\section{The following subthemes were identified during Session 4:}

\section{Table 4.6: Session 4 Subthemes}

- Anxiety

\section{- Denial/Escaping/Avoiding Behaviour}

- Expression of sadness

- Internal locus of control/taking control of her feelings

- Longing for/Need to experience happiness

- Love/intimate family relations

- Mutual respect

- Need for security

- Need for structure

- Negative body-image

- Optimism

- Rational thinking

- Recovery

\footnotetext{
${ }^{18}$ Emotional stability in this context refers to the degree of a) support individuals have; b) how adaptable they are to situations; c) how they perceive threat; and d) what coping mechanisms they display during times of distress or trauma.
} 


\section{- Self-insight}

- Self-knowledge/self-awareness

\subsubsection{Session 5: RSCA, Drawing (What will overcome obstacles?)}

\subsubsection{General comments and researcher's observations}

Suzi came into the fifth and last session very relaxed and happy to engage in the work. We started with the RSCA and she answered all the questions willingly and with confidence. We started the drawing and she again put a lot of emphasis on her creativity and how she used all the materials at her exposure to ensure that she makes the best picture that she can. She was very proud of her drawing and how she was able to create a drawing that makes her happy. We ended the session after she completed the drawing and talked for a while on what she could expect in future.

\subsubsection{Course of the session and subthemes identified}

Suzi was asked to complete the RSCA questionnaire again (post-intervention) by ticking the relevant response to each question. Figure 4.3 indicates Suzi's Resiliency Profile ${ }^{19}$ as well as the combined scores of all the subscales (Figure 4.4) as per our first session.

\section{i. Quantitative results}

a. Results obtained from the administration of the Resiliency Scales for Children and Adolescents (post-therapeutic intervention)

The following results were obtained during the post-therapeutic intervention on the $R S C A$ along with its descriptive categories.

\footnotetext{
${ }^{19}$ The resiliency profile is made up of three self-report scales designed to identify areas of perceived strength and/or vulnerability in a way that translates these qualities into wording that is easily understood by youths and their caregivers (Prince-Embury, 2006).
} 


\section{Resiliency Profile}

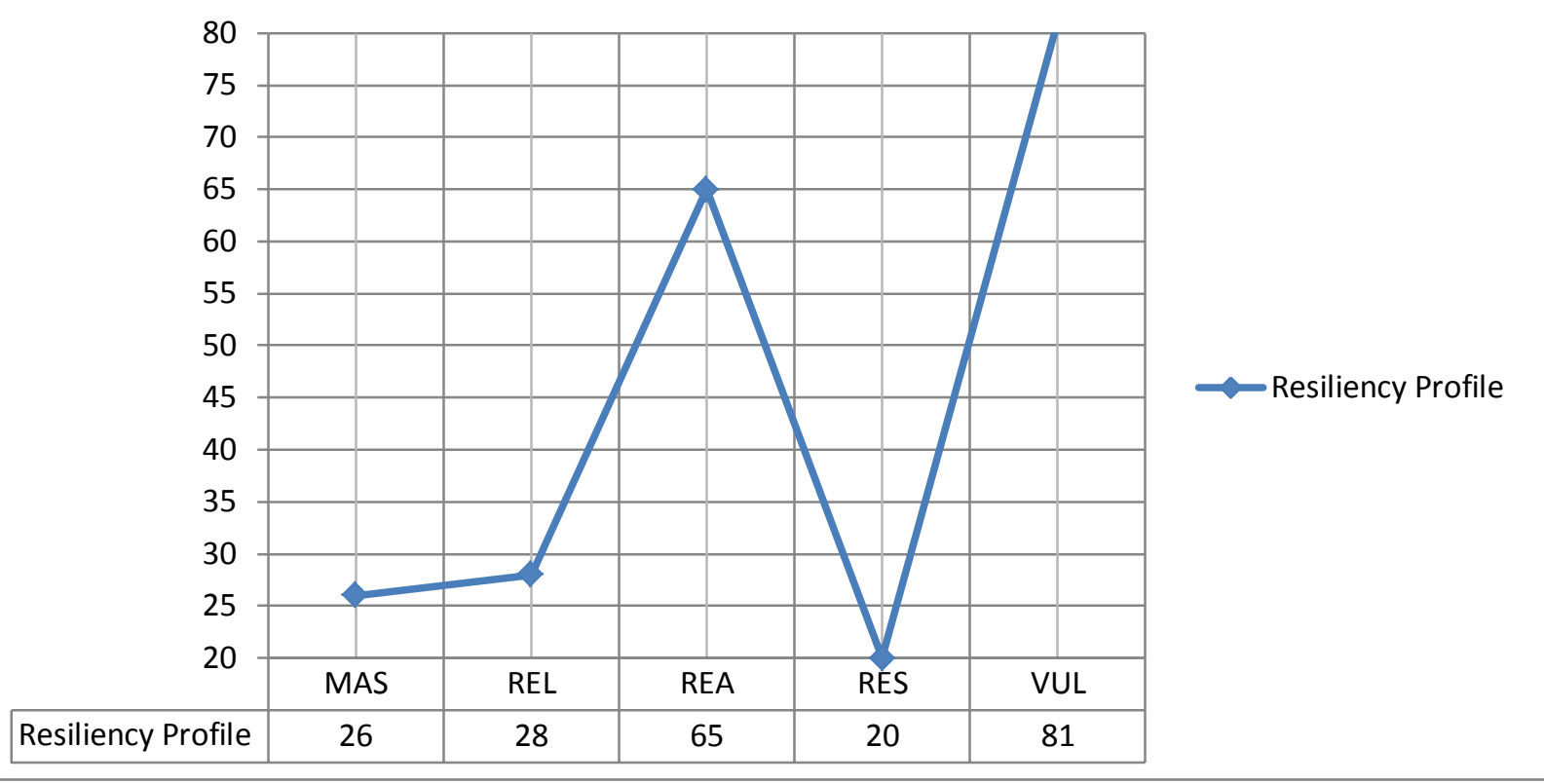

Figure 4.3: Post-intervention resiliency profile

Table 4.7: Post-intervention resiliency scale - descriptive categories

\begin{tabular}{|l|l|l|}
\hline Resiliency Scale & Subscales & Scale descriptions \\
\hline $\begin{array}{l}\text { SENSE OF } \\
\text { MASTERY } \\
\text { (MAS) }\end{array}$ & Optimism & Low \\
\cline { 2 - 3 } & Self-efficacy & Below average \\
\cline { 2 - 3 } & Adaptability & Low \\
\hline $\begin{array}{l}\text { SENSE OF } \\
\text { RELATEDNESS } \\
\text { (REL) }\end{array}$ & Trust & Low \\
\cline { 2 - 3 } & Support & Below average \\
\cline { 2 - 3 } & Comfort & Below average \\
\cline { 2 - 3 } & Tolerance & Low \\
\hline \multirow{2}{*}{$\begin{array}{l}\text { EMOTIONAL } \\
\text { REACTIVITY } \\
\text { (REA) }\end{array}$} & Sensitivity & Average \\
\cline { 2 - 3 } & Recovery & Above average \\
\cline { 2 - 3 } & Impairment & Above average \\
\hline
\end{tabular}




\section{Resiliency Scale Subscales}

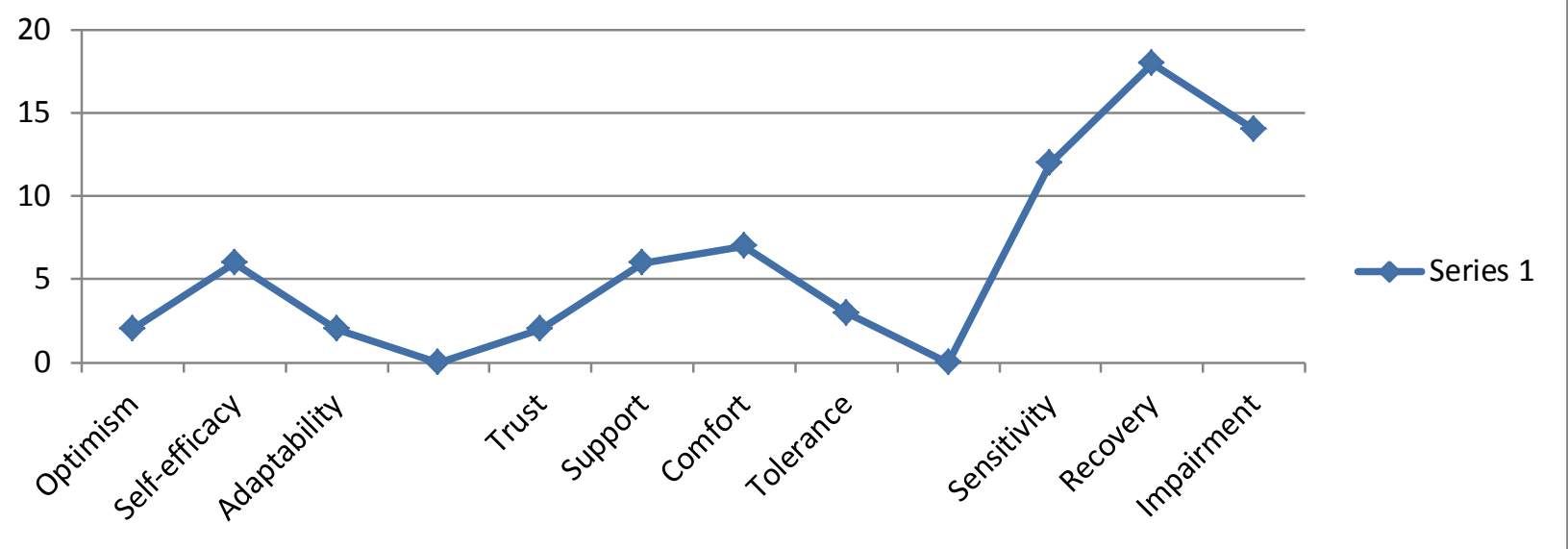

Figure 4.4: Post-intervention Resiliency Subscale Composition

\section{ii. Qualitative results}

\section{a. Resiliency scales for children and adolescents}

When she completed the sense of mastery (MAS) subscale of the questionnaire, Suzi again stated (as with the first RSCA): "I don't like to ask for help as I like to do things myself" (11;15;385). Suzi continued during the emotional reactivity subscale (REA) by saying: "When I am upset, I hurt someone (with my words)" (11;16;387). She was much more decisive in her answers than the first time and much more confident in how she approached the questionnaire. Erickson (1964) ${ }^{20}$ posited that trust is the first stage of emotional development, upon which all other aspects of an individual's social development are built. My findings in Section 4.4.5.2 indicated that Suzi was finding it difficult to trust other individuals as she preferred to be independent in her actions. She chose not to engage in a trusting relationship with any individuals outside of her family circle. In the light of Erickson's position, my finding suggested that Suzi's future career resilience was not bound to improve without due intervention.

\footnotetext{
${ }^{20}$ The inclusion of recent sources confirms the comprehensiveness of the literature survey. Moreover, the inclusion of older, seminal citations (such as this one) for the sake of academic thoroughness is standard practice (J. G. Maree, personal; communication 21 July 2016).
} 
The findings reported in Table 4.7 furthermore indicated Average to Above Average scores for all three emotional reactivity subscales, ${ }^{21}$ which imply a greater degree of vulnerability. The current study confirmed and agreed with the findings of the study done by Carmel, Sigad, Lev-Wiesel and Eisikovits (2015) involving a sample of 40 Israeli victims of childhood sexual abuse. The latter study postulates that risk factors associated with childhood sexual abuse interfere with developmental processes and outcomes of these individuals, having a direct impact on educational and occupational achievement, i.e. career resilience.

\section{b. Drawing (What will overcome obstacles)}

Suzi started the drawing by asking if she could get some "creative stationery", for example, glue, glitter, beads and colour pens. She started by drawing a Christian cross (Appendix F) and said: "I drew a cross so it can remind me of God. A colourful one" (12;15;359). When asked what about the cross allows her or will allow her to overcome obstacles in the future, she replied: "because it is a colourful cross and not a pitch black one" $(15 ; 15 ; 362)$. She also commented that "the cross gives me safety. God is big and powerful. He is strong and He can protect me. God loves everybody".

Suzi placed a lot of emphasis during this session on the role religion plays in her life and said: "after all the things that happened to me, faith plays a big role in my life. Bigger than before the bad thing that happened because I need it now and God is busy giving it to me" (12;15;375). When asked what else the cross gives her, she replied "it gives me happiness because it is colourful" (12;15;381).

The following subthemes were identified during Session 5 :

\section{Table 4.8: Session 5 Subthemes}

- Adaptability

- Comfort

- Conditional forgiveness

${ }^{21}$ Contradictory to the first two scales of the RSCA, a high score on the emotional reactivity scale indicates vulnerability, while a low score is indicative of resilience within an individual. 
- Creativity

- Feelings of acceptance

- Impairment

- Longing for/Need to experience happiness

- Love/intimate family relationships

- Need for security/protection

- Optimism

- Poor tolerance

- Recovery

- Religion

- Self-efficacy

- Self-insight

- Self-knowledge/self-awareness

- Sensitivity

- Support

- Tolerance

- Trust

- Unforgiving/Vindictive

\subsection{Categorisation and summary of the identified themes}

As discussed in Chapter 3, a variety of postmodern techniques were implemented to guide Suzi's self-exploration and meaning making during the life design counselling process. Various subthemes were identified and colour-coded in this chapter up to this point. Table 4.13 presents a summary of all the main themes, and it includes all the subthemes along with their corresponding colour codes. The numbers in the right-hand column (Sessions) signify the sessions in which this theme was prominent. Inclusion and exclusion criteria for the selected subthemes are also presented and explained. (Refer to Appendix $G$ for an outline of all subthemes that were identified.) 
Table 4.9: Summary of main and subthemes

\begin{tabular}{|c|c|c|c|c|}
\hline \multicolumn{5}{|c|}{ THEME 1: PERSONAL CHARACTERISTICS } \\
\hline \multirow[t]{2}{*}{ Subthemes } & Inclusion criteria & \multicolumn{2}{|l|}{ Exclusion criteria } & Sessions \\
\hline & $\begin{array}{l}\text { Phrases, sentences an } \\
\text { words that refer to } \\
\text { specific aspects of the } \\
\text { individual's personality. }\end{array}$ & \multicolumn{2}{|c|}{$\begin{array}{l}\text { Phrases, sentences } \\
\text { and words that do not } \\
\text { refer to specific } \\
\text { aspects of the } \\
\text { individual's } \\
\text { personality. }\end{array}$} & \\
\hline Subtheme 1.1 & \multicolumn{3}{|l|}{ Optimism } & $1,2,4,5$ \\
\hline Subtheme 1.2 & \multicolumn{3}{|l|}{ Self-efficacy } & $1,3,5$ \\
\hline Subtheme 1.3 & \multicolumn{3}{|l|}{ Adaptability } & 1,5 \\
\hline \multicolumn{5}{|c|}{ THEME 2: PERSONAL VALUES } \\
\hline \multicolumn{5}{|c|}{$\begin{array}{l}\text { Definition: Personal values are people's internal conceptions of what is good, beneficial, } \\
\text { important, useful, desirable and constructive - such values can increase their life } \\
\text { satisfaction and help them to live a meaningful life. }\end{array}$} \\
\hline \multirow[t]{2}{*}{ Subthemes } & Inclusion criteria & Exclusion criteria & & isions \\
\hline & $\begin{array}{l}\text { Phrases, sentences } \\
\text { and words that refer } \\
\text { to the importance of } \\
\text { internal, } \\
\text { constructive values. }\end{array}$ & $\begin{array}{l}\text { Phrases, sentences } \\
\text { and words that do } \\
\text { not refer to the } \\
\text { importance of } \\
\text { internal, } \\
\text { constructive beliefs. }\end{array}$ & & \\
\hline Subtheme 2.1 & \multicolumn{2}{|l|}{ Work ethic } & 1,4 & \\
\hline Subtheme 2.2 & \multicolumn{2}{|c|}{ Love/intimate family relationships } & 1,3 & \\
\hline Subtheme 2.3 & \multicolumn{2}{|l|}{ Pride } & 2,5 & \\
\hline
\end{tabular}




\begin{tabular}{|c|c|c|c|}
\hline \multicolumn{4}{|c|}{ THEME 3: INTRAPERSONAL SKILLS } \\
\hline \multicolumn{4}{|c|}{$\begin{array}{l}\text { Definition: Intrapersonal skills in this context refer to the foundations of a successful } \\
\text { career. They refer to emotional intelligence, the ability to know, understand and manage } \\
\text { one's own emotions. }\end{array}$} \\
\hline \multirow[t]{2}{*}{ Subthemes } & Inclusion criteria & Exclusion criteria & Sessions \\
\hline & $\begin{array}{l}\text { Phrases, sentences } \\
\text { and words that } \\
\text { include the } \\
\text { significance of } \\
\text { personal skills and } \\
\text { relating to other } \\
\text { people. }\end{array}$ & $\begin{array}{l}\text { Phrases, sentences } \\
\text { and words that do } \\
\text { not include the } \\
\text { significance of } \\
\text { personal skills and } \\
\text { relating to other } \\
\text { people. }\end{array}$ & \\
\hline Subtheme 3.1 & \multicolumn{2}{|l|}{ Self-actualisation } & 3,4 \\
\hline Subtheme 3.2 & \multicolumn{2}{|l|}{ Self-insight } & $3,4,5$ \\
\hline Subtheme 3.3 & \multicolumn{2}{|c|}{ Self-knowledge/self-awareness } & 4,5 \\
\hline
\end{tabular}

\begin{tabular}{|l|l|l|l|}
\hline Subthemes & Inclusion criteria & Exclusion criteria & Sessions \\
\hline & $\begin{array}{l}\text { Phrases, sentences } \\
\text { and words that } \\
\text { include past } \\
\text { experiences which } \\
\text { refer to feelings of } \\
\text { misuse or being } \\
\text { powerless. }\end{array}$ & $\begin{array}{l}\text { Phrases, sentences } \\
\text { and words that do } \\
\text { not include past } \\
\text { experiences which } \\
\text { refer to feelings of } \\
\text { misuse or being } \\
\text { powerless. }\end{array}$ & \\
\hline Subtheme 4.1 & $\begin{array}{l}\text { Expression of sadness } \\
\text { Subtheme 4.2 }\end{array}$ & $\begin{array}{l}\text { Denial/Escaping/Avoiding Behaviour } \\
\text { THEME 5: INTERPERSONAL RELATIONSHIP DYNAMICS }\end{array}$ \\
\hline Definition: This refers to the participant's relationship with others and her motivation to \\
\hline
\end{tabular}




\begin{tabular}{|c|c|c|c|}
\hline Subthemes & Inclusion criteria & Exclusion criteria & Sessions \\
\hline & $\begin{array}{l}\text { Phrases, sentences } \\
\text { and words that } \\
\text { include the } \\
\text { significance of } \\
\text { relationships for the } \\
\text { participant. }\end{array}$ & $\begin{array}{l}\text { Phrases, sentences } \\
\text { and words that do } \\
\text { not include the } \\
\text { significance of } \\
\text { relationships for the } \\
\text { participant. }\end{array}$ & \\
\hline Subtheme 5.1 & \multicolumn{2}{|c|}{ Feelings of acceptance } & 1,5 \\
\hline Subtheme 5.2 & \multicolumn{2}{|l|}{ Trust } & $1,3,5$ \\
\hline Subtheme 5.3 & \multicolumn{2}{|l|}{ Support } & 1,5 \\
\hline Subtheme 5.4 & \multicolumn{2}{|l|}{ Comfort } & 1,5 \\
\hline Subtheme 5.5 & \multicolumn{2}{|l|}{ Tolerance } & 1,5 \\
\hline \multicolumn{4}{|c|}{ THEME 6: PERSONAL MOTIVATORS } \\
\hline \multicolumn{4}{|c|}{$\begin{array}{l}\text { Definition: This theme refers to intrinsic personal values or goals that activate, guide } \\
\text { and motivate the participant's behaviour. }\end{array}$} \\
\hline \multirow[t]{2}{*}{ Subthemes } & Inclusion criteria & Exclusion criteria & Sessions \\
\hline & $\begin{array}{l}\text { Phrases, sentences } \\
\text { and words that } \\
\text { indicate the } \\
\text { significance of } \\
\text { achievements for } \\
\text { the participant. }\end{array}$ & $\begin{array}{l}\text { Phrases, sentences } \\
\text { and words that do } \\
\text { not indicate the } \\
\text { significance of } \\
\text { achievements for } \\
\text { the participant. }\end{array}$ & \\
\hline Subtheme 6.1 & \multicolumn{2}{|c|}{ Need for security/protection } & 2,5 \\
\hline Subtheme 6.2 & \multicolumn{2}{|c|}{ Longing for/Need to experience happiness } & $2,3,4,5$ \\
\hline Subtheme 6.3 & \multicolumn{2}{|c|}{ Conditional forgiveness } & 2,5 \\
\hline Subtheme 6.4 & \multicolumn{2}{|l|}{ Unforgiving/Vindictive } & 2,5 \\
\hline \multicolumn{4}{|c|}{$\begin{array}{l}\text { THEME 7: THINKING STYLE THAT INFLUENCES THE PARTICIPANT'S DECISION- } \\
\text { MAKING STYLE }\end{array}$} \\
\hline
\end{tabular}




\begin{tabular}{|c|c|c|c|}
\hline Subthemes & Inclusion criteria & Exclusion criteria & Sessions \\
\hline & $\begin{array}{l}\text { Phrases, sentences } \\
\text { and words that refer } \\
\text { to solving problems } \\
\text { in her immediate } \\
\text { environment or } \\
\text { future career. }\end{array}$ & $\begin{array}{l}\text { Phrases, sentences } \\
\text { and words that do } \\
\text { not refer to solving } \\
\text { problems in her } \\
\text { immediate } \\
\text { environment or } \\
\text { future career. }\end{array}$ & \\
\hline Subtheme 7.1 & \multicolumn{2}{|c|}{ Concrete thinking pattern } & $2,3,4$ \\
\hline \multicolumn{4}{|c|}{ THEME 8: FUTURE ORIENTATION } \\
\hline \multicolumn{4}{|c|}{$\begin{array}{l}\text { Definition: This refers to the participant's perspective on the future and how to achieve } \\
\text { future goals and/or dreams. }\end{array}$} \\
\hline \multirow[t]{2}{*}{ Subthemes } & Inclusion criteria & Exclusion criteria & Sessions \\
\hline & $\begin{array}{l}\text { Phrases, sentences } \\
\text { and words that refer } \\
\text { to the significance } \\
\text { of achievements for } \\
\text { the participant. }\end{array}$ & $\begin{array}{l}\text { Phrases, sentences } \\
\text { and words that do } \\
\text { not refer to the } \\
\text { significance of } \\
\text { achievements for } \\
\text { the participant. }\end{array}$ & \\
\hline Subtheme 8.1 & \multicolumn{2}{|c|}{$\begin{array}{l}\text { Internal locus of control/taking control of } \\
\text { her feelings }\end{array}$} & $2,3,4$ \\
\hline \multicolumn{4}{|c|}{ THEME 9: COPING STRATEGIES } \\
\hline \multicolumn{4}{|c|}{$\begin{array}{l}\text { Definition: This theme refers to the participant's efforts, both behavioural and } \\
\text { psychological, to reduce or minimise stressful events and/or traumatic memories. }\end{array}$} \\
\hline \multirow[t]{2}{*}{ Subthemes } & Inclusion criteria & Exclusion criteria & Sessions \\
\hline & $\begin{array}{l}\text { Phrases, sentences } \\
\text { and words that refer } \\
\text { to the act of } \\
\text { controlling her }\end{array}$ & $\begin{array}{l}\text { Phrases, sentences } \\
\text { and words that do } \\
\text { not refer to the act } \\
\text { of controlling her }\end{array}$ & \\
\hline
\end{tabular}




\begin{tabular}{|l|l|l|l|}
\hline & emotions. & emotions. & \\
\hline Subtheme 9.1 & Anxiety & $1,2,4$ \\
\hline Subtheme 9.2 & Sensitivity & 1,5 \\
\hline Subtheme 9.3 & Recovery & $1,2,3,4,5$ \\
\hline Subtheme 9.4 & Impairment & $1,2,5$ \\
\hline Subtheme 9.5 & Creativity & 2,5 \\
\hline
\end{tabular}

A recent research study conducted by Consentino and Collins (2006) on the prevalence, effects and treatment of sexual abuse in children, states that a child who has been sexually abused is more vulnerable to psychological symptoms of anxiety, depression and avoidance behaviour. Findings from the current study (p. 75-76, Theme 4, Table 4.9) indicate that Suzi continually engaged in avoidance behavior as a coping mechanism in order to come to terms with a painful past. Schultheiss (2003) asserts that interpersonal relationships contribute not only to how an individual adapts to career tasks, but also to his/her social and emotional well-being. She furthermore argues that constructs such as support, comfort and tolerance play an important part in interpersonal relationships and ultimately career resilience and success. My finding (Theme 5, Table 4.9) in terms of Suzi's interpersonal relationship dynamics seems to bode well for Suzi's career development future. However, it should be emphasised that Suzi's trust and her perception of being supported only applied to a small number of people (family members), namely her mother and sister.

\subsection{Comparison of resiliency scales and scale descriptions: Pre- and post-intervention}

Table 4.10 presents the participant's resiliency scale descriptions, before and after intervention. 
Table 4.10: Comparison of resiliency scales and scale descriptions

\begin{tabular}{|l|l|l|}
\hline Scale descriptions & Before intervention & After intervention \\
\hline Optimism & Low & Low \\
\hline Self-efficacy & Below average & Below average \\
\hline Adaptability & Low & Low \\
\hline & & \\
\hline Trust & Low & Low \\
\hline Support & Low & Below average \\
\hline Comfort & Below average & Below average \\
\hline Tolerance & Below average & Low \\
\hline & & \\
\hline Sensitivity & Above average & Average \\
\hline Recovery & Average & Above average \\
\hline Impairment & Average & Above average \\
\hline
\end{tabular}

\begin{tabular}{|l|l|}
\hline Decrease in score \\
\hline & Increase in score \\
\hline No difference \\
\hline
\end{tabular}

Information from the above table indicates that Suzi's level of trust and comfort remained the same, but that there had been an increase in her perceived access to support and/or the availability of support. Her level of tolerance declined, which could indicate apprehension from Suzi's side to engage in assertive behaviour. Her inability to engage in assertive behaviour could clearly be verified through the qualitative data gathered.

Considering the sense of mastery scale (MAS), we can derive from Table 4.10 that no meaningful differences occurred with regard to the descriptive categories between pre- and post-intervention testing. Based on these descriptive categories it can be concluded that the life design counselling process did not have a substantially 
positive impact on Suzi's personal characteristics of optimism, self-efficacy or adaptability; as the descriptive categories remained the same.

Qualitative data suggests that the personality characteristics of optimism, selfefficacy and adaptability exist intrinsically within the participant in relation to a) her positive attributional style and approach to the future, b) her intrinsic belief that she can overcome obstacles in her environment, and c) her different conceptualisations of problems and how to overcome such challenges. As can be seen from the qualitative results, it does appear as if the participant's optimism, self-efficacy and adaptability improved somewhat during the intervention.

\subsection{Summary}

In concluding this chapter I systematically reported on the results of my study through engaging in a thorough discussion of the main themes as well as subthemes that emerged. A short description was provided on the history and background information of the participant as applicable to this study. Finally, some of the findings of the current study were related to existing literature (to the extent that it was possible).

Chapter 5 contains a brief summary of the current study, its findings and recommendations. It also presents a critical reflection on the results and discussion that was presented in Chapter 4. 


\section{CHAPTER 5: SUMMARY AND RECOMMENDATIONS}

\subsection{Introduction}

This study was set up to determine whether an individual's career resilience could be enhanced through the narrative approach. It specifically focused on a participant who is a survivor of sexual abuse and still resides in the environment in which the abuse transpired. The aim was to enhance the participant's career resilience through the process of life design counselling, which forms part of the narrative approach.

In this chapter I briefly provide an overview of the first four chapters before I attempt to answer all the research questions and state possible limitations as applicable to this study. A brief discussion of the ethical aspects pertaining to this study is next, followed by my recommendations. These recommendations will be made with the main focus on guiding future research and practice in creating a more comprehensive understanding of the phenomenon, and taking into consideration the fact that South Africa is a resource-constrained country.

\subsection{Overview of the chapters}

\subsubsection{Chapter 1: Introduction and orientation}

In an attempt to fully explain the dilemma surrounding the research question, namely "Improving the career resilience of a survivor of sexual abuse", I endeavoured to explain the relevance and purpose of this study. I began by providing an overview of CSA in a South African context and how literature illustrates the devastating and long-term impact of sexual abuse on the emotional and psychological functioning of survivors. I highlighted the manner in which these experiences form part of a survivor's subjective experiences. Career counselling in a postmodern era was also discussed with the focus on subjective experiences and the meaning that individuals assign to such experiences.

Next was a brief discussion on life design counselling, how it approaches career counselling from a holistic viewpoint, taking into consideration all the various influences of the surrounding system, and the impact it has on the individual. The primary and secondary research questions were subsequently addressed, followed by a discussion 
of the metatheoretical, conceptual framework. A discussion of all the relevant concepts applicable to this study was next, followed by what I perceived as potential problems that might arise throughout the study. The research and methodological design, as well as the various ethical considerations that governed the current study were lastly discussed briefly.

\subsubsection{Chapter 2: Literature review}

This chapter started with an overview of career construction theory, how this theory emphasised the meaning attached to personal experiences, as well as the various psychological waves associated with it - which ended with life design counselling. I continued with an in-depth discussion of career adaptability with a focus on adaptability in childhood and the importance of early childhood experiences in the construction of the future self. Next, I discussed career resilience and contextualised it within the effects and etiology of sexual abuse, and I emphasised the importance of intervention strategies aimed at limiting or reducing the long-term effects of CSA.

Narrative career counselling was discussed with a focus on life design counselling that directly promotes the management of career issues and indirectly promotes narratability and adaptability. The chapter was concluded with a discussion on sexual abuse and the various aspects that influence career resilience in survivors of CSA. This discussion supported the whole notion that a unique intervention strategy was called for in order to try and prevent or mediate negative psychological consequences associated with childhood sexual abuse.

\subsubsection{Chapter 3: Research methodology}

This chapter dealt with research methodology by first discussing the paradigmatic perspective underlying this study from an interpretivist-constructivist point of view. The research design and data collection techniques (including measures to be used) received attention. Various qualitative as well as postmodern data collection techniques that would be used were discussed next, including the general purpose and motivation behind the use of the selected techniques. This was followed by a discussion on how quality assurance in this study would be facilitated. Special attention was given to 
various ethical aspects, and the focus lastly fell on the roles and responsibilities of the researcher to ensure the safety and psychological wellbeing of the participant.

\subsubsection{Chapter 4: Results and discussions}

This chapter commenced with a brief background and history of the participant in this study. A descriptive account was provided of the five sessions that took place, including the various counselling activities that were administered. During this chapter the specific subthemes and main themes that emerged from the study were identified and reported on. To conclude the chapter, the researcher provided some of his findings and related them to existing literature (to the extent that that was possible, given the paucity of research and limited reporting on this matter).

\subsection{Answering the primary and secondary research questions}

In an attempt to answer the primary research question, namely: "In which ways can using narrative career counselling enhance the career resilience of a survivor of sexual abuse?", various postmodern techniques were applied in the current study to attain comprehensive answers.

The four secondary research questions are discussed next, before returning to the primary research question in an attempt to better support the answering of the primary research question.

\subsubsection{What are the essential characteristics of sexual abuse, career resilience and life design counselling?}

Essentially, the characteristics of sexual abuse as defined by South African legislation are "the exploitation of a child, whether with their consent or not, for the purposes of sexual or erotic gratification" (Criminal Law Amendment Act, 2007, p. 14). Sexual abuse in the context of this study was characterised as any sexual act that took place between a minor and an adult without consent.

The essential characteristics of career resilience (see Chapter 2, Section 2.4) are conceptualised as an individual's ability to recover from trauma and/or diversity. Moffett, Matthew and Fawcett (2015) warn that resilience is not to be confused with recovery 
and imply that it is the individual's ability to maintain equilibrium through trauma or diversity. This also correlates with the characteristics of career resilience in that it refers to the degree to which an individual can maintain equilibrium through times of stress, diversity, negative or challenging workplace environments and/or events (Moffett et al., 2015). Suzi's resilience mainly involved a focus on emotional resilience as she could successfully recover emotionally from the trauma she had experienced. She managed to retain a sense of control over her environment while moving forward in a positive manner (Jackson, Firtko \& Edenborough, 2007).

The life design counselling process involves a holistic process that focuses on all the influences that the environment exert on a person and which thereby have an impact on various career aspects (Maree, 2010). Life design counselling can be characterised as holistic, contextual and preventative (Nota \& Rossier, 2015).

\subsubsection{What is the influence of sexual abuse on the career resilience of a sexual abuse survivor?}

Literature generally agrees about the devastating and detrimental effects of CSA on the career resilience of the victim. A recent study portrays a grim prognosis by suggesting that if a child has been sexually abused before the age of 11 years, it is unlikely that the child will ever develop healthy levels of resilience in the future (Marriot et al., 2014). Simon, Smith, Fava and Feiring (2015), however, state that long after the occurrence of CSA, survivors still seek to derive meaning from their experiences - which most of them incorporate into their sense of self, the world, as well as other individuals.

The observations and qualitative findings of the current study also suggest that CSA does influence survivors' intrinsic representations about themselves as well as about others. The findings seem to confirm the impact of CSA on survivors, highlighting previous research on CSA and its influence on future development (personal and emotional), as well as future career resilience and career adaptability. 


\subsubsection{How can sexual abuse survivors be assisted/how can their career resilience be enhanced through life design counselling?}

The characteristics of life design counselling (explained in Section 5.3.1.) make it suitable as an intervention to be used with survivors of sexual abuse since it explores clients' subjective identity forms as influenced by their experiences and culminates in the writing of new stories (Crous, 2011). Life design counselling can ultimately assist people in enhancing their career resilience through becoming more resilient to changing needs, interests and experiences, and, especially, through becoming more aware of the power of their thoughts and actions (Maree, 2012). Throughout the life design counselling process as implemented in this study, these focal points were evident in that Suzi at various times displayed a good level of awareness of her actions. They were particularly evident in Chapter 4, Section 4.4.4.2, where Suzi displayed increased insight into her actions by becoming aware of how changing her current behaviour could have a positive impact on her future.

\subsubsection{How can the proposed study contribute to the theory and practice of life design counselling for sexual abuse survivors?}

The results from this study can make a contribution towards the theory and practice of life design counselling in that the study highlights the value of life design counselling for survivors of sexual abuse. Although quantitative results did not indicate any significant enhancement in Suzi's resiliency levels, the qualitative results of the study suggested that some intrinsic changes occurred. These intrinsic 'shifts' altered the way in which Suzi reasoned and thought about her future aspirations and current social and emotional functioning.

The postmodern techniques included in this study as part of life design counselling increased Suzi's self-insight and personal experience, as is highlighted by her remark: "Like when I choose sad, I cry and my eyes hurt and I am just angry the whole time and I hit people. But when I choose happy, I do things that make me happy like watch television". This comment seems to confirm the validity and effectiveness of life design counselling techniques in promoting and increasing participant's involvement within future studies containing life design counselling. 
The study also contributed to a more complete and comprehensive understanding of the phenomenon being studied and indicated that the life design counselling therapeutic intervention positively enhanced Suzi's self-insight into her current situation and aided in her development of proactive behaviour to reach future career goals.

\subsubsection{In which ways can using narrative career counselling enhance the career resilience of a survivor of sexual abuse?}

The above secondary questions partially addressed the primary research question. Working from a strictly quantitative perspective, my observation was that narrative career counselling had not been successful in its attempt to enhance the career resilience of a survivor of sexual abuse. From a qualitative perspective, however, I believe that the narrative career counselling intervention was successful in bringing about change in Suzi's thought processes concerning herself, her current emotional functioning and the manner in which her existing behaviour could be expected to influence her future success. According to Rehfuss and Di Fabio (2012) traditional quantitative measures failed to successfully capture the qualitative changes that took place within the individual's self-narrative, and consequently they ask for more research utilising the life design approach.

Suzi actively engaged with the process and as a result came to new insights regarding her current behaviour. She became cognisant of the impact that her experiences had on her perceptions about herself and her current decision making. As a result, she started to become the author of her own story (a new, healthier story), which was evident in the way she began to take ownership of her actions (school, social, emotional) and her life by making better choices to ensure a better future for herself. I strongly believe that life design counselling can be used as a useful qualitative intervention model for survivors of sexual abuse with the aim to enhance their future career paths and future selves. My observation accentuates Savickas's (2011) belief, namely that life design counselling allows individuals to successfully reflect on a problem and ultimately engage in the necessary actions to build new future selves. 


\subsection{Limitations of the study}

As stated in Chapter 1, Section 1.16, this was a single case study as its aim was not to generalise the results, but rather to focus on their trustworthiness. Other possible limitations (that were unforeseen variables) could potentially have had an impact on the results. These include:

- Suzi's parents deciding to separate and ultimately beginning the legal process to finalise the divorce.

- The removal of Suzi's best friend by the welfare to a place of safety, which had a devastating effect on her as this was her only friend.

Quality control criteria were put in place (see Chapter 3, Section 3.8) to ensure that credibility, confirmability, transferability, dependability and trustworthiness were achieved. My role as researcher did however come with a degree of subjectivity and another researcher could well have interpreted the results and subsequent findings in a different way. The questionnaire (RSCA) was also administered in English, despite the fact that Suzi's mother tongue is Afrikaans.

\subsection{Ethical aspects}

Throughout the research project I aligned myself with the ethical guidelines as delineated in Chapter 3 to ensure that the best interest of the participant was always my first priority. Informed consent and assent was obtained from parents as well as the participant and the option to withdraw from the study without any consequences was provided. A pseudonym was used throughout the writing of the report and/or recording of results in an attempt to protect the identity of the participant and her family members. Careful attention was paid to ensure that no identifying information was included that could reveal the identity of the participant in any other way or form.

Due to unforeseen variables (see Section 5.4 (a) \& (b)), certain postponements were made in relation to the planned time frame of the intervention model. The postponement of sessions and subsequent activities occurred in an attempt to accommodate Suzi and support her in dealing with the emotional distress that was caused by the circumstances mentioned above. Throughout the study I gave feedback to both the participant and her parents to ensure that the process was as transparent as 
possible. Continued support was also offered after the study was concluded, which they chose not to accept.

\subsection{Recommendations}

When considering the various unforeseen circumstances (personal, social and contextual) that could possibly have influenced the results, I acknowledge that in future research a greater degree of practical control would need to be exercised over the external influences to which the participant(s) is/are subjected. Moreover, research should be undertaken to assess the possibility of conducting life design counselling in a group context to support survivors of sexual abuse and enable them to reconstruct a narrative for their future selves and careers.

The summarised recommendations below should be considered against the framework of South Africa being a resource-constrained country. Further research in the following areas may be useful:

- The possibilities and effectiveness of life design counselling with survivors of sexual abuse within a group context.

- The effectiveness of life design counselling with survivors of sexual abuse within a culturally diverse group.

- A study investigating the long-term impact of life design counselling on the career resilience of survivors of sexual abuse.

- A comparative study involving more than one participant, where the impact of life design counselling can be measured in various participants within a bounded system.

\subsection{Personal learning}

Reflecting on the process and the impact it had on me, I feel it necessary to highlight various aspects that have been incredibly valuable and insightful to me. Unfortunately sexual abuse is an overwhelming reality in our lives and my respect for survivors of sexual abuse has increased tremendously. I found life design counselling to be an invaluable approach towards supporting this 11-year-old girl who was a survivor of 
sexual abuse and believe that it helped her create a new, healthier future narrative despite the multitude of personal and emotional challenges she faced.

My professional development throughout this process was enormous and the knowledge gained from the recordings and process notes was invaluable. Learning how to implement life design counselling as an intervention, learning from my mistakes and learning how I could possibly change my strategy in future, greatly enhanced my ability as an educational psychologist in training. My appreciation for research and the valuable contributions it offers has exceeded all my expectations and will be an aspect of psychology that I will always value.

\subsection{Conclusion}

This study involved the use of the narrative approach to enhance the career resilience of a survivor of sexual abuse. A single case study was used, which proved that various narrative techniques can be used to enhance a CSA victim's career resilience. Qualitative results could however not be confirmed and the study findings were not supported by quantitative results. Nonetheless, once the results had been critically analysed, it appeared that my study findings agreed with the opinion of Di Fabio (2016), who suggested that life design counselling appears to be a useful intervention modality. I found it to be a useful strategy for dealing with survivors of sexual abuse. It is indeed a strategy that aims to construct, deconstruct, co-construct (collaboration between client and counsellor) and reconstruct (Savickas, 2011) experiences and associated meanings that may influence career adaptability and resilience when choosing and constructing future careers and designing successful lives. 


\section{REFERENCE LIST}

Artz, L., Burton, P., Ward, C. L., Leoschut, L., Phyfer, J., Lloyed, S., . . Le Mottee, C. (2016). Optimus study South Africa: Technical report. Sexual victimisation of children in South Africa. Final report of the Optimus foundation study. The Centre for Justice and Crime Prevention (CJCP), The University of Cape Town: South Africa.

Arora, R., \& Rangnekar, S. (2015). Relationships between emotional stability, psychosocial mentoring support and career resilience. Europe's Journal of Psychology, 11(1), 16-33. DOI:10.5964/ejop.v1111.835

Baxter, P., \& Jack, S. (2008). Qualitative case study methodology: Study design and implementation for novice researchers. The Qualitative Report, 13(4), 544-559. Retrieved from http://www.nsuworks.nova.edu/tgr/vol13/iss4/2

Bimrose, J., \& Hearne, L. (2012). Resilience and career adaptability: Qualitative studies of adult career counseling. Journal of Vocational Behavior, 81, 338-344. DOI:10.1016/j.jvb.2012.08.002

Boik, B. L., \& Goodwin, E. A. (2000). Sandplay therapy: A step-by-step manual for psychotherapists of diverse orientations (1st ed.). New York: Norton

Braun, V. \& Clarke, V. (2006). Using thematic analysis in psychology. Qualitative Research in Psychology, 3(2), 77-101. DOI:10.1191/1478088706qp063oa

Brown, S. D., \& Lent, R. W. (2005). Career development and counseling: Putting theory and research to work. Hoboken, NJ: John Wiley and Sons.

Brown, A., Bimrose, J., Barnes, S. A., \& Hughes, D. (2012). The role of career adaptabilities for mid-career changers. Journal of Vocational Behavior, 80, 754761. DOI:10.1016/j.jvb.2012.01.003 
Burr, V. (2015). Social constructionism ( ${ }^{\text {rd }}$ ed.). Hove, East Sussex: Routledge.

Cambron, C., Gringeri, C., \& Vogel-Ferguson, M. B. (2014). Physical and mental health correlates of adverse childhood experiences among low-income women. Health and Social Work, 39(4), 221-229. DOI:10.1093/hsw/hlu029

Carmel, Y., Sigad, L., Lev-Wiesel, R., \& Eisikovits, Z. (2015). Pathways to resilience among Israeli child victims of abuse and neglect. Child Indicators Research, 8(3), 551-570. DOI:10.1007/s12187-014-9255-5

Cochran, L. (1997). Career counselling: A narrative approach. Thousand Oaks: Sage.

Cochran, L. (2011). The promise of narrative career counselling. In K. Maree (Ed.), Shaping the story - a guide to facilitating narrative counselling (pp. 7-19). Rotterdam, The Netherlands: Sense.

Coles, J., Lee, A., Taft, A., Mazza, D., \& Loxton, D. (2015). Childhood sexual abuse and its association with adult physical and mental health: Results from a national cohort of young Australian women. Journal of Interpersonal Violence, 30(11), 1929-1944. DOI:10.1177/0886260514555270

Collin-Vézina, D., De La Sablonnière-Griffin, M., Palmer, A. M., \& Milne, L. (2015). A preliminary mapping of individual, relational, and social factors that impede disclosure of childhood sexual abuse. Child Abuse and Neglect, 43, 123-134. DOI:10.1016/j.chiabu.2015.03.010

Consentino, C. E., \& Collins, M. (2006). Sexual abuse of children: Prevalence, effects, and treatment. Annals of the New York Academy of Sciences, 789, 45-66. DOI:10.1111/j.1749-6632.1996.tb55636.x 
Creed, P. A., Fallon, T., \& Hood, M. (2009). The relationship between career adaptability, person and situation variables and career concerns in young adults. Journal of Vocational Behavior, 74(2), 219-229. DOI:10.1016/j.jvb.2008.12.004

Creswell, J.W. (2003). Research design: qualitative, quantitative, and mixed methods approaches (2nd Ed.). Thousand Oaks, CA: Sage.

Creswell, J. W. (2008). Educational research: Planning, conducting and evaluating qualitative research ( $3^{\text {rd }}$ ed.). New Jersey, NJ: Pearson Education.

Criminal Law (Sexual Offences and Related Matters) Amendment Act, 2007 (Act No. 32 of 2007). Retrieved from http://www.justice.gov.za/legislation/acts/2007-032.pdf (accessed 20 April 2014).

Crous, S. (2011). Possibility and limits of life design counseling with an abandoned adolescent. (Master's thesis) University of Pretoria, Pretoria. Retrieved from http://upetd.up.ac.za/thesis/available/etd-12202011-142008 / >

Crowe, S., Cresswell, K., Robertson, A., Huby, G., Avery, A. \& Sheikh, A. (2011). The case study approach. BMC Medical Research Methodology (11)100, 1-9.

Cutcliffe, J. R., \& McKenna, H. P. (1999). Establishing the credibility of qualitative research findings: the plot thickens. Journal of Advanced Nursing, 30(2), 374380. DOI:10.1046/j.1365-2648.1999.01090.x

De Jongh, A., \& Ten Broeke, E. (2014). Response to "Treatment compliance and effectiveness in complex PTSD patients with co-morbid personality disorder undergoing stabilizing cognitive behavioral group treatment: a preliminary study". European Journal of Psychotraumatology, 5, 1-3. DOI:10.3402/ejpt.v5.23489. 
Denis, P. (2005). Never too small to remember: Memory work and resilience in times of AIDS. Pietermaritzburg, South Africa: Cluster Publications.

Di Fabio, A., \& Maree, J. G. (2012). Ensuring quality in scholarly writing. In J. G. Maree (Ed.), Complete your thesis or dissertation successfully: Practical guidelines (pp. 136-144). Pretoria, South Africa: Juta.

Di Fabio, A., \& Maree, J. G. (2013). Psychology of career counselling: New challenges for a new era. New York, NY: Nova Science Publisher.

Di Fabio, A. (2016). Life design and career counselling innovative outcomes. The Career Development Quarterly, 64(1), 35-48. DOI:10.1002/cdq.12039

Dorrepaal, E., Thomaes, K., Smit, J. H., Veltman, D. J., Hoogendoorn, W. A., van Balkom, A. J. L. M., \& Draijer, N. (2013). Treatment compliance and effectiveness in complex PTSD patients with co-morbid personality disorder undergoing stabilizing cognitive behavioral group treatment: a preliminary study. European Journal of Psychotraumatology, 4. DOI:10.3402/ejpt.v4i0.21171

Duarte, M. E. (2010, July). Restructuring career counselling: objectives and instruments. Symposium conducted at the meeting of the 27th International Congress of Applied Psychology. Melbourne, Australia.

Ebersöhn, L. (2007). Utilising reminiscences: constructing boxes of memories to tell stories for life choices. In K. Maree, (Ed.), Shaping the story - a guide to facilitating narrative career counselling (pp. 152-162). Rotterdam, The Netherlands: Sense. 
Ebersöhn, L., Ferreira, R., \& Mnguni, M. (2008). Teachers' use of memory-box-making to provide psychosocial support in their pastoral role. Journal of Psychology in Africa, 18(3), 465-475. DOI:10.1080/14330237.2008.10820223

Ebersöhn, L., Eloff, I., \& Swanepoel-Opper, A. (2010). 'Memory boxes' as tool for community-based volunteers. Education as Change, 14(S1), S73-S84. DOI:10.1080/16823206.2010.517930

Ebersöhn, L. (2010). Resilience and career counseling: Describing the utility of quadrant mapping. Journal of Psychology in Africa, 20(3), 385-393. DOI:10.1080/14330237.2010.10820390

Erikson, E. H. (1963). Childhood and society. NY: Norton.

Finfgeld-Connett, D. (2010). Generalizability and transferability of meta-synthesis research findings. Journal of Advanced Nursing, 66(2), 246-254. DOI:10.1111/j.1365-2648.2009.05250.x

Fortin, K., \& Jenny, C. (2012). Sexual abuse. Pediatrics in Review, 33(1), 19-32. Retrieved from http://www.pedsinreview.aappublications.org

Fritz, E., \& Beekman, L. (2007). Engaging clients actively in telling stories and actualising dreams. In K. Maree, (Ed.), Shaping the story - a guide to facilitating narrative career counselling (pp. 152-162). Rotterdam, The Netherlands: Sense.

Fryda, C. M., \& Hulme, P. A. (2015). School-based childhood sexual abuse prevention programs: An integrative review. The Journal of School Nursing, 31(3), 167-182. DOI:10.1177/1059840514544125 
Gallerani T., \& Dybicz P. (2011). Postmodern sandplay: An introduction for play therapists. International Journal of Play Therapy, 20(3), 165-177. DOI:10.1037/a0023440

Gergen, K. J. (2015). The quantitative/qualitative distinction: blessed are the impure. Qualitative Psychology, 2(2), 210-213. DOI:10.1037/qup0000034

Glatthorn, A. A., \& Joyner, R. L. (2005). Writing the winning thesis or dissertation: A step by step guide. Thousand Oaks, CA: Corwin Press.

Gough, B., \& Deatrick, J. A. (2015). Qualitative health psychology research: diversity, power, and impact. Health Psychology, 34(4), 289-292. DOI:10.1037/hea0000206

Grandy, G. (2010). Intrinsic case study. In A. Mills, G. Durepos, \& E. Wiebe (Eds.), Encyclopedia of case study research (pp. 500-502). Thousand Oaks, CA: Sage.

Guan, Y., Deng, H., Sun, J., Wang, Y., Cai, Z., Ye, L., . . . Li, Y. (2013). Career adaptability, job search self-efficacy and outcomes: A three-wave investigation among Chinese university graduates. Journal of Vocational Behavior, 83, 561570. DOI:10.1016/j.jvb.2013.09.003

Guichard, J. (2005). Life-long self-construction. International Journal for Educational and Vocational Guidance, 5, 111-124. DOI:10.1007/s10775-005-8789-y

Guichard, J., Pouyaud, J., de Calan, C., \& Dumora, B. (2012). Identity construction and career development interventions with emerging adults. Journal of Vocational Behavior, 81, 52-58. DOI:10.1016/j.jvb.2012.04.004 
Hartung, P. J., Porfeli, E. J., \& Vondracek, F. W. (2008). Career adaptability in childhood. The Career Development Quarterly, 57, 63-74. DOI:10.1002/j.21610045.2008.tb00166.x

Hartung, P. J., \& Taber, B. J. (2008). Career construction and subjective well-being. Journal of Career Assessment, 16, 75-85. DOI:10.1177/1069072707305772

Hartung, P. J. (2013). Career construction counseling. In A. Di Fabio \& J. G. Maree (Eds.), Psychology of career counseling: New challenges for a new era (p. 17). New York, NY: Nova Science.

Haverkamp, B. E. (2005). Ethical perspectives on qualitative research in applied psychology. Journal of Counseling Psychology, 52(2), 146-155. DOI:10.1037/0022-0167.52.2.146

Henning, H., Van Rensburg, W., \& Smit, B. (2004). Finding your way in qualitative research. Pretoria, South Africa: Van Schaik

Hill, C. E. (1990). Exploratory in-session process research in individual psychotherapy: A review. Journal of Consulting and Clinical Psychology, 58(3), 288-294. DOI:10.1037/0022-006X.58.3.288

Himelein, M. J., \& McElrath, J. V. (1996). Resilient child sexual abuse survivors: Cognitive coping and illusion. Child Abuse and Neglect, 20(8), 747-758. DOI:10.1016/0145-2134(96)00062-2

Hirschi, A. (2009). Career adaptability development in adolescence: Multiple predictors and effect on sense of power and life satisfaction. Journal of Vocational Behavior, 74(2), 145-155. DOI:10.1016/j.jvb.2009.01.002 
Ikiugu, M. N., \& Ciaravino, E. A. (2007). Psychosocial conceptual practice models in occupational therapy: building adaptive capabilities. St. Louis, MS: Mosby.

Jackson, D., Firtko, A., \& Edenborough, M. (2007). Personal resilience as a strategy for surviving and thriving in the face of workplace adversity: a literature review. Journal of Advanced Nursing, 60(1), 1-9. DOI:10.1111/j.1365-2648.2007.04412.x

Jackson, M. R. (2015). Resistance to qual/quant parity: Why the "paradigm" discussion can't be avoided. Qualitative Psychology, 2(2), 181-198. DOI:10.1037/qup0000031

Kelliher, F. (2012). Interpretivism and the pursuit of research legitimization: An integrated approach to single case design. The Electronic Journal of Business Research Methodology, 3(2), 123-132. Retrieved from http://www.ejbrm.com/front/search/index.html

King, A., Wardecker, B. M., \& Edelstein, R. S. (2015). Personal mastery buffers the effects of childhood sexual abuse on women's health and family functioning. Journal of Family Violence, 30(7), 887-897. DOI:10.1007/s10896-015-9728-4

Koen, J., Klehe, U., \& van Vianen, A. E. M. (2012). Training career adaptability to facilitate a successful school-to-work transition. Journal of Vocational Behavior, 81, 395-408. DOI:10.1016/j.jvb.2012.10.003

Landrum, B., \& Garza, G. (2015). Mending fences: defining the domains and approaches of quantitative and qualitative research. Qualitative Psychology, 2(2), 199-209. DOI:10.1037/qup0000030

Lara, T. M., \& Vess, L. R. (2014). Life trajectories: Teaching counselors how to assist clients with their working lives. Vistas Career Counseling and Development, 47, 
1-8. Retrieved from http://www.counseling.org/knowledge-center/vistas/bysubject2/vistas-career/docs/default-source/vistas/article_47

Leech, N. L., \& Onwuegbuzie, A. J. (2007). An array of qualitative data analysis tools: A call for data analysis triangulation. School Psychology Quarterly, 22(4), 557-584. DOI:10.1037/1045-3830.22.4.557

Leech, N. L., \& Onwuegbuzie, A. J. (2011). Beyond constant comparison qualitative data analysis: Using NVivo. School Psychology Quarterly, 26(1), 70-84. DOI:10.1037/a0022711

Liebenberg, L., \& Ungar, M. (2008). Resilience in action. Toronto, Canada: University of Toronto Press.

Madill, A. (2015). Qualitative research is not a paradigm: commentary on Jackson (2015) and Landrum and Garza (2015). Qualitative Psychology, 2(2), 214-220. DOI:10.1037/qup0000032

Maree, K. (Ed.) (2007). Shaping the story - a guide to facilitating narrative career counselling. Rotterdam, The Netherlands: Sense.

Maree, K. (2007). First steps in research. Pretoria, South Africa: Van Schaik.

Maree, K., \& Van der Westhuizen, C. (2009). Head start in designing research proposals in the social sciences. Cape Town, South Africa: Juta \& Company.

Maree, J. G. (2010). Brief overview of the advancement of postmodern ${ }^{1}$ approaches to career counseling. Journal of Psychology in Africa, 20(3), 361-368. DOI:10.1080/14330237.2010.10820387 
Maree, J. G. (2012). Career Adapt-Abilities Scale: South African form: Psychometric properties and construct validity. Journal of Vocational Behavior, 80, 730-733. DOI:10.1016/j.jvb.2012.01.005

Maree, J. G. (2012). The Career Interest Profile (Version 4). Randburg, South Africa: Jopie van Rooyen \& Partners.

Maree, J. G. (Ed.). (2012). Complete your thesis or dissertation successfully: Practical guidelines. Pretoria, South Africa: Juta.

Maree, J. G. (2013). Counselling for career construction: Connecting life themes to construct life portraits. Turning pain into hope. Rotterdam, The Netherlands: Sense.

Marriott, C., Giachritsis, C. H., \& Harrop, C. (2014). Factors promoting resilience following childhood sexual abuse: A structured, narrative review of the literature. Child Abuse Review, 23, 17-34. DOI:10.1002/car.2258

Mason, J. (2013). Qualitative Researching (2 ${ }^{\text {nd }}$ ed.). London: Sage.

Mathews, S., Loots, L., Sikweyiya, Y., \& Jewkes, R. (2012). Sexual Abuse. In A. van Niekerk, S. Suffla, \& M. Seedat (Eds.), Crime, violence and injury in South Africa: 21st Century solutions for child safety. (3 $3^{\text {rd }}$ review) (pp. 84-96). Houghton, Johannesburg: Psychological Society of South Africa. Retrieved from http://www.mrc.ac.za/crime/Chapter7.pdf

Maxwell, J. A. (2008). Designing a qualitative study. In L. Bickman \& D. J. Rog (Eds.), The Sage handbook of applied social research methods ( $2^{\text {nd }}$ ed) (pp. 214-253). Thousand Oaks, California: Sage. 
Maxwell, J. A. (2012). Qualitative research design: An interactive approach (3 ${ }^{\text {rd }}$ ed.). Thousand Oaks, California: Sage.

McElvaney, J. (n.d.). Childhood abuse: Tips to change child abuse effects. Retrieved from http://www.gotospirit.com/what-will-healing-bring-me

Mcllveen, P., \& Patton, W. (2007). Narrative career counselling: theory and exemplars of practice. Australian Psychologist, 42(3), 226-23. DOI:10.1080/00050060701405592

McMahon, M., Watson, M., Chetty, C., \& Hoelson, C. N. (2012). Examining process constructs of narrative career counseling: An exploratory case study. British Journal of Guidance \& Counseling, $\quad 40(2), \quad 127-141$. DOI:10.1080/03069885.2011.646949

McMahon, M. (2014). New trends in theory development in career psychology. In G. Arulmani, A. J. Bakshi, F. T. L. Leong, \& T. Watts (Eds.), Handbook of career development: International and cultural psychology (pp. 13-27). Brisbane, Australia: Springer Science and Business Media. DOI:10.1007/978-1-4614-94607_2

Moffett, J., Matthew, S., \& Fawcett, A. (2015). Building career resilience. In Practice, 37(1), 38-41. DOI:10.1136/inp.g3958

Morrow, M. L. (2005). Quality and trustworthiness in qualitative research in counseling psychology. Journal of Counseling Psychology, 52(2), 250-260. DOI:10.1037/0022-0167.52.2.250

Natsuake, M. N., Leve, L. D., \& Mendle, J. (2011). Going through the rites of passage: Timing and transition of menarche, childhood sexual abuse, and anxiety 
symptoms in girls. Journal of Youth and Adolescence, 40(10), 1357-1370. DOI:10.1007/s10964-010-9622-6

Nieuwenhuis, J. (2007). Qualitative research designs and data-gathering techniques. In K. Maree (Ed.), First steps in research (pp. 70-97). Pretoria, South Africa: Van Schaik.

Nota, L., \& Rossier, J. (Eds.). (2015). Handbook of the life design paradigm: From practice to theory and from theory to practice. Boston, MA: Hogrefe.

Orb, A., Eisenhauer, L., \& Wynaden, D. (2001). Ethics in qualitative research. Journal of Nursing Scholarship, 33(1), 93-96. DOI:10.1111/j.1547-5069.2001.00093.

Paul, H., \& Garg, P. (2014). Factor structure of the Resilience Scale-14: Insights from an Indian sample. South Asian Journal of Management, 21, 70-86.

Pearce, J., \& Morrison, C. (2011). Teacher identity and early career resilience: Exploring the links. Australian Journal of Teacher Education, 36(1), 48-59. DOI: 10.14221/ajte.2011v36n1.4

Polkinghorne, D. E. (2005). Language and meaning: Data collection in qualitative research. Journal of Counseling Psychology, 52(2), 137-145. DOI:10.1037/00220167.52.2.137

Ponterotto, J. G. (2005). Qualitative research in counseling psychology: A primer on research paradigms and philosophy of science. Journal of Counseling Psychology, 52(2), 126-136. DOI:10.1037/0022-0167.52.2.126

Prince-Embury, S. (2007). Resiliency scales for children and adolescents: A profile of personal strengths. San Antonio, TX: Pearson. 
Raabe, S., Ehring, T., Marquenie, L., Olff, M., \& Kindt, M. (2015). Imagery rescripting as stand-alone treatment for posttraumatic stress disorder related to childhood abuse. Journal of Behaviour Therapy and Experiential Psychiatry, 48, 170-176. DOI:10.1016/j.jbtep.2015.03.013

Raskin, J. D. (2011). On essences in constructivist psychology. Journal of Theoretical and Philosophical Psychology, 31(4), 223-239. DOI:10.1037/a0025006

Rehfuss, M., \& Di Fabio, A. (2012). Validating the future career autobiography as a measure of narrative change. Journal of Career Assessment, 20, 452-462. DOI:10.1177/1069072712450005

Richards, H. M., \& Schwartz, L. J. (2002). Ethics of qualitative research: Are there special issues for health services research? Family Practice, 19(2), 135-139. DOI:10.1093/fampra/19.2.135

Richardson, L. (2000). Evaluating ethnography. Qualitative enquiry, 6(2), 253-255.

Savickas, M. L. (2002). Career construction: A developmental theory of vocational behavior. In D. Brown (Ed.), Career choice and development ( ${ }^{\text {th }}$ ed., pp. 149205). San Francisco: Jossey-Bass.

Savickas, M. L. (2005). The theory and practice of career construction. In R. W. Lent \& S. D. Brown (Eds.), Career development and counseling: Putting theory and research to work (pp. 42-70). Hoboken, NJ: John Wiley \& Sons.

Savickas, M. L., Nota, L., Rossier, J., Dauwalder, J. P., Duarte, M. E., Guichard, J., . . . Van Vianen, A. E. M. (2009). Life designing: A paradigm for career construction in the $21^{\text {st }}$ century. Journal of Vocational Behavior, 75, 239-250. DOI:10.1016/j.jvb.2009.04.004 
Savickas, M. L. (2011). Career counseling. Washington, DC: American Psychological Association.

Savickas, M. L. (2012). The 2012 Leona Tyler award address: Constructing careers actors, agents, and authors. The Counseling Psychologist, 41(4), 648-662. DOI:10.1177/0011000012468339

Savickas, M. L., \& Porfeli, E. J. (2012). Career Adapt-Abilities Scale: construction, reliability, and measurement equivalence across 13 countries. Journal of Vocational Behavior, 80(3), 661-673. DOI:10.1016/j.jvb.2012.01.011

Savickas, M. L. (2013). Career construction theory and practice. In R. W. Lent \& S. D. Brown (Eds.), Career development and counseling: Putting theory and research to work ( $2^{\text {nd }}$ ed., pp. 147-183). Hoboken, New Jersey: John Wiley \& Sons.

Schreuder, A. M. G., \& Coetzee, M. (2011). Careers: An organizational perspective $\left(^{\text {th }}\right.$ ed.). Cape Town, South Africa: Juta.

Schultheiss, D. E. P. (2003). A relational approach to career counseling: Theoretical integration and practical application. Journal of Counseling and Development, 81, 301-310. DOI:10.1002/j.1556-6678.2003.tb00257.x

Sigurdardottir, S., \& Halldorsdottir, S. (2013). Repressed and silent suffering: consequences of childhood sexual abuse for women's health and well-being. Scandinavian Journal of Caring Sciences, 27(2), 422-432. DOI:10.1111/j.1471$6712.2012 .01049 . x$

Simon, V. A., Smith, E., Fava., N. \& Feiring, C. (2015). Positive and negative posttraumatic change following childhood sexual abuse are associated with 
youths' adjustment. Child Maltreatment, 20(4), 278-290. DOI:10.1177/1077559515590872

Singh, M. M., Parsekar, S. S., \& Nair, S. N. (2014). An epidemiological overview of child sexual abuse. Journal of Family Medicine and Primary Care, 3(4), 430-435. DOI:10.4103/2249-4863.148139

Spaccarelli, S., \& Kim, S. (1995). Resilience criteria and factors associated with resilience in sexually abused girls. Child Abuse and Neglect, 19(9), 1171-1182. DOI:10.1016/0145-2134(95)00077-L

Stake, R. E. (1995). The art of case study research. Thousand Oaks, CA: Sage.

Stake, R. E. (2005). Qualitative case studies. In N. K. Densin \& Y. S. Lincoln (Eds.), The Sage handbook of qualitative research (3 ${ }^{\text {rd }}$ ed.) (pp. 442-466). Thousand Oaks, CA: Sage.

Stead, G. B., \& Watson, M. B. (2006). Career psychology in the South African context ( $2^{\text {nd }}$ ed.). Pretoria, South Africa: Van Schaik.

Stebbins, R. A. (2001). Exploratory research in the social sciences. Thousand Oaks, California: Sage.

Super, D. E., Savickas, M. L., \& Super, C. M. (1996). The life-span, life-space approach to careers. In D. Brown, L. Brooks \& Associates (Eds.), Career choice and development ( $3^{\text {rd }}$ ed., pp. 121-178). San Francisco, CA: Jossey-Bass.

Taber, B. J., Hartung, P. J., Briddick, H., Briddick, W. C., \& Rehfus, M. C. (2011). Career Style Interview: A Contextualized Approach to Career Counseling. The Career Development Quarterly, 59(3), 274-287. DOl:10.1002/j.21610045.2011.tb00069.x 
Teixeira, M. A. P., \& Gomes, W. B. (2000). Autonomous career change among professionals: An empirical phenomenological study. Journal of Phenomenological Psychology, 31(1), 78-96. Retrieved from http://www.search.proquest.com/docview/1308107102?accountid=14717

Terre Blanche, M., Durrheim, K., \& Painter, D. (2006). Research in practice: Applied methods for the social sciences ( $2^{\text {nd }}$ ed.). Cape Town, South Africa: University of Cape Town Press.

Tuason, M. T. G. (2013). Those who were born poor: A qualitative study of Philippine poverty. Qualitative Psychology, 1(S), 95-115. DOI:10.1037/2326-3598.1.S.95

Turban, D. B., Stevens, S. K., \& Lee, F. K. (2009). Effects of conscientiousness and extraversion on new labor market entrants' job search: The mediating role of metacognitive activities and positive emotions. Personnel Psychology, 62, 553573. Retrieved from http://www.trulaske.missouri.edu/sites/default/files/ publication/turban_stevens_lee_2009_p_psyc.pdf

Ungar, M. (2008). Resilience across cultures. British Journal of Social Work, 38, 218235. DOI:10.1093/bjsw/bcl343

Valentine, L., \& Feinauer, L. L. (1993). Resilience factors associated with female survivors of childhood sexual abuse. The American Journal of Family Therapy, 21(3), 216-224. DOI:10.1080/01926189308250920

Van Esbroeck, R., \& Maree, K. (July, 2010). Life designing: A paradigm for career construction in the $21^{\text {st }}$ century. A symposium conducted at the meeting of the 27th International Congress of Applied Psychology, Melbourne, Australia. 
Van Rensburg, E., \& Barnard, C. (2005). Psychological resilience among sexually molested girls in the late middle-childhood: a case study approach. Child Abuse Research in South Africa, 6(1), 1-12. Retrieved from http://www.0reference.Sabinet.co.za.innopac.up.ac.za/webx/access/electronic_journals/carsa /carsa_v6_n1_a1.pdf

Van Wyk, B. (2012). Lecture 1: Research design and methods Part I [PowerPoint slides]. Retrieved from file: ///C:/Users/User/Downloads/Research_and_ Design_I.pdf

Vithal, R., \& Jansen, J. (2004). Designing your first research proposal: A manual for researchers in education and the social sciences. Claremont, South Africa: Juta and Company.

Walsh, W. A., Dawson, J., \& Mattingly, M. J. (2010). How are we measuring resilience following childhood maltreatment? Is the research adequate and consistent? What is the impact on research, practice, and policy? Trauma, Violence and Abuse, 11(1), 27-41. DOI:10.1177/1524838009358892

Walsh, R. T. G. (2015). Making discursive space in psychology for qualitative reportwriting. Qualitative Psychology, 2(1), 29-49. DOI:10.1037/qup0000020

Wasserman, R. H., Levy, K. N., \& Loken, E. (2009). Generalizability theory in psychotherapy research: The impact of multiple sources of variance on the dependability of psychotherapy process ratings. Psychotherapy Research, 19(45), 397-408. DOI:10.1080/10503300802579156

Wingo, A. P., Wrenn, G., Pelletier, T., Gutman, A. R., Bradley, B., \& Resslera, K. J. (2010). Moderating effects of resilience on depression in individuals with a history 
of childhood abuse or trauma exposure. Journal of Affective Disorders, 126(3), 411-414. DOI:10.1016/j.jad.2010.04.009

Zacher, H. (2014). Career adaptability predicts subjective career success above and beyond personality traits and core self-evaluations. Journal of Vocational Behavior, 84, 21-30. DOI:10.1016/j.jvb.2013.10.002

Zunker, V. G. (1998). Career counselling: Applied concepts of life planning ( $5^{\text {th }}$ ed.). Pacific Grove: Brooks/Cole. 


\section{ANNEXURE A: RSCA Resiliency Scales}

\section{RSCA Sense of Mastery Scale}

The Sense of Master Scale determines how children and youth interact with and enjoy cause-and-effect relationships in the environment. The scale distinguishes three personal characteristics that combine to form the underpinnings of a youth's sense of mastery, namely Optimism, Self-efficacy and Adaptability (Prince-Embury, 2006).

- Optimism is seen as a positive attitude of a person in general in relation to their view about themselves and the world/life. It also refers to an attributional style, positive self-esteem and perception of control.

- Self-efficacy is seen as the approach an individual adopts towards obstacles or problems. It is the feeling that one can master one's own environment.

- Adaptability refers to a person's flexibility to consider different options in problem solving.

\section{RSCA Sense of Relatedness Scale}

This scale is based on the assumption that to be in a relationship is a basic human need. Relatedness is defined as feeling securely connected to individuals in a social context (Prince-Embury, 2006). Four component aspects were identified, namely:

- Trust - the degree to which a person perceives others as reliable and accepting.

- Support - a person's perception and/or idea that there are individuals around them to whom they can turn when they need support or deal with adversity.

- Comfort - the degree to which an individual can be in the presence of others without discomfort or anxiety.

- Tolerance - an individual's belief that they can safely express their opinions within a relationship. 


\section{RSCA Emotional Reactivity Scale}

This scale indicates the individual's pre-existing vulnerability, arousal, or threshold of tolerance to stimulation, prior to the occurrence of adverse events or circumstances (Prince-Embury, 2006). It includes the following subscales:

- Sensitivity - the threshold for reaction and the intensity of the reaction.

- Recovery - the capacity of individuals to bounce back or recover from emotional adversity and return to normal functioning.

- Impairment - the degree to which an individual's daily functioning is impaired due to emotional arousal. 


\section{ANNEXURE B: Memory Box}
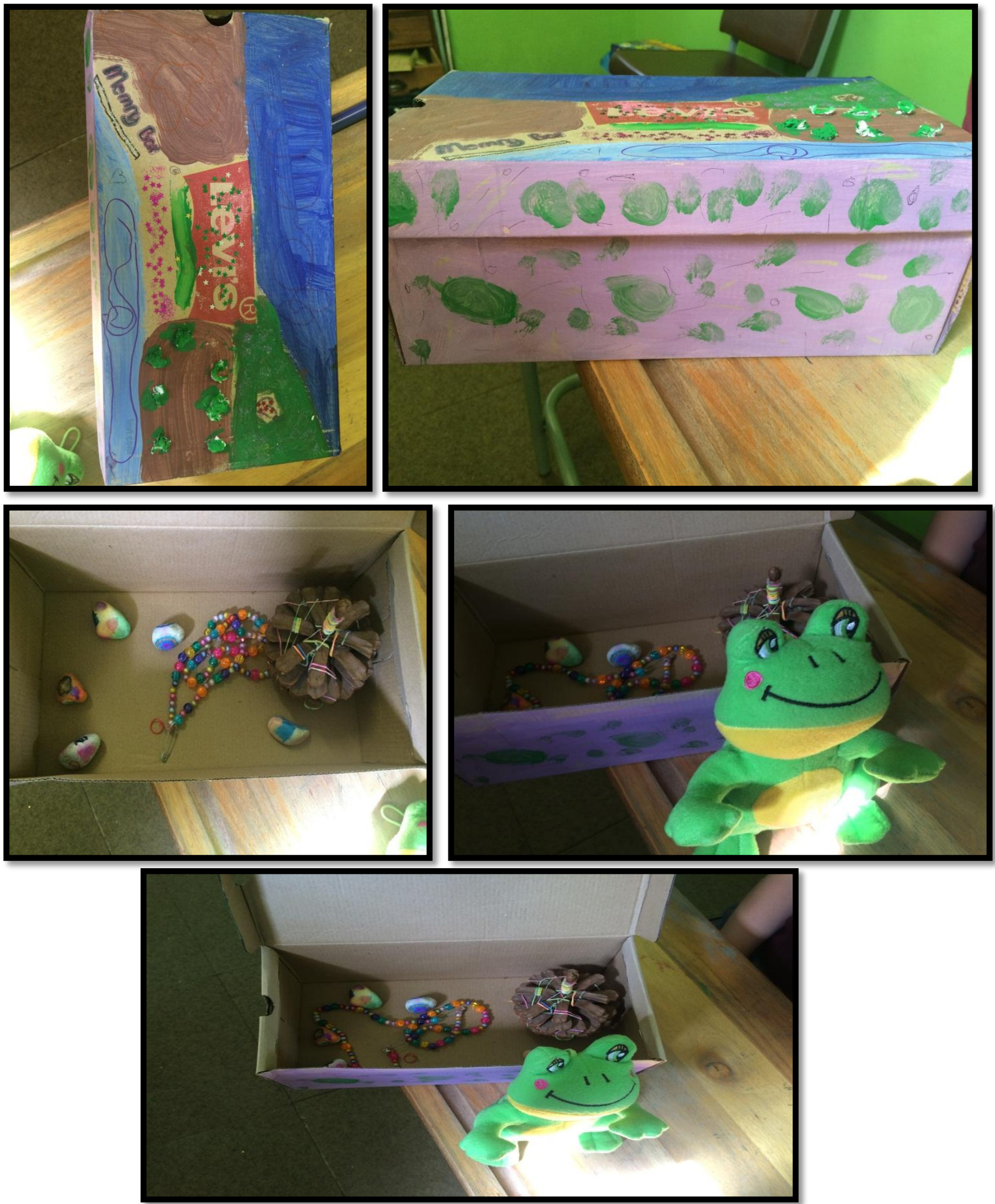
ANNEXURE C: Sandtray
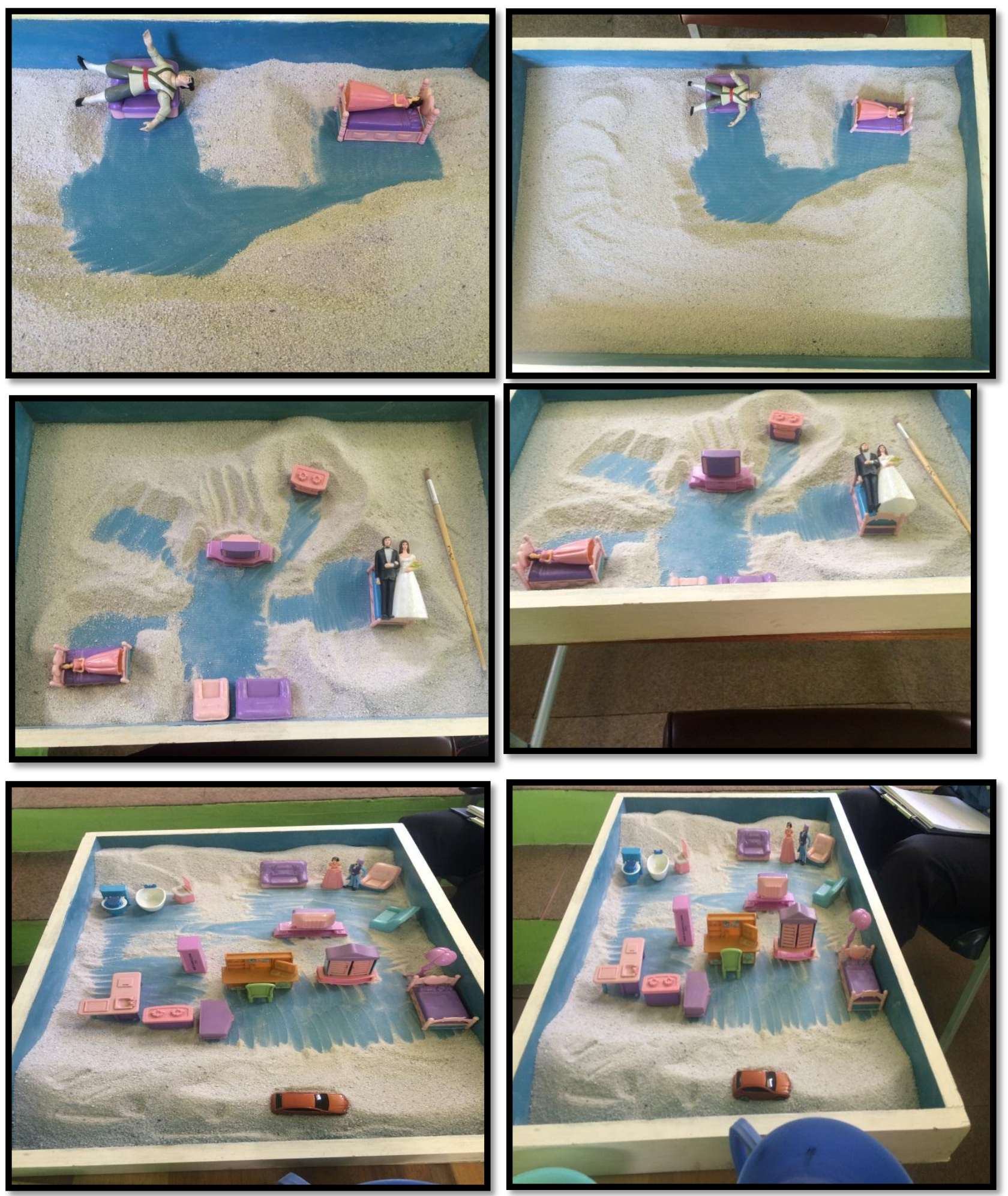


\section{ANNEXURE D: Collage}

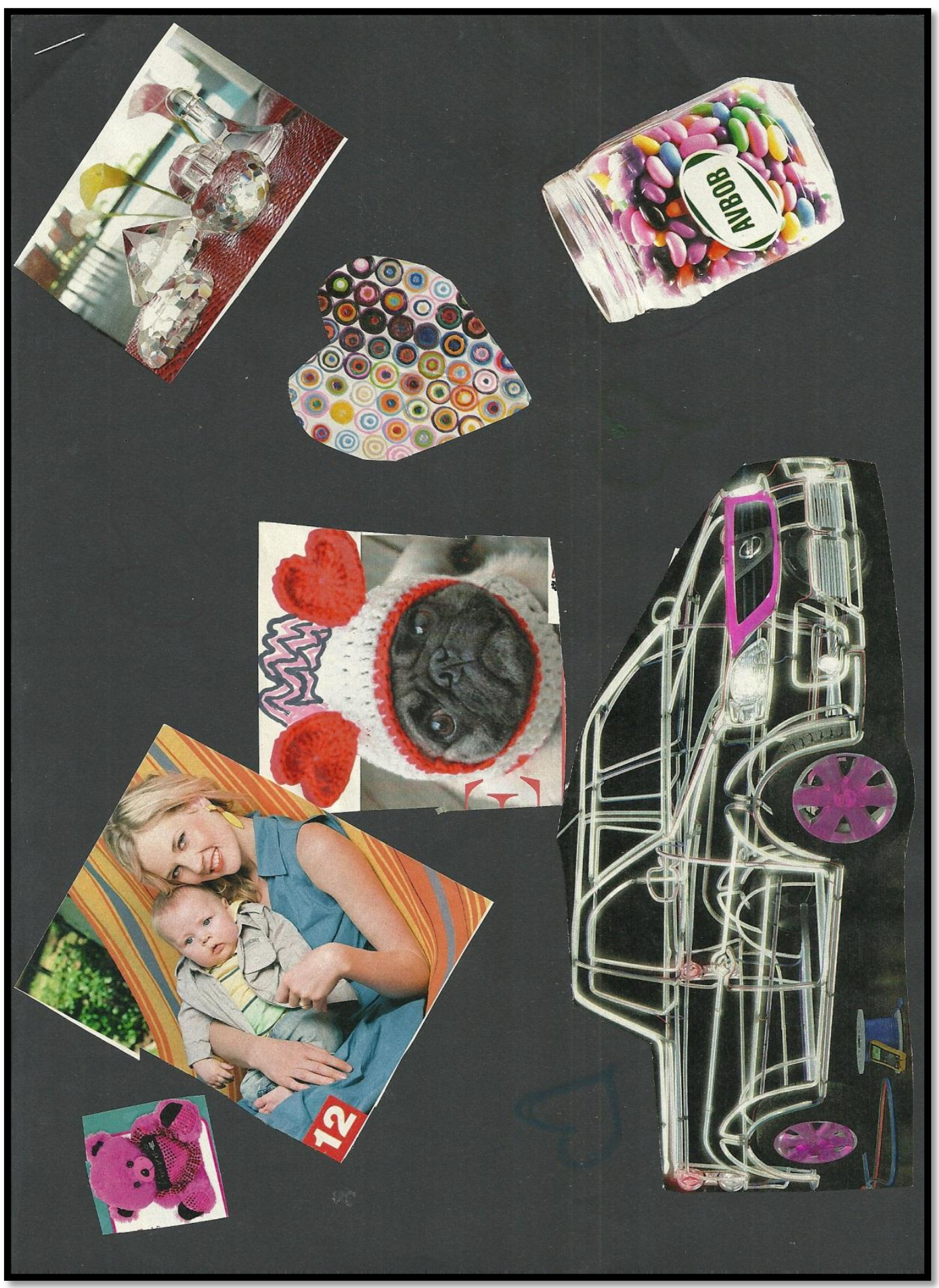


ANNEXURE E: Lifeline
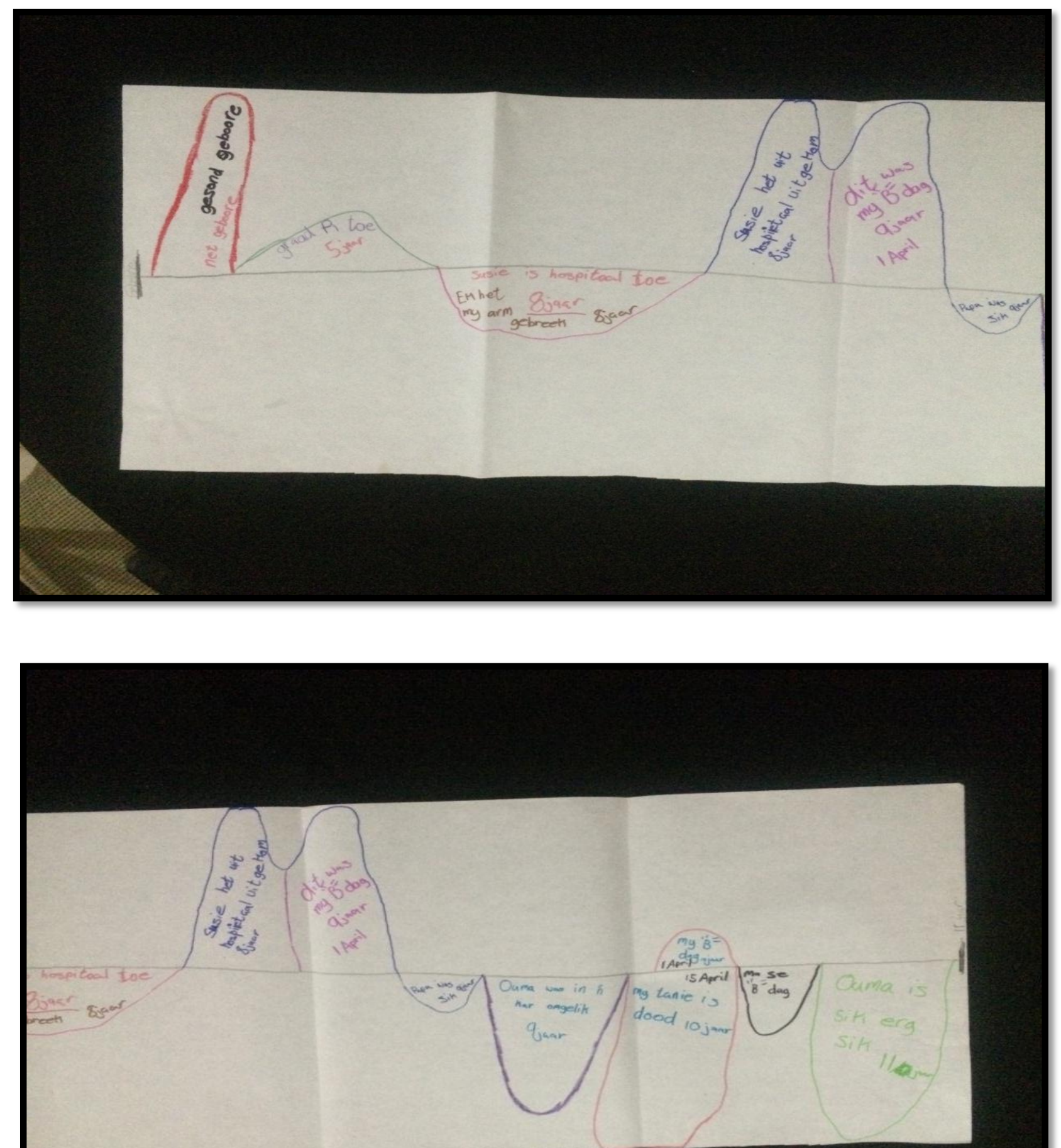


\section{ANNEXURE F: Drawing}

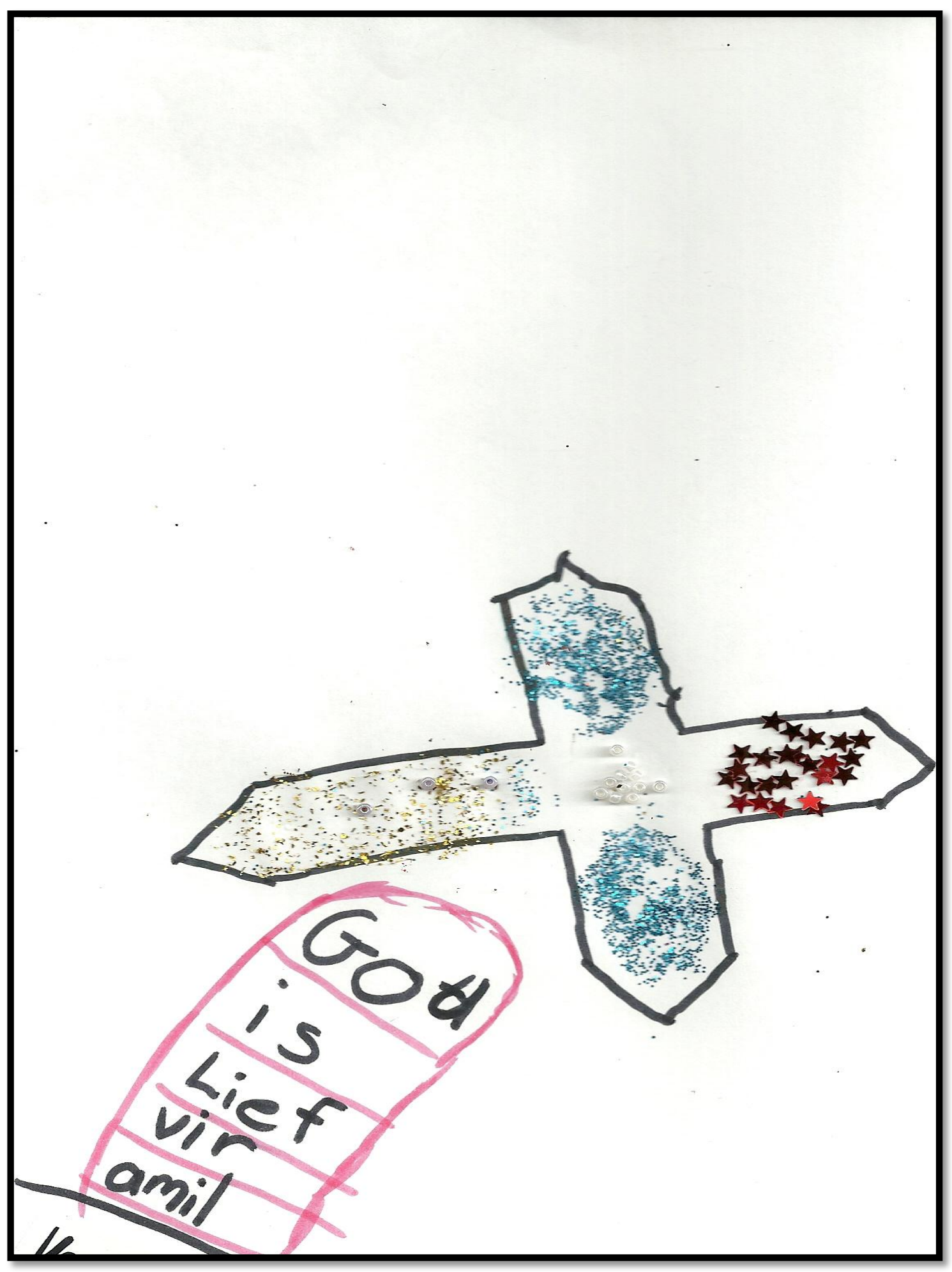




\section{ANNEXURE G: Subthemes}

\begin{tabular}{|c|c|c|c|c|c|}
\hline Subthemes & Session 1 & Session 2 & Session 3 & Session 4 & Session 5 \\
\hline Unforgiving/Vindictive & $\mathbf{X}$ & & & & $\mathbf{X}$ \\
\hline Anxiety & $\mathbf{X}$ & $\mathbf{X}$ & & $\mathbf{X}$ & \\
\hline Comfort & $\mathbf{x}$ & & & & $\mathbf{X}$ \\
\hline Work ethic & $\mathbf{X}$ & & & $\mathbf{X}$ & \\
\hline Conditional forgiveness & $\mathbf{X}$ & & & & $\mathbf{x}$ \\
\hline Feelings of acceptance & $\mathbf{X}$ & & & & $\mathbf{X}$ \\
\hline Recovery/Resilience & $\mathbf{X}$ & $\mathbf{X}$ & $\mathbf{X}$ & $\mathbf{X}$ & $\mathbf{x}$ \\
\hline Pride & & $\mathbf{X}$ & & & $\mathbf{x}$ \\
\hline Optimism & $\mathbf{X}$ & $\mathbf{X}$ & & $\mathbf{X}$ & $\mathbf{X}$ \\
\hline $\begin{array}{l}\text { Need to experience } \\
\text { happiness }\end{array}$ & & $\mathbf{X}$ & $\mathbf{X}$ & $\mathbf{X}$ & $\mathbf{X}$ \\
\hline $\begin{array}{l}\text { Need for } \\
\text { security/protection }\end{array}$ & & $\mathbf{X}$ & & & $\mathbf{X}$ \\
\hline $\begin{array}{l}\text { Internal locus of } \\
\text { control/Taking control of } \\
\text { her feelings }\end{array}$ & & $\mathbf{X}$ & $\mathbf{X}$ & $\mathbf{x}$ & \\
\hline $\begin{array}{l}\text { Denial/Escaping/Avoiding } \\
\text { behaviour }\end{array}$ & & $\mathbf{X}$ & $\mathbf{X}$ & $\mathbf{x}$ & \\
\hline
\end{tabular}




\begin{tabular}{|c|c|c|c|c|c|}
\hline Creativity & & $\mathbf{X}$ & & & $\mathbf{X}$ \\
\hline Concrete thinking pattern & & $\mathbf{X}$ & $\mathbf{X}$ & $\mathbf{X}$ & \\
\hline Trust & $\mathbf{X}$ & & $\mathbf{X}$ & & $\mathbf{X}$ \\
\hline Tolerance & $\mathbf{X}$ & & & & $\mathbf{X}$ \\
\hline Support & $\mathbf{X}$ & & & & $\mathbf{X}$ \\
\hline Sensitivity & $\mathbf{X}$ & & & & $\mathbf{X}$ \\
\hline Impairment & $\mathbf{X}$ & $\mathbf{X}$ & & & $\mathbf{X}$ \\
\hline Self-efficacy & $\mathbf{X}$ & & $\mathbf{X}$ & & $\mathbf{X}$ \\
\hline Adaptability & $\mathbf{X}$ & & & & $\mathbf{X}$ \\
\hline $\begin{array}{l}\text { Love/Intimate family } \\
\text { relationships }\end{array}$ & $\mathbf{X}$ & & $\mathbf{X}$ & & $\mathbf{X}$ \\
\hline Poor tolerance & $\mathbf{X}$ & & & & $\mathbf{X}$ \\
\hline Autonomy/Independence & $\mathbf{X}$ & & & & \\
\hline $\begin{array}{l}\text { Comfort around others } \\
\text { (emotional reactivity) }\end{array}$ & $\mathbf{X}$ & & & & \\
\hline Self-insight & & & $\mathbf{X}$ & $\mathbf{X}$ & $\mathbf{X}$ \\
\hline $\begin{array}{l}\text { Self-knowledge/Self- } \\
\text { awareness }\end{array}$ & & & & $\mathbf{X}$ & $\mathbf{X}$ \\
\hline
\end{tabular}




\begin{tabular}{|c|c|c|c|}
\hline Rational thinking & & $\mathbf{X}$ & \\
\hline Mutual respect & & $\mathbf{X}$ & \\
\hline Expression of sadness & $\mathbf{X}$ & $\mathbf{X}$ & \\
\hline Need to nurture & $\mathbf{X}$ & & \\
\hline Good judge of character & $\mathbf{X}$ & & \\
\hline Experience of loss & $\mathbf{X}$ & & \\
\hline Religion & & & $\mathbf{X}$ \\
\hline Negative body image & & $\mathbf{X}$ & \\
\hline Self-actualisation & $\mathbf{X}$ & $\mathbf{X}$ & \\
\hline Self-assertive behaviour & $\mathbf{X}$ & & \\
\hline
\end{tabular}


ANNEXURE H: Referencing system

\begin{tabular}{|l|l|l|l|}
\hline \multicolumn{2}{|l|}{ Data source } & Page number & Line number \\
\hline 1 & RSCA & 1 & 3 \\
\hline 2 & Family contellation & & \\
\hline 3 & Genogram & & \\
\hline 4 & Sandtray & & \\
\hline 5 & Memory box & & \\
\hline 6 & Early recollections & & \\
\hline 7 & Collage & & \\
\hline 8 & Lifeline & & \\
\hline 9 & Life chapters & & \\
\hline 10 & Success experiences & & \\
\hline 11 & RSCA & & \\
\hline 12 & Drawing & & \\
\hline
\end{tabular}


ANNEXURE I: Request for informed consent from the participants' parents/guardians.

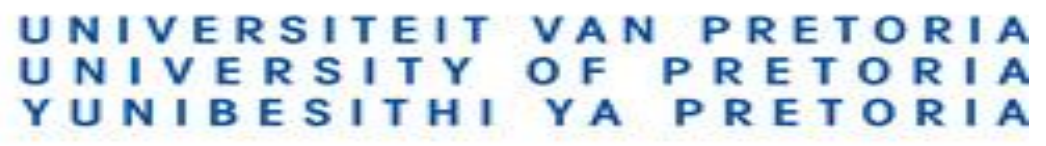

\section{Parental Consent Form}

Study Title: Will narrative career counselling enhance the career resilience of a sexual abuse survivor?

Principal Researcher: Mr. Cobus J. Venter

\section{The Research Team:}

\begin{tabular}{|l|l|l|}
\hline Name/Degree & Phone Number & E-mail \\
\hline $\begin{array}{l}\text { Mr. Cobus J. Venter } \\
\text { Prof. Kobus Maree } \\
\text { (Supervisor) }\end{array}$ & 0723130126 & cbsventer@gmail.com \\
\hline
\end{tabular}

24 hour Emergency Contact Number: 0723130126

\section{Researcher's statement}

Parents/Guardians: You have the option of having your child join a research study. This is a parental permission form. This form provides a summary of the important information that the research team will discuss with you. If you decide that your child can take part in this study, you would be required to sign this form to confirm your decision. If you sign this form, you will receive a signed copy for your records. The term "you" throughout this form refers to your child/teenager. 


\section{What should I know about this study}

- This form explains what would happen if your child joins this research study.

- Please read it carefully. Take as much time as you need.

- Please ask the research team any questions about any aspects that might not be clear to you.

- You can ask questions about the study at any time before, during or after the study.

- If you say 'Yes' now, you can still change your mind later.

- Your child can choose to stop his/her participation in the study at any time.

\section{What is the purpose of this study?}

The purpose of the study is to determine whether we can enhance the career resilience of a sexual abuse survivor through life-design counselling. The research study will therefore attempt to contribute in finding a novel strategy to enhance the career resilience within children who are survivors of sexual abuse.

\section{Why do I have the option of joining the study?}

You have the option of allowing your child to take part in this research study because participation is voluntary and both the parents/guardians as well as the child may refuse to take part in the study or stop at any time without giving any reason. If your child decides not to participate or wants to stop taking part in the study after they said yes, this would not affect you or the child in any way.

\section{If I agree to join this study, what would I need to do?}

If your child joins the study, he/she will be required to complete some questionnaires and other fun activities. These questionnaires and activities will help us to find out if being in this study enhances the career resilience of survivors of sexual abuse. These activities are not harmful in any manner and will contribute to the knowledge and information gathered by this study. We therefore use the information gained from these activities to determine if the intervention is successful or not. 


\section{How long would my child be in the study?}

If your child takes part in all the study visits, he/she would be in the study for a maximum of 8 weeks. If your child joins the study, you can decide to stop his or her participation at any time for any reason. If you decide to stop, you would need to talk with Mr. Cobus J. Venter so your child leaves the study in a safe manner. The safety and psychological health of your child is of great importance to us and making sure that your child leaves the study in the correct manner is our utmost priority.

\section{What are the potential harm or risks associated with the study?}

We do not foresee any risks for your child participating in this study. If any problems do arise, we will speak to the child and make sure he/she understands what is going on and feels comfortable to continue in the study. The identity of the child will not be revealed to anyone and any information that we get from the study will be kept private.

Observations will be done throughout the study, looking for any signs of distress such as avoidance, denial, detachment, anger, frustration, increased behavioural problems, etc. If the child shows signs of trauma (acute or generalized) then the appropriate treatment recommendations will be made. When the participant shows signs of distress, the researcher will change the intervention strategy accordingly or cease the activity immediately and replace it with a non-threatening, fun activity. Mr. Venter will not continue in any way with the study if the child's emotional and/or psychological wellbeing is at risk.

\section{What are the potential benefits of this study?}

We hope this study will benefit your child and contribute towards the development of his/her career one day. This however cannot be guaranteed. It is also important to take note of the fact that there will be no financial benefits of any kind when participating in this study. 


\section{How would you keep information confidential?}

All of the information that we get from the study will be kept strictly confidential and will

only be available to the research team. No information will be shared with anyone else and will be kept safe on the premises of the University of Pretoria for the next 15 years. The only exception will be if there is a serious problem regarding the safety of the child or any other person, in which case we are required to inform the appropriate statutory bodies. If such a situation does arise, we will make every effort to discuss the matter with you before taking any action. All the information we get from the study will be stored in locked files and a pseudonym will be used throughout the study. Because confidentiality is important, we would expect that any information you provide is also private and that we would not discuss this information with anyone.

\section{What would my signature on this form mean?}

Your signature on this form would mean:

- The research study was explained in detail to you.

- You had a chance to ask all the questions you have at this time and that all your questions has been answered in a way that is clear.

- You understand that the persons listed on this form will answer any other questions you may have about the study or your rights as a research study participant.

- You have rights as a research participant. We will tell you about new information or changes to the study that may affect your health or your willingness to stay in the study.

- By signing this consent form, you do not give up any of your legal rights. The researcher is therefore not relieved of any liability they may have.

- You agree to have your child take part in this research study.

Name of Research Participant (Child):

Printed Name of Parent/Legal Guardian: 
Signature of Parent or Legal Guardian:

Date:

\section{$\underline{\text { Researcher's Signature }}$}

I have fully explained the research study described by this form. I have answered the participant and/or parent/guardians questions and will answer any future questions to the best of my ability. I will tell the family and/or the person taking part in this research of any changes in the procedures or in the possible harms/possible benefits of the study that may affect their health or their willingness to stay in the study.

Name of Researcher:

Signature of Researcher:

Date: 


\title{
ANNEXURE J: Request for informed assent from the participant
}

\author{
UNIVERSITEIT VAN PRETORIA \\ U N I VERS I T Y OF PRETOR I A \\ YUN I B ESITHI YA PRETORIA
}

\section{Research Assent Form}

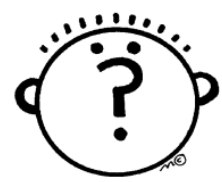

\section{What is a research study?}

Research studies help us learn new things and test new ideas about people. First, we ask a question and then we try to find the answer. This paper talks about our research and the choice that you have to take part in it. We want you to ask us any questions that you might have whenever you feel uncertain about anything that we talk about.

\section{Important things to know...}

- You get to decide if you want to take part.

- You can say 'No' or you can say 'Yes'.

- $\quad$ No one will be upset if you say 'No'.

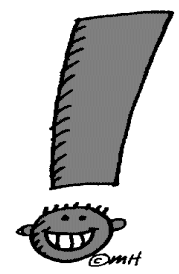

- If you say 'Yes', you can always say 'No' later.

- You can say 'No' at anytime.

- We would still take good care of you no matter what you decide.

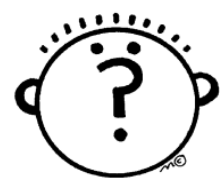

\section{Why are we doing this research?}

The reason why we are doing this research is to find out more about how we can enhance career resilience in children who have been sexually abused. 


\section{What would happen if I join this research?}

If you decide to be a part of the research, we would ask you to do the following:

- Questions: We would ask you to read questions on a piece of paper. Then you would mark your answers on the paper. We would help you wherever you struggle and we will make it as easy as possible for you to understand the questions.

- Talking: A person on the research team would be asking you some questions. You will then be required to answer these questions out loud.

- Drawing activities: Various drawing activities form part of the research which will provide valuable information to us. As part of the research you will be asked to make some drawings.

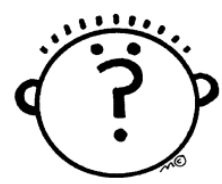

\section{Could bad things happen if I join this research?}

Some of the activities in the research might make you uncomfortable or the questions might be difficult and hard to answer. We will try to make sure that no bad things happen to you and that you feel safe at all times throughout the study. You can say 'no' at any time if you are uncomfortable and we will stop. If at any time during the activities you feel that you do not want to go on and stop or take a break then you can just say so. I will not continue with the activities if you feel that you want to stop.

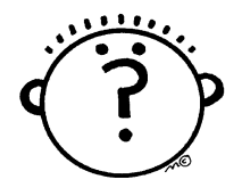

\section{Could the research help me?}

We believe that being involved in this research may help you in the future because it could possibly enhance your career resilience and help address the negative effects of the sexual abuse that took place. 


\section{What else should I know about this research?}

If you feel that you don't want to be involved in the study, you don't have to be. It is also acceptable to say 'yes' and change your mind later. You can stop your participation in the research at any time. If you want to stop, please tell the researchers. You can ask Mr. Cobus Venter questions at any time during the study. Take the time you need to make your choice.

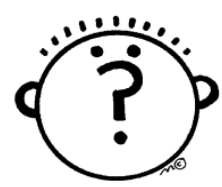

\section{Is there anything else?}

If you want to be in the research after we talk, please write your name below. We will write our name too. This shows we talked about the research and that you want to take part.

Name of Participant:

(To be written by child/adolescent)

Printed Name of Researcher:

Signature of Researcher:

Date: 


\section{ANNEXURE K: Ethical clearance certificate}

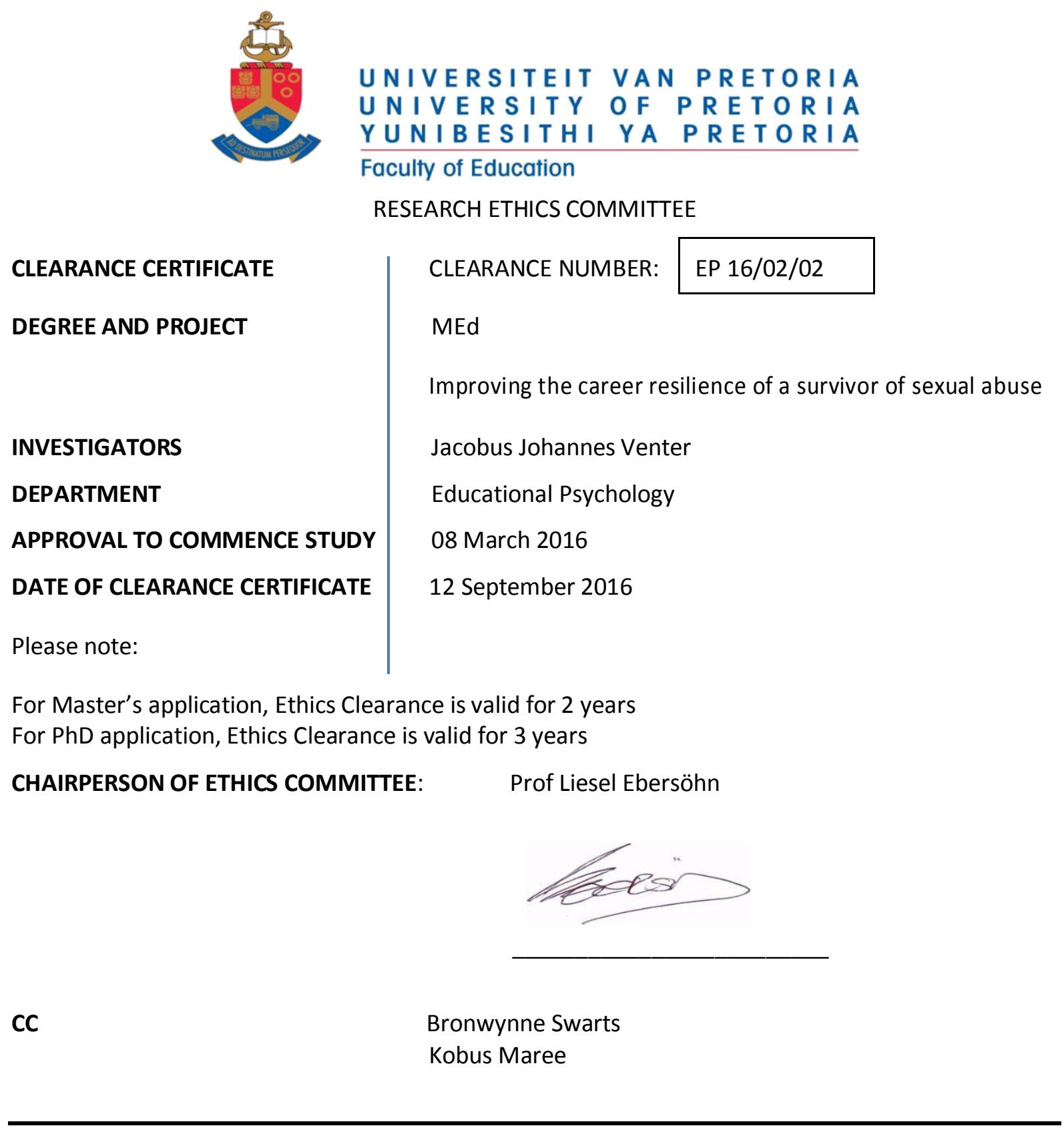

This Ethics Clearance Certificate if issued subject to the following conditions:

1. A signed personal declaration of responsibility

2. If the research question changes significantly so as to alter the nature of the study, a new application of ethical clearance must be submitted

3. It remains the student's responsibility to ensure that all the necessary forms for informed consent are kept for future queries

Please quote the clearance number in all enquiries 
ANNEXURE L: Cerificates of attendance for the research support sessions 


\section{ANNEXURE M: CD with relevant transcripts}

(C) University of Pretoria 